\title{
Adsorption and decomposition of tar model compounds over the surface of gasification char and active carbon within the temperature range $250-800{ }^{\circ} \mathrm{C}$
}

\author{
Ravenni, G.; Elhami, O. H.; Ahrenfeldt, J.; Henriksen, U. B.; Neubauer, Y.
}

Published in:

Applied Energy

Link to article, DOI:

10.1016/j.apenergy.2019.03.032

Publication date:

2019

Document Version

Peer reviewed version

Link back to DTU Orbit

Citation (APA):

Ravenni, G., Elhami, O. H., Ahrenfeldt, J., Henriksen, U. B., \& Neubauer, Y. (2019). Adsorption and decomposition of tar model compounds over the surface of gasification char and active carbon within the temperature range $250-800^{\circ} \mathrm{C}$. Applied Energy, 241, 139-151. https://doi.org/10.1016/j.apenergy.2019.03.032

\section{General rights}

Copyright and moral rights for the publications made accessible in the public portal are retained by the authors and/or other copyright owners and it is a condition of accessing publications that users recognise and abide by the legal requirements associated with these rights.

- Users may download and print one copy of any publication from the public portal for the purpose of private study or research.

- You may not further distribute the material or use it for any profit-making activity or commercial gain

- You may freely distribute the URL identifying the publication in the public portal 


\title{
Adsorption and decomposition of tar model compounds over the surface of gasification char and active carbon within the temperature range $250-800^{\circ} \mathrm{C}$
}

\author{
G. Ravenni $^{1 *}$, O.H. Elhami ${ }^{2}$, J. Ahrenfeldt ${ }^{1}$, U.B. Henriksen ${ }^{1}$, Y. Neubauer ${ }^{2}$ \\ ${ }^{1}$ Technical University of Denmark (DTU), Department of Chemical and Biochemical Engineering, \\ Frederiksborgvej 399, 4000 Roskilde, Denmark \\ ${ }^{2}$ Technische Universität Berlin, Institute of Energy Technology
}

Fasanenstrasse 89, 10623 Berlin, Germany

\begin{abstract}
The carbonaceous products of gasification or pyrolysis (chars) and active carbon (AC) have been found effective as adsorbents for tar species and active as catalysts for tar conversion. However, a deeper understanding of the interaction between aromatic compounds and carbonaceous surfaces is needed for the practical implementation and optimization of carbon-based gas cleaning systems. The aim of this work is to investigate the performance of various wood-derived chars and AC within a wide temperature range $\left(250-800^{\circ} \mathrm{C}\right)$. Residual char from gasification, pyrolysis char and two types of AC were tested for their capability to remove tar model compounds (toluene and naphthalene) from a gaseous flow. A dedicated setup was used for this purpose, while post-experimental characterization revealed the modifications occurring at the surface of chars. Adsorption was observed in the lower temperature range, whereas cracking reactions were found to initiate at $600^{\circ} \mathrm{C}$ and to become significant at $800^{\circ} \mathrm{C}$. Results suggested that $\mathrm{AC}$ represents a better option for tar adsorption applications (e.g. carbon filters) operating at temperatures of $250^{\circ} \mathrm{C}$ and possibly below, whereas gasification residual char resulted as the most promising substrate for tar cracking at temperatures of $800^{\circ} \mathrm{C}$ and above.
\end{abstract}

*Corresponding author Tel: +4593511592 E-mail: grav@kt.dtu.dk (Giulia Ravenni) 


\section{Introduction}

The quality of producer gas generated by gasification of biomass is one of the main issues hindering the commercialization of this thermochemical conversion process. In general, biomass producer gas contains tar, a mixture of condensable substances including light 1-ring aromatics, polycyclic aromatic hydrocarbons and heterocyclic aromatics [1]. Tar contamination prevents the widespread use of biomass producer gas as an alternative to fossil resources. If the gas quality issue is overcome, it could be used to fuel engines and turbines or for synthesis of biofuels and bio-chemicals.

Several options for producer gas treatment have been proposed and implemented including cold gas cleaning, hot gas filtration, thermal cracking, catalytic cracking by using metal-based catalysts (e.g. nickel, iron, noble metals) or mineral catalysts (e.g. dolomite, olivine) [2].

The use of char and active carbon (AC) to reduce the content of tar in producer gas has been suggested by a number of authors who worked with tar model compounds [3-6] and with tar derived from pyrolysis or gasification [7-12]. Overall, these carbonaceous materials appear as a viable alternative to metal and mineral catalysts, with manifold advantages. Firstly, they can be inexpensive, especially if residual char is used (for example from gasification plants). Secondly, they can be less harmful for the environment and for human health in comparison with synthetic catalysts [13], especially if not impregnated with metals, but directly used as a gas cleaning substrate. In addition, chars and AC can find several end-life applications such as being recycled as a solid fuel or as a precursor for carbon materials. Potentially they could even be used as biochar for soil amendment and carbon sequestration, if the relevant thresholds for noxious contaminants (e.g. heavy metals, polycyclic aromatic hydrocarbons, dioxins) are verified.

The solid residue of gasification is a specific kind of char which is usually considered as a waste material or a by-product of gasification plants. The properties of this char vary significantly depending on the feedstock and on the operating conditions of the gasifier. In general, it contains inorganics such as alkali and alkaline earth metals, which are naturally contained in the feedstock, and is rich in carbon. Indeed, only the carbon atoms arranged in the most stable structures endure gasification reactions. Such reactions are also responsible for the physical activation of char, which can produce a microporous material with a significant specific surface area. Oftentimes this material presents surface properties which are comparable to commercial AC [14]. For this reason, gasification char has been considered for various applications as a cheaper alternative to manufactured AC [15-19], as well as for tar removal 
and conversion applications [20,21]. The latter solution would be economically and environmentally beneficial for gasification plants: indeed the valorization of the solid by-product, which often does not meet the requirements for soil application as biochar, would improve the economic feasibility especially for small-scale systems [22].

The TwoStage gasification platform developed at DTU, Risø Campus (also known as "Viking gasifier") is able to produce a virtually tar-free gas as described in [9]. The solid residue of the TwoStage gasification process (hereby called "Viking char") presents a high carbon content and a very large specific surface area in comparison with chars generated from other gasification processes $[14,23]$. For these reasons it could be especially effective for gas treatment applications.

The practical implementation of carbon-based gas cleaning systems is still at the initial stage, as it is not yet clear which are the char characteristic and the reaction conditions required to optimize the removal of tar. In particular, some authors considered char as an adsorbent for tar [24-26], whereas others used it as a substrate for tar cracking [8,10,12,27,28] and reforming [11,29-32].

Adsorption on carbon surfaces has been extensively studied and used for removal of organic contaminants from gaseous streams [33,34]. Being an exothermic process, adsorption is hindered at high temperatures [35], as a consequence of the increased vapor pressure of the adsorbate [33]. Nevertheless, for adsorption of tar compounds on chars, it is advisable to work at a minimum temperature of $250^{\circ} \mathrm{C}$, as lower temperatures could lead to condensation of tar from the producer gas.

On the other hand, cracking of aromatic molecules making up the tar mixture requires much higher temperatures: around $1200^{\circ} \mathrm{C}$ in homogeneous conditions [36]. Char is able to act as a catalyst for cracking and reforming of aromatics. Indeed, an enhancement in the conversion of aromatic structures at temperatures as low as $600^{\circ} \mathrm{C}$ has been observed in presence of char [27,37-39].

Under inert atmosphere, the decomposition of aromatics on the surface of chars and activated carbons is considered to take place through carbon deposition by coking according to reaction (1) [4]:

$$
\begin{aligned}
& \mathrm{C}_{\mathrm{m}} \mathrm{H}_{\mathrm{n}}(\text { aromatic })=\mathrm{C}_{\mathrm{m}} \mathrm{H}_{\mathrm{x}}(\text { coke })+(\mathrm{n}-\mathrm{x}) / 2 \mathrm{H}_{z} \\
& C_{m} H_{n}(\text { aromatic })=C_{m} H_{x}(\text { coke })+\frac{n-x}{2} H_{2}
\end{aligned}
$$


Such reaction is catalyzed by active sites. In absence of a reforming agent that can gasify the newly formed deposits, the carbon build-up gradually deactivates the carbonaceous surface. As a consequence, in practical applications it is advisable to consider the addition of air, steam or $\mathrm{CO}_{2}$ to prolong the activity of carbonaceous surfaces. The process has been documented by several authors in the temperature range $700-1000^{\circ} \mathrm{C}$ for different chars: commercial charcoal [4], activated carbons [4042], char from pyrolysis of wood [31,43], rice straw [44], coal [29,45] or waste [10].

On these grounds, temperature appears as the determinant factor defining the nature of the interaction between char and aromatic compounds. With this in mind, the purpose of this work was to observe the course of interaction between aromatics and the surface of char within the temperature range $250-$ $800^{\circ} \mathrm{C}$, differentiating between adsorption and cracking phenomena. A dedicated setup developed at TU Berlin has been used to examine the effects of char beds on selected tar model compounds, namely toluene and naphthalene. Both these substances are commonly used as tar model compounds, as representatives of light 1-ring aromatics and light polycyclic aromatic hydrocarbons, respectively. Naphthalene is also one of the most refractory and stable substances found in biomass tar [46].

To the best of our knowledge, this is the first time that the interaction between tar model compounds and chars was studied covering such a wide range of temperatures. This was done with the aim Moreover, to gain useful information for the design of an actual carbon-based tar removal system. In $\underline{\text { addition, }}$, residual gasification char was compared with-to similar-carbonaceous materials with different surface structures, including a commercial microporous $\mathrm{AC}_{2}$ and two pyrolysis-derived chars: one of them $\mathrm{CO}_{2}$-activated and the other one heat treated under $\mathrm{N}_{z}$-atmosphere.

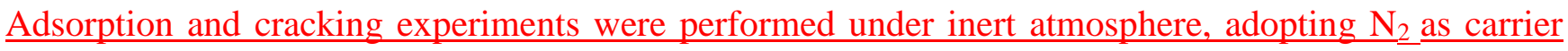
gas. In an actual gasification process, other gas species $\left(\mathrm{CO}_{2} \mathrm{H}_{2}, \mathrm{CH}_{4}, \mathrm{CO}_{2}\right.$, steam) would be present and influence adsorption and cracking of tar at the surface of char. Nevertheless, results obtained from tests in inert atmosphere can be used to compare the performance of different carbonaceous materials and to understand the relationship between the properties of chars and their effectiveness in tar reduction. In order to evaluate the suitability of the tested chars for tar reduction applications at high temperature, their surface structure was also analyzed in detail

Tar removal and conversion efficiencies were evaluated and surface characterization was performed before and after the experiments. The results provided valuable insight to investigate into -the 
mechanism of deactivation and interaction between aromatics and the surface of chars - in the mentioned temperature range.

\section{Materials and Method}

\subsection{Chars and activated carbons}

Four carbonaceous materials were tested in the setup. Residual gasification char was collected at the TwoStage demonstration plant at DTU (the Viking gasifier), where the solid residue is stockpiled inside a dedicated container. Before being used as a bed material in the experiments, the Viking char was crushed and sieved to obtain a particle size similar the other chars (1.4 to $2 \mathrm{~mm}$ ). The commercial $\mathrm{AC}$ has been kindly provided by Silcarbon Aktivkohle GmbH (Kirchhundem, Germany). According to the manufacturer this was a wood-derived $\mathrm{AC}$ which had been activated with steam for about 120 minutes at $800^{\circ} \mathrm{C}$. In the following it will be referred to as $\mathrm{AC}-\mathrm{H}_{2} \mathrm{O}$. The remaining two materials were produced in a screw pyrolysis unit at TU Berlin. Here, beech wood chips (Räuchergold ®, intended for food smoking) were pyrolyzed at $400^{\circ} \mathrm{C}$. After pyrolysis, char was subject to $\mathrm{CO}_{2}$ activation for 180 minutes at $750^{\circ} \mathrm{C}$ : the final product is referred to as $\mathrm{AC}-\mathrm{CO}_{2}$. Some of the material pyrolyzed at $400^{\circ} \mathrm{C}$ did not undergo activation, but heat treatment at $900^{\circ} \mathrm{C}$ under $\mathrm{N}_{2}$ atmosphere, to guarantee its thermal stability during high temperature experiments. Such pyrolysis-derived char will be referred to as PC$\mathrm{N}_{2}$. Figure 1 shows the different production and activation pathways. All chars were dried at $105^{\circ} \mathrm{C}$ for 3 hours and stored in a desiccator prior to be used in the experiments. 


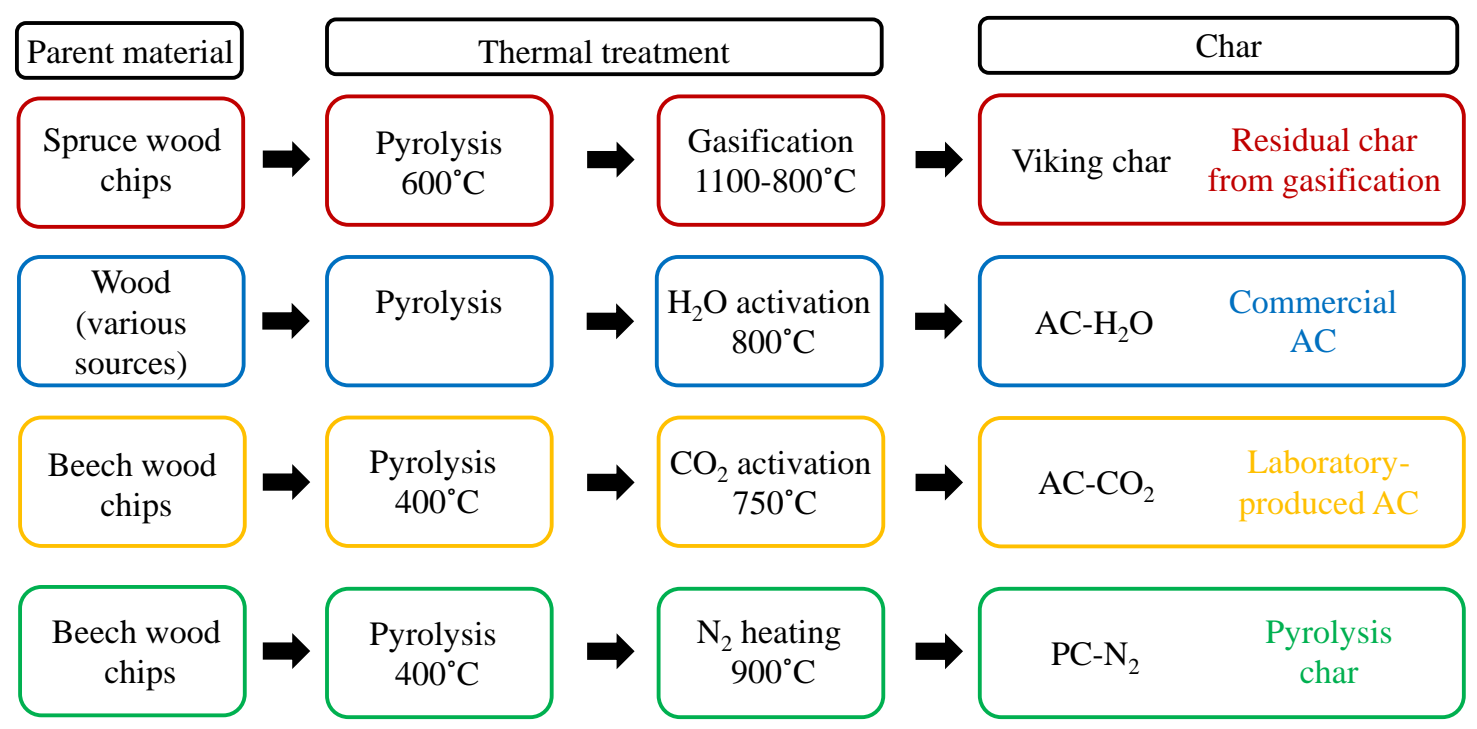

Figure 1: Production and activation of the tested chars.

\subsection{Characterization of chars}

All the selected chars were characterized in terms of composition and surface properties. Prior to any analysis, chars were reduced to powder in a ball mill. The volatile and ash content of chars were evaluated by using a muffle furnace, following CEN/TS 15148 and DIN $51719\left(815^{\circ} \mathrm{C}\right)$ respectively. The fixed carbon content was calculated by difference. The elemental composition (CHNS) was measured with a VarioEL III (Elementar Analysensystem GmbH, Germany). The trace elements present in the chars were detected by Inductively Coupled Plasma- Optical Emission Spectrometry (ICP-OES) (Varian 720 ES).

The specific surface area was quantified by Brunauer-Emmett-Teller (BET) analysis through $\mathrm{N}_{2}$ adsorption at 77 K (Nova 2200, Quantachrome Instruments, USA). Before each measurement, char samples were degassed at $150^{\circ} \mathrm{C}$ for 6 hours. The pore volume distribution was evaluated through Quenched Solid Density Functional Theory (QSDFT) using the calculation model for slit and cylindrical pores on the adsorption branch: this method is recommended for chemically and physically activated carbons [47]. The densities of char powders, used as inputs for the BET and DFT calculations, were measured with a helium pycnometer (Quantachrome Instruments, USA).

The bulk density of the chars used as bed materials (not grinded) was evaluated by using a scale and a graduated cylinder. The elemental composition (CHNS) and BET surface area were measured also on chars recovered after the tests, to evaluate the differences with fresh materials. 


\subsection{Experimental setup}

The experimental setup for testing the performance of char beds (Figure 2) was designed and built at TU Berlin. The setup consisted of a stainless steel tube reactor $500 \mathrm{~mm}$ in length, with an internal diameter of $36 \mathrm{~mm}$ to contain the char bed. The reactor was placed inside an electric furnace (Lenton, UK) and connected at the top with a gas generation system, whereas the outlet at the bottom was connected to the gas analysis train. A $\mathrm{N}_{2}$ flow $(4.7 \mathrm{l} / \mathrm{min})$ was controlled with a mass flow controller (Vögtlin, Switzerland) and was mixed with vapors of a toluene-naphthalene solution dosed with a syringe pump (Nemesys, Cetoni, Germany). The feed solution was prepared by mixing analytical grade toluene (purity $>=99.5 \%$, Carl Roth, Germany) with naphthalene crystals (purity >=99\%, Carl Roth, Germany). The solution was prepared with a concentration of $0.63 \mathrm{~mol} / \mathrm{L}$. The dosing of the syringe was set between 107-109 $\mu \mathrm{l} / \mathrm{min}$, according to the exact concentration of naphthalene in the solution, so to maintain a stable feed in all tests. The concentrations of toluene and naphthalene in the $\mathrm{N}_{2}$ were calculated to be $18345 \pm 0.5 \%$ and $1852 \pm 0.1 \% \mathrm{mg} / \mathrm{Nm}^{3}$, respectively. Evaporation of the solution took place inside a capillary which was kept at a temperature of $200^{\circ} \mathrm{C}$ by a dedicated oven. Vapors were mixed with a pre-heated flow of $\mathrm{N}_{2}$ in the tubing contained in the oven. The aromatics-enriched gas was delivered to the char reactor through heated lines $\left(180^{\circ} \mathrm{C}\right)$ to avoid condensation. The system was equipped with a 3-way switching valve allowing the aromatics-enriched $\mathrm{N}_{2}$ flow to be conveyed directly to the analytical instruments for background measurements (reactor bypass mode), or to be passed through the heated reactor during experiments.

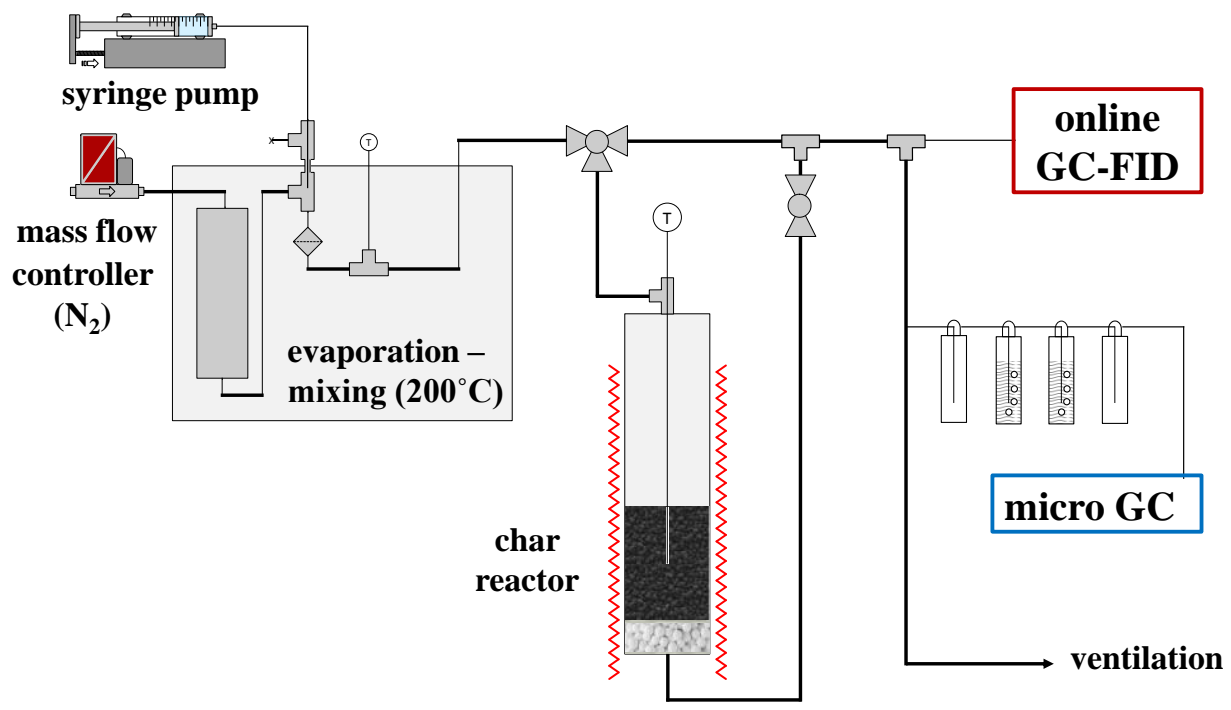

Figure 2: Diagram of the experimental setup. 


\subsection{Online gas analysis}

The online analysis consisted of a compact GC-FID (SRI Instruments, USA) for detection of toluene and naphthalene in the flow: the samples were eluted through a $30 \mathrm{~m}$ FS Supreme-5ms (5\% Phenylpolysilphenylenphase) column, heated to a constant temperature of $180^{\circ} \mathrm{C}$. A system of valves was used for automatic sampling of the gas: injections were made in series of ten, every 2 minutes. For the duration of the experiment, each series was set to start automatically after 1 minute. Downstream, the flow was washed through cooled bottles filled with 2-propanol before being fed to a double channel micro-GC (Inficon, Switzerland) with TCD detectors. Channel A was equipped with a Molar Sieve $5 \AA$ column $(10 \mathrm{~m} \times 320 \mu \mathrm{m})$ for detection of $\mathrm{N}_{2}, \mathrm{O}_{2}, \mathrm{H}_{2}, \mathrm{CO}$ and $\mathrm{CH}_{4}$. Samples were injected at $70^{\circ} \mathrm{C}$ and eluted at $80^{\circ} \mathrm{C}$ and 1.72 bar with Argon as carrier gas. Channel B mounted a PoraPlotQ column (8m x $320 \mu \mathrm{m}$ ) for detection of $\mathrm{CO}_{2}$ and light hydrocarbons. Samples were injected at $70^{\circ} \mathrm{C}$ and eluted at $100^{\circ} \mathrm{C}$ and 1.38 bar with Helium as carrier gas. The micro-GC was programmed to inject a gas sample in both channels every 4.5 minutes.

\subsection{Adsorption and cracking tests}

Prior to each test, the reactor was carefully cleaned with compressed air. At the bottom of the reactor, $30 \mathrm{~g}$ of $\mathrm{Al}_{2} \mathrm{O}_{3}$ cylindrical beads 5x5_mm (Sasol, Germany) were placed between two plugs of quartz wool to create a $5 \mathrm{~cm}$ tall support for the char. According to the producer, $\mathrm{Al}_{2} \underline{\mathrm{O}}_{3} \underline{\text { beads had a surface }}$ area of $204 \mathrm{~m}^{2} / \mathrm{g}$. The support was necessary so that the char bed would be positioned in the central part of the furnace, where the temperature was the closest to the oven set point. The bed material was then added in the reactor. The height of the char bed was kept constant in all experiments $(10 \mathrm{~cm})$ and the weight of the fresh bed varied from $8 \mathrm{~g}$ to $22 \mathrm{~g}$ depending on the bulk density of each char. In this way, the gas residence time in the char bed was maintained constant in the tests at the same temperature, varying from $0.72 \mathrm{~s}$ at $250^{\circ} \mathrm{C}$ to $0.35 \mathrm{~s}$ at $800^{\circ} \mathrm{C}$. The reactor was then sealed and placed inside the furnace. A thermocouple with the tip placed in the middle of the char bed was used to monitor the temperature inside the reactor.

Before the start of each experiment, the system was flushed with $\mathrm{N}_{2}$ to remove any oxygen present in the reactor or in the lines. As soon as no oxygen was detected by the micro-GC, the furnace and the lines were heated up to the desired set point. When the temperature set points in the system were reached and stable, the char bed was flushed with $\mathrm{N}_{2}$ for 60 minutes. Afterwards the syringe pump 
started dosing with the system in bypass mode, to verify the stability of the baseline concentrations. Each experiment was started by turning the 3-way valve so that the aromatics-enriched flow would pass through the reactor before encountering the gas analysis train. Long tests had to be interrupted for a refill of the syringe pump with fresh toluene-naphthalene solution. During refilling (1-2 minutes) the system was switched to bypass mode. Viking char and the two types of active carbon were tested at $250,400,600$ and $800^{\circ} \mathrm{C}$. PC- $\mathrm{N}_{2}$ char was tested only at the lowest and the highest temperature. An additional test was run with Viking char at the intermediate temperature of $500^{\circ} \mathrm{C}$. An overview of the experimental conditions is given in Table 1.

\begin{tabular}{cccccc}
\hline Temperature $\left[{ }^{\circ} \mathbf{C}\right]$ & 250 & 400 & 500 & 600 & 800 \\
\hline Residence time $[\mathbf{s}]$ & 0.72 & 0.56 & 0.49 & 0.43 & 0.35 \\
\hline Char bed $(\mathbf{1 0 0}$ & Viking & Viking & Viking & Viking & Viking \\
$\mathbf{m m})$ & $\mathrm{AC}-\mathrm{H}_{2} \mathrm{O}$ & $\mathrm{AC}-\mathrm{H}_{2} \mathrm{O}$ & & $\mathrm{AC}-\mathrm{H}_{2} \mathrm{O}$ & $\mathrm{AC}-\mathrm{H}_{2} \mathrm{O}$ \\
& $\mathrm{AC}-\mathrm{CO}_{2}$ & $\mathrm{AC}-\mathrm{CO}_{2}$ & & $\mathrm{AC}-\mathrm{CO}_{2}$ & $\mathrm{AC}-\mathrm{CO}_{2}$ \\
& $\mathrm{PC}-\mathrm{N}_{2}$ & & & & ${\mathrm{PC}-\mathrm{N}_{2}}$ \\
& & & & & \\
\hline
\end{tabular}

Table 1: Overview of experimental conditions. The gas residence time was calculated dividing the char bed height to the gas superficial velocity.

The baseline concentrations $\left(\mathrm{C}_{0}\right)$ of both toluene and naphthalene were measured with dedicated bypass runs for each experiment. During the whole campaign, the uncertainty on the baseline measurements was $7 \%$ for both compounds. This relatively large deviation was caused by the limited volume available in the lines between the syringe pump injection port and the measuring instrument. Whenever the flow was deviated through the reactor, therefore covering a longer path before reaching the instrument, the measured concentrations appeared more stable. Despite the oscillations recorded in the bypass mode, the average baseline values were stable from test to test. On these premises, the steadiness of the concentrations delivered by the mixing system was deemed satisfactory. 


\section{Results and Discussion}

\subsection{Preliminary char characterization}

Table 2 and 3 show the results of char compositional analysis, while Table 4 shows the results obtained by BET and DFT analysis, together with the bulk density of the bed materials.

\begin{tabular}{lccccccc}
\hline & \multicolumn{3}{c}{ Proximate composition (dry basis) } & \multicolumn{5}{c}{ Elemental composition } \\
& Volatiles & Fixed C & Ash & C & H & N & S \\
\hline Viking [wt\%] & 6.8 & 83.7 & 9.4 & 87.6 & 0.6 & 0.1 & $<0.1$ \\
$\mathbf{A C}-\mathbf{H}_{2} \mathbf{O}[\mathbf{w t} \%]$ & 4.4 & 90.8 & 4.9 & 88.9 & 0.2 & 0.3 & $<0.1$ \\
$\mathbf{A C - C O} \mathbf{C}_{\mathbf{2}}[\mathbf{w t} \%]$ & 4.1 & 93.1 & 2.6 & 90.9 & 0.7 & 0.3 & $<0.1$ \\
$\mathbf{P C}-\mathbf{N}_{2}[\mathbf{w t} \%]$ & 2.4 & 94.9 & 2.7 & 91.4 & 0.5 & 0.8 & $<0.1$ \\
\hline
\end{tabular}

Table 2: Proximate and elemental composition (dry basis) of the tested chars.

\begin{tabular}{cccccccccccc}
\hline & Na & Mg & $\mathbf{P}$ & $\mathbf{K}$ & $\mathbf{C a}$ & Al & $\mathbf{S}$ & $\mathbf{C r}$ & $\mathbf{M n}$ & $\mathbf{F e}$ & $\mathbf{N i}$ \\
\hline Viking [wt\%] & 0.101 & 0.205 & 0.124 & 2.070 & 2.092 & 0.024 & 0.081 & 0.002 & 0.047 & 0.089 & 0.001 \\
AC-H $\mathbf{H}_{2} \mathbf{O}[\mathbf{w t} \%]$ & 0.027 & 0.258 & 0.109 & 2.358 & 0.141 & 0.151 & 0.075 & 0.005 & 0.043 & 0.138 & 0.001 \\
AC-CO $_{2}[\mathbf{w t} \%]$ & 0.026 & 0.204 & 0.061 & 0.720 & 1.065 & 0.034 & 0.061 & 0.004 & 0.036 & 0.048 & 0 \\
\hline
\end{tabular}

Table 3: Overview of results of ICP-OES analysis.

The compositional analysis showed that the Viking char, in comparison with the other materials, had a smaller fraction of fixed carbon and higher ash content. This was expected considering that the Viking char had been exposed to harsh gasification reactions, as the TwoStage gasifier is known to achieve a carbon conversion efficiency close to 99\% [48]. The most abundant elements in the ashes were Ca and $\mathrm{K}$, followed by $\mathrm{Mg}, \mathrm{Fe}$ and $\mathrm{P}$. The largest difference among the tested materials was found in the abundance of $\mathrm{Ca}$ in the Viking char, and of $\mathrm{K}$ in both Viking char and $\mathrm{AC}-\mathrm{H}_{2} \mathrm{O}$. 
Table 4: Surface properties obtained with $\mathrm{N}_{2}$ adsorption at $77 \mathrm{~K}$.

The BET analysis showed that Viking char had the largest specific surface area, whereas PC-N $\mathrm{N}_{2}$ char had by far the lowest. The other two chars, that had undergone similar activation treatments, had a comparable BET area and pore volume. In order to understand the difference in the surface morphology of the tested materials, it is useful to consider the isotherms obtained with $\mathrm{N}_{2}$ adsorption at $77 \mathrm{~K}$ (Figure 3). Following the IUPAC classification [49], the isotherms obtained from both $\mathrm{AC}-\mathrm{H}_{2} \mathrm{O}$ and $\mathrm{AC}-\mathrm{CO}_{2}$ resemble a reversible type I, suggesting that these materials are microporous. Particularly the latter shows the narrowest pore size distribution. PC- $\mathrm{N}_{2}$ char also generated an isotherm resembling type $\mathrm{I}$, but with much lower $\mathrm{N}_{2}$-uptake. In contrast, the isotherm obtained from Viking char is a composite of type I and II, with a marked hysteresis (type H4). This kind of isotherm indicates a micro - mesoporous materials, and is often associated with slit-shaped pores [49,50]. The adsorbed volume increasing at higher relative pressures indicates the presence of mesopores $(>2 \mathrm{~nm})$ and macropores (> $50 \mathrm{~nm})$. 

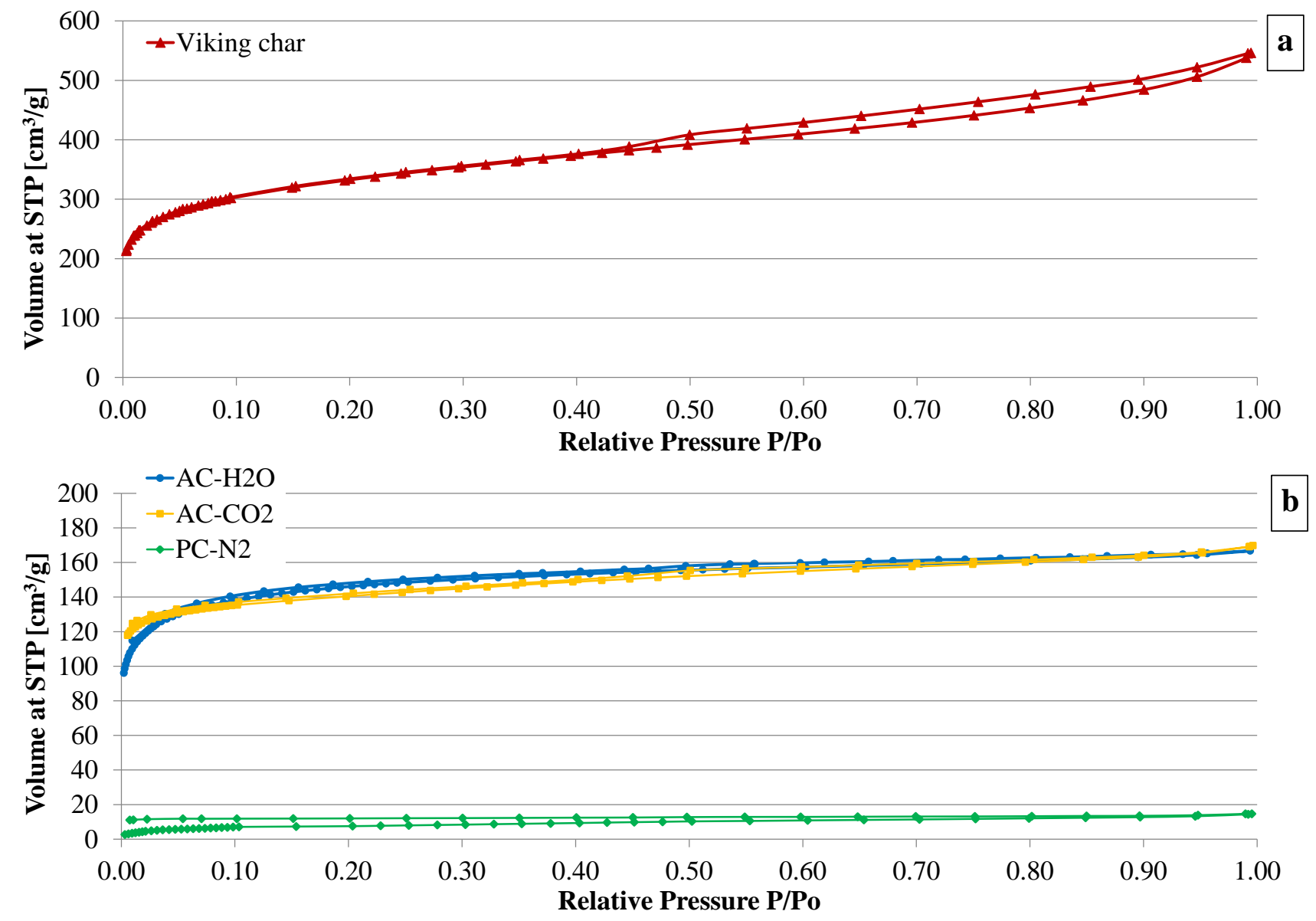

Figure 3: Comparison of isotherms obtained with $\mathrm{N}_{2}$ adsorption at $77 \mathrm{~K}$ on Viking char (a), $\mathrm{AC}-\mathrm{H}_{2} \mathrm{O}$, $A C-\mathrm{CO}_{2}$ and $\mathrm{PC}-\mathrm{N}_{2}(\mathrm{~b})$. Isotherms are plotted separately as they have a different scale on the $y$-axis.

Even though $\mathrm{N}_{2}$ adsorption at $77 \mathrm{~K}$ is not the optimal method to determine the micropore size distribution, in this instance it has been used to estimate the total micropore volumes for the sake of comparing the chars. The total pore volumes and micropore volumes obtained through DFT analysis are reported in Table 4. As for the BET surface area, the highest and lowest values were observed for the Viking char and the PC-N 2 char, respectively. The differences in the textural characteristics of the chars were confirmed by the distribution of the surface area over the pore sizes: significant deviations were observed in the pore size range between 2 and $15 \mathrm{~nm}$, showed in Figure 4.

Viking char appears to have the largest surface associated with mesopores, with pore width spanning from 2 to $12 \mathrm{~nm}$. AC- $\mathrm{H}_{2} \mathrm{O}$ exhibits a narrower distribution, confined between 2 and $5 \mathrm{~nm}$. In this size range, $\mathrm{PC}-\mathrm{N}_{2}$ and $\mathrm{AC}-\mathrm{CO}_{2}$ show similar distributions. This is not unexpected, as they are derived from 
the same parent material; however the effect of $\mathrm{CO}_{2}$ activation is evident not only in the increased surface area associated with micropores but also with mesopores between 2.5 and $6 \mathrm{~nm}$.

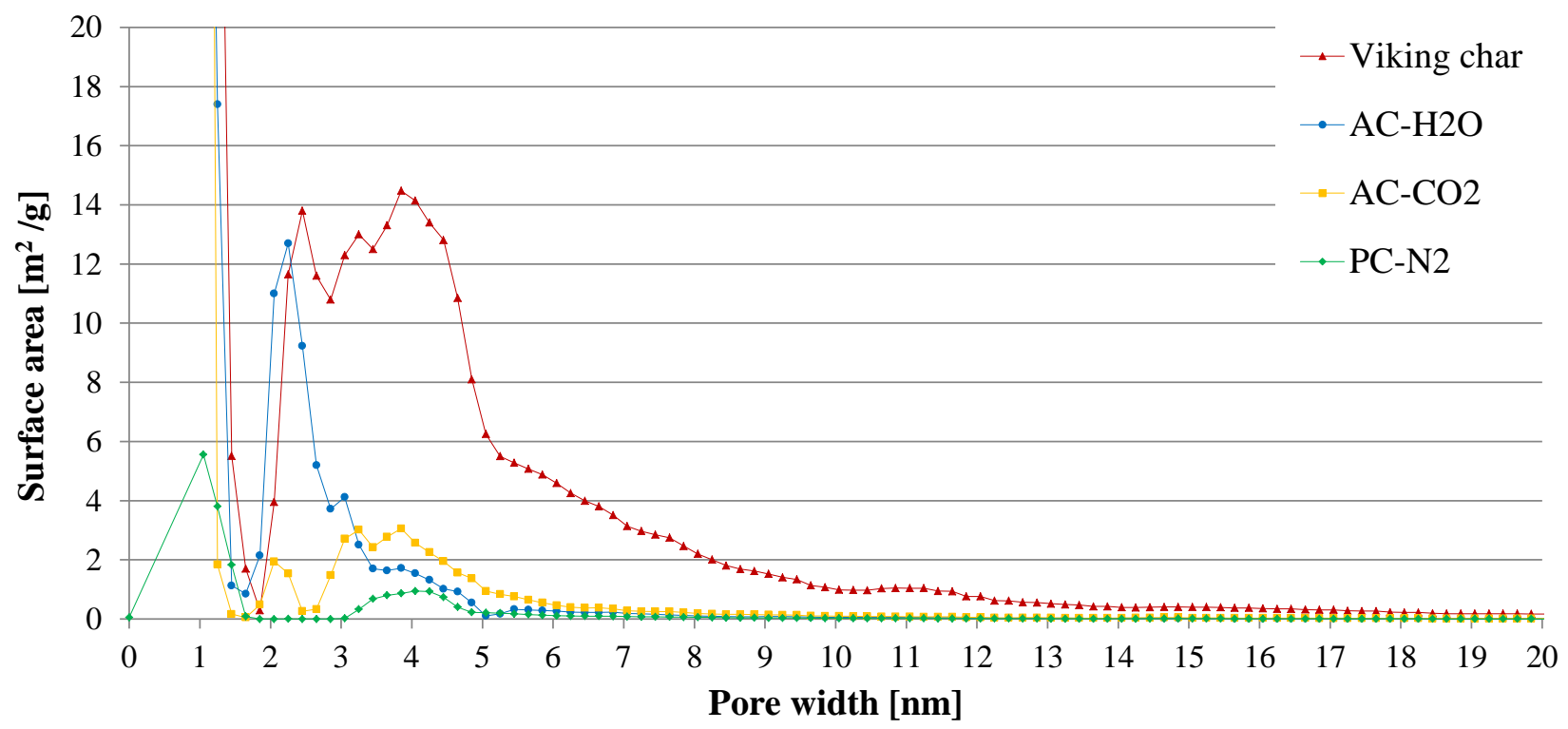

Figure 4: Comparison of surface area distributions in the small mesopores range, obtained with QSDFT analysis for the different chars.

The characterization analysis on the tested materials showed the marked differences among them, especially in regard to surface structure and pore distribution. The different surface properties affected significantly the interaction with the tested aromatic compounds.

The surface oxygen groups present on the surface of chars (lactones, carboxylic acid or phenol and basic groups such as carbonylic, quinonic and pyrone structures) are known to have an influence on the adsorption capacity at low adsorbate concentrations [51]. They might also affect the catalytic properties of chars [52]. However, the oxygen content of active carbon is known to decrease with increasing activation temperatures, reaching a minimum at temperatures above $1000^{\circ} \mathrm{C}$ [53]. Moreover, oxygen groups were found to desorb from the surface of chars at temperatures lower than $800^{\circ} \mathrm{C}$ [54]. In light of this, because the chars that have been tested in this work were treated at temperatures of $750^{\circ} \mathrm{C}$ or higher before being used as bed materials, oxygen functional groups were not considered to significantly affect the performances of chars. 
3.2 Results from experiments in the temperature range $250-400^{\circ} \mathrm{C}$

During the experiments performed with reactor temperatures of 250 and $400^{\circ} \mathrm{C}$, toluene permeated very quickly through the char beds. It regained the baseline concentration level after 10 minutes when the reactor contained Viking char, and in about 20 minutes with the two types of AC. When PC- $\mathrm{N}_{2}$ char was used in the reactor, the toluene concentration was hardly affected. The abrupt breakthroughs did not allow a reliable calculation of the adsorption capacity of toluene for the tested materials.

In contrast, chars and AC had a more pronounced effect on the concentration of naphthalene, which took a longer time to breakthrough in all tests. This effect can be ascribed to the high concentration of toluene that prompted a sudden breakthrough, but also to the predilection of the char surfaces for purely aromatic compounds. This is due to the specific interactions between $\pi$-electron rich regions of solid carbon and the aromatic rings and has been described for low adsorbate concentrations [25,55].

The breakthrough curves traced by the relative concentration of naphthalene $C / C_{0}$ are shown in Figure 5. $\mathrm{C}$ and $\mathrm{C}_{0}$ indicate the instantaneous concentration and the baseline concentration, respectively.

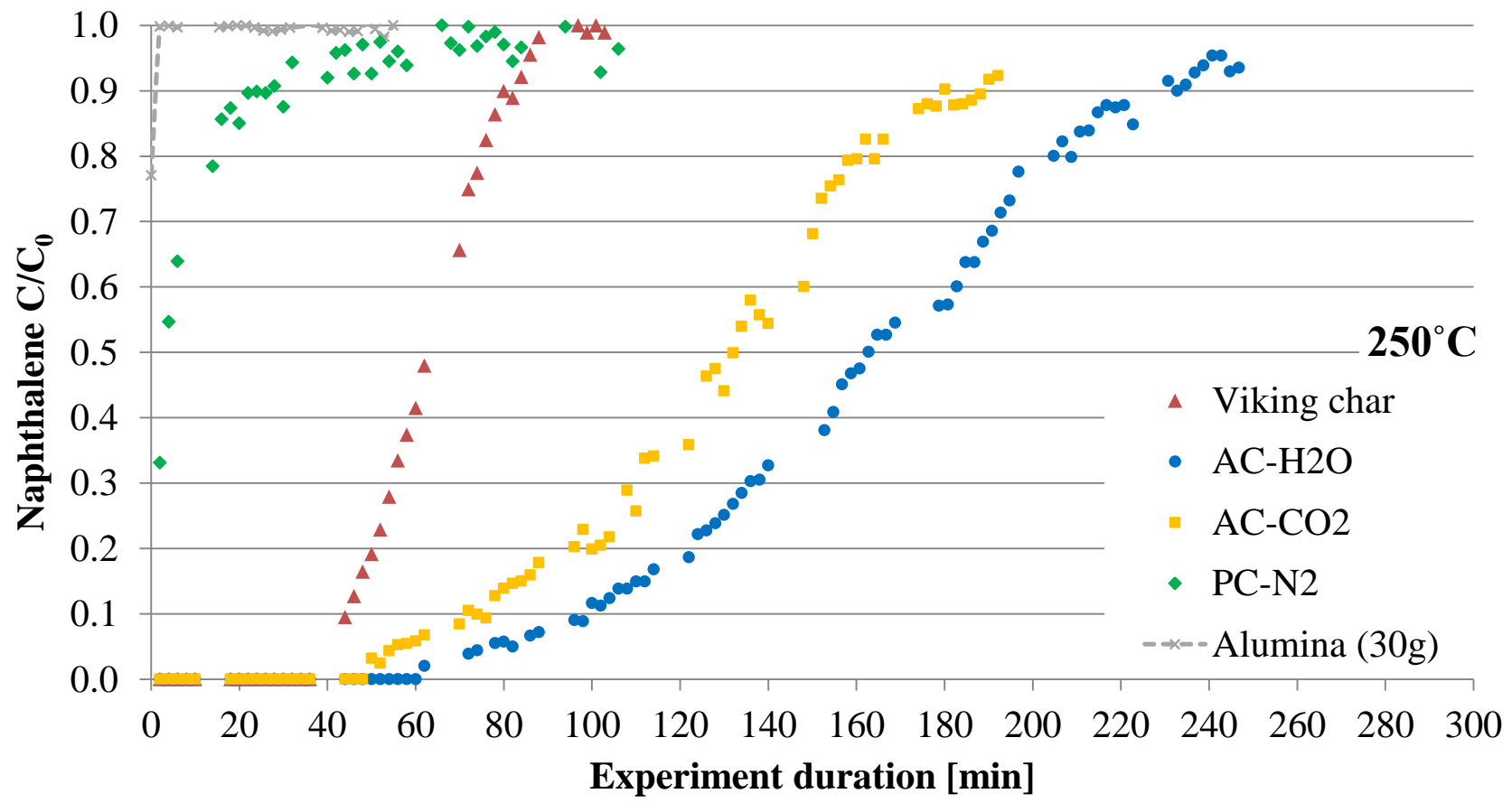

Figure 5: Naphthalene breakthrough curves obtained with different chars, bed temperature $250^{\circ} \mathrm{C}$. 
The tested chars showed different effects on the naphthalene concentration. $\mathrm{AC}-\mathrm{H}_{2} \mathrm{O}$ attained the longest breakthrough time, followed by $\mathrm{AC}-\mathrm{CO}_{2}$. Both chars produced a similar, gradual breakthrough curve. The long time to breakthrough was partly due to their well-developed microporosity, but also to the higher bulk density of these chars (see Table 4). Indeed, even if the bed volume was constant, the Viking char bed weighed $8 \mathrm{~g}$, while the beds of $\mathrm{AC}-\mathrm{H}_{2} \mathrm{O}$ and $\mathrm{AC}-\mathrm{CO}_{2}$ weighed 22.5 and $15 \mathrm{~g}$, respectively.

Despite the shorter breakthrough time, the specific adsorption capacity of Viking char was comparable with the two activated materials. The bed of $\mathrm{PC}-\mathrm{N}_{2}$ char had a minor effect on the naphthalene concentration, and the very short breakthrough time reflected a very low adsorption capacity.

The breakthrough curves obtained from the GC-FID measurements were used to calculate adsorption capacity $\mathrm{q}\left(\mathrm{mg} / \mathrm{g}_{\mathrm{char}}\right)$ of the chars following (2)

$q=\frac{Q}{W}\left[C_{0} t_{f}-\frac{1}{2} \sum_{0}^{t_{f}}\left[C\left(t_{n}\right)+C\left(t_{n-1}\right)\right] * \Delta t\right]$

Where $\mathrm{Q}$ is the nitrogen flow $\left(\mathrm{Nm}^{3} / \mathrm{min}\right), \mathrm{W}$ is the weight of the bed material in the reactor $(\mathrm{g}), \mathrm{C}_{0}$ is the inlet concentration $\left(\mathrm{mg} / \mathrm{Nm}^{3}\right), \mathrm{t}_{\mathrm{n}}$ is the $\mathrm{n}_{\mathrm{th}}$ data point, $\mathrm{t}_{\mathrm{f}}$ is the time (min) when complete breakthrough is reached and $\Delta \mathrm{t}=\mathrm{t}_{\mathrm{n}}-\mathrm{t}_{\mathrm{n}-1}$.

Viking char, $\mathrm{AC}-\mathrm{H}_{2} \mathrm{O}$ and $\mathrm{AC}-\mathrm{CO}_{2}$ were also tested for adsorption at $400^{\circ} \mathrm{C}$. At this temperature, breakthroughs were significantly faster: for Viking char, less than 30 minutes were sufficient for the relative concentration of naphthalene to reach 1 . Table 5 collects the calculated adsorption capacities for the tested materials.

\begin{tabular}{ccc}
\hline & \multicolumn{2}{c}{ Adsorption capacity for naphthalene } \\
\hline Char bed temperature & $250^{\circ} \mathrm{C}$ & $400^{\circ} \mathrm{C}$ \\
\hline & $\mathrm{mg} / \mathrm{g}_{\mathrm{char}}$ & $\mathrm{mg} / \mathrm{g}_{\mathrm{char}}$ \\
\hline Viking & 66.7 & 9.5 \\
$\mathbf{A C}-\mathbf{H}_{\mathbf{2}} \mathbf{O}$ & 60.5 & 9.7 \\
$\mathbf{A C}-\mathbf{C O}_{2}$ & 75.4 & 21.1 \\
$\mathbf{P C}-\mathbf{N}_{\mathbf{2}}$ & 4.1 & Not measured \\
\hline Table 5: Naphthalene adsorption capacities at $250^{\circ} \mathrm{C}$ and $400^{\circ} \mathrm{C}$.
\end{tabular}

Table 5: Naphthalene adsorption capacities at $250^{\circ} \mathrm{C}$ and $400^{\circ} \mathrm{C}$. 
The increase in bed temperature caused a sharp decline in the adsorption capacity for the tested chars. The negative correlation between adsorption capacity and temperature is due to the exothermic nature of the adsorption process and has been observed in previous works $[26,35,56]$. This trend was confirmed with an experiment performed with Viking char at $500^{\circ} \mathrm{C}$ : the breakthroughs of both toluene and naphthalene were almost instantaneous and the naphthalene adsorption capacity was found to drop further to $1.3 \mathrm{mg} / \mathrm{g}_{\text {char }}$. Figure 6 (a-c) shows the breakthrough curves obtained at different temperatures using Viking char, $\mathrm{AC}-\mathrm{H}_{2} \mathrm{O}$ and $\mathrm{AC}-\mathrm{CO}_{2}$ as bed materials.
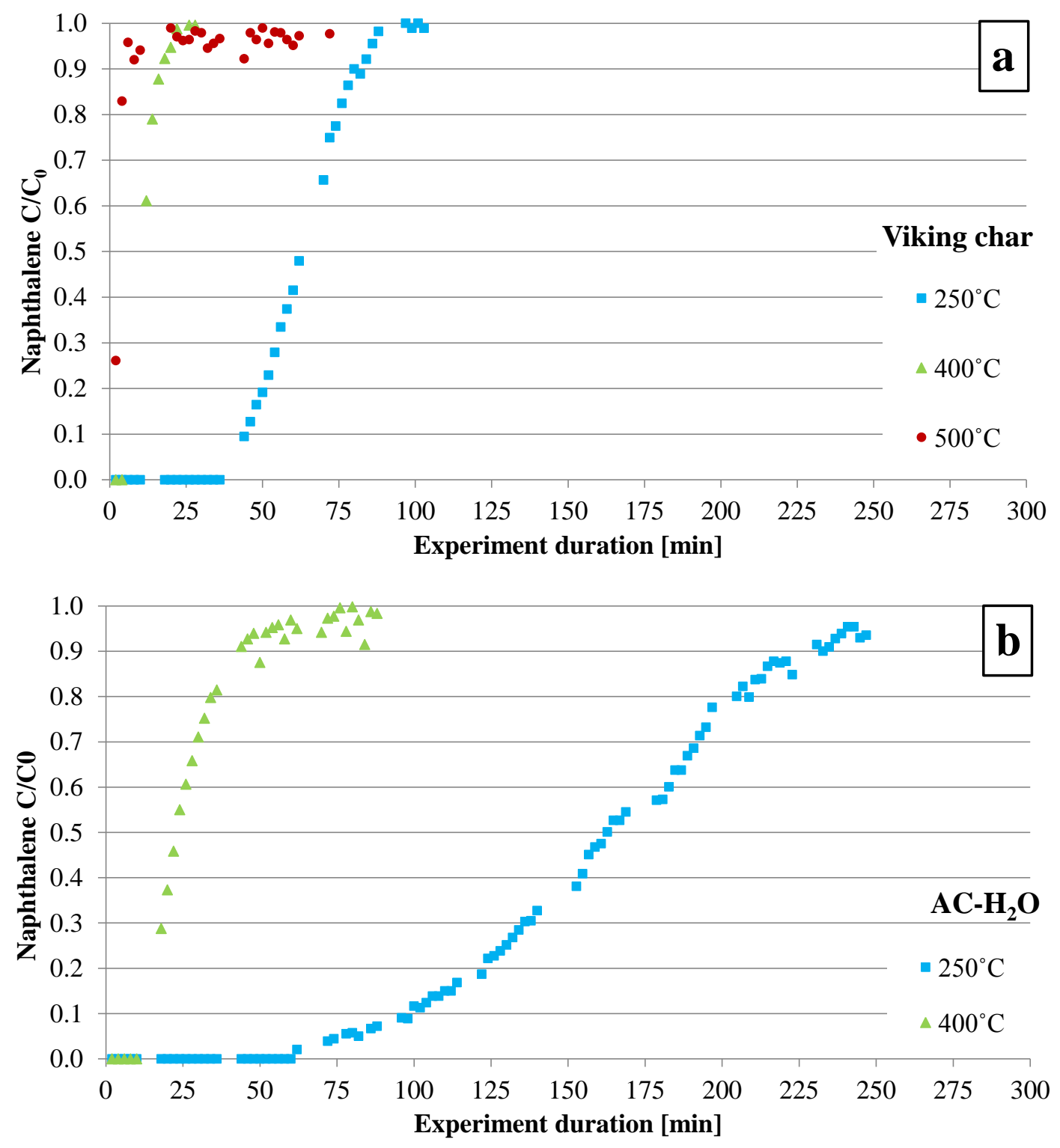


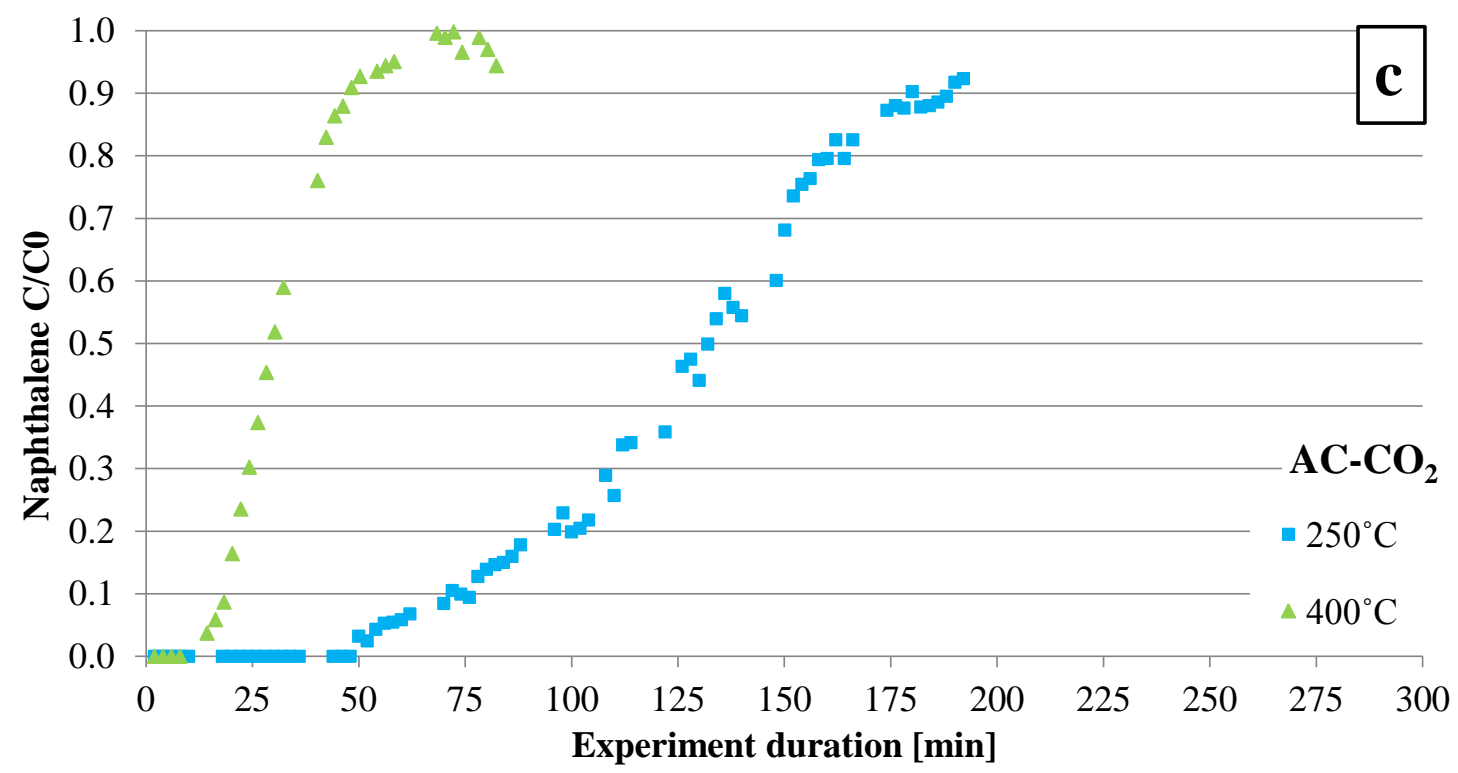

Figure 6: Naphthalene breakthrough obtained with Viking char (a), $\mathrm{AC}-\mathrm{H}_{2} \mathrm{O}(\mathrm{b})$ and $\mathrm{AC}-\mathrm{CO}_{2}(\mathrm{c})$ at different temperature levels.

These results suggested that adsorption performance of chars and activated carbons (e.g. if used in carbon filters) can be hindered by medium-high temperatures.

At 250 and $400^{\circ} \mathrm{C}, \mathrm{AC}-\mathrm{CO}_{2}$ showed the highest adsorption capacity for naphthalene: this can be ascribed to the surface texture of this char, which is the richest in micropores as a consequence of $\mathrm{CO}_{2}$ activation [57]. Viking char and $\mathrm{AC}-\mathrm{H}_{2} \mathrm{O}$ exhibited somehow comparable adsorption capacities, even though the highest density of char $\mathrm{AC}-\mathrm{H}_{2} \mathrm{O}$ led to a longer time to breakthrough. $\mathrm{PC}-\mathrm{N}_{2}$ showed a dramatically lower adsorption capacity in comparison with the other materials. According to Mastral et al. [58], total microporosity is the main factor influencing adsorption of aromatics on the surface of AC: the lack of micropores explains the poor performance of non-activated char.

Overall, microporous AC with high bulk density appeared as a promising material for tar adsorption applications at temperatures of $250^{\circ} \mathrm{C}$ and below. The performance of $\mathrm{AC}$ could be improved if the activation process during manufacturing would be optimized for this specific application. In real conditions, the tar mixture also contains aromatics larger than naphthalene (4- or 5- rings) which would also require pores in the mesoporous range for optimal adsorption [24]. In this instance, AC could be particularly useful in the fine cleaning of biomass producer gas, with low levels of tar contamination. It is worth to point out that in the temperature range 250 to $400^{\circ} \mathrm{C}$ no gases other than $\mathrm{N}_{2}$ were detected 
with micro-GC in the exit gas. The typical shape of breakthrough curves associated with adsorption phenomena and the absence of other gas species at the outlet of the system confirmed that no decomposition reactions took place in these conditions. Only in the experiment at $500^{\circ} \mathrm{C}$ with Viking char, traces of hydrogen were detected $(<0.01 \mathrm{Vol} \%)$, suggesting that cracking reactions were incipient at this temperature.

\subsection{Cracking of aromatics at 600 and $800^{\circ} \mathrm{C}$}

During experiments carried out at higher temperatures, the concentration of both toluene and naphthalene at the outlet of the system evolved somehow differently, and at the highest temperature complete breakthrough was not achieved. The evolution of relative concentrations $\left(\mathrm{C} / \mathrm{C}_{0}\right)$ of naphthalene and toluene at $600^{\circ} \mathrm{C}$ are depicted in Figure 7. The relative conversion of aromatics was calculated by using the average bypass concentration values measured for each experiment.
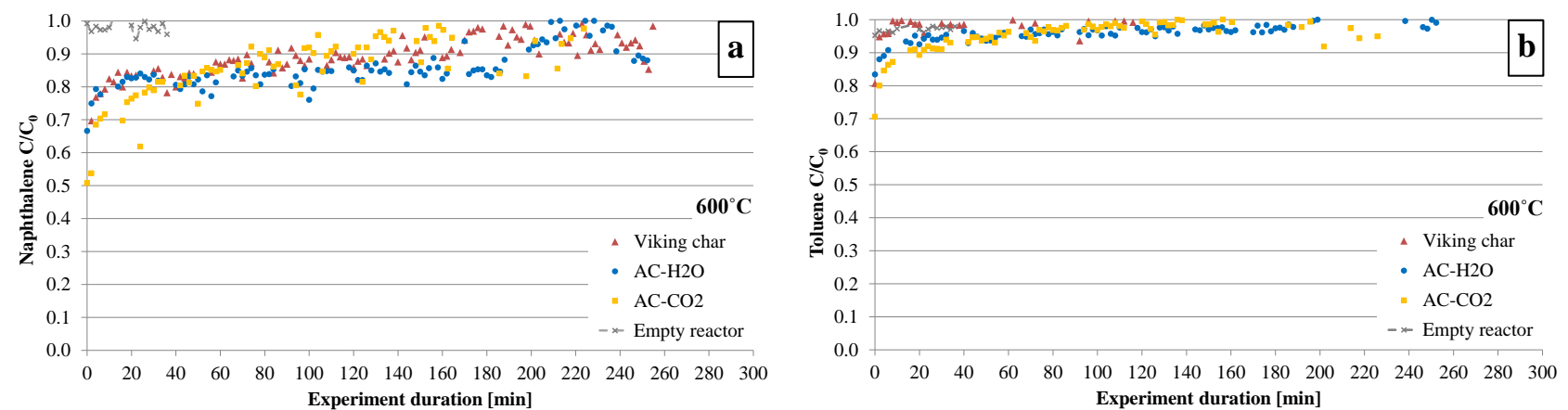

Figure 7: Evolution of the relative concentrations of naphthalene $(a)$ and toluene $(b)$ at the outlet of the reactor during experiments at $600^{\circ} \mathrm{C}$.

The change of $\mathrm{C} / \mathrm{C}_{0}$ over time shows that at $600^{\circ} \mathrm{C}$ the char beds had a limited effect on the concentration of aromatics in the gaseous flow, particularly in the case of toluene. Viking char, AC$\mathrm{H}_{2} \mathrm{O}$ and $\mathrm{AC}-\mathrm{CO}_{2}$ were tested in these conditions, but the type of char used in the reactor did not appear to significantly influence the conversion values. For all tested chars, small amounts of $\mathrm{H}_{2}$ were detected at the outlet of the system. $\mathrm{H}_{2}$ concentration in the exit gas exhibited similar trends over time with the three chars, peaking around $0.07 \mathrm{Vol} \%$ during the first hour of experiment, to decrease gradually afterwards and stabilizing around 0.03-0.04 Vol\%. 

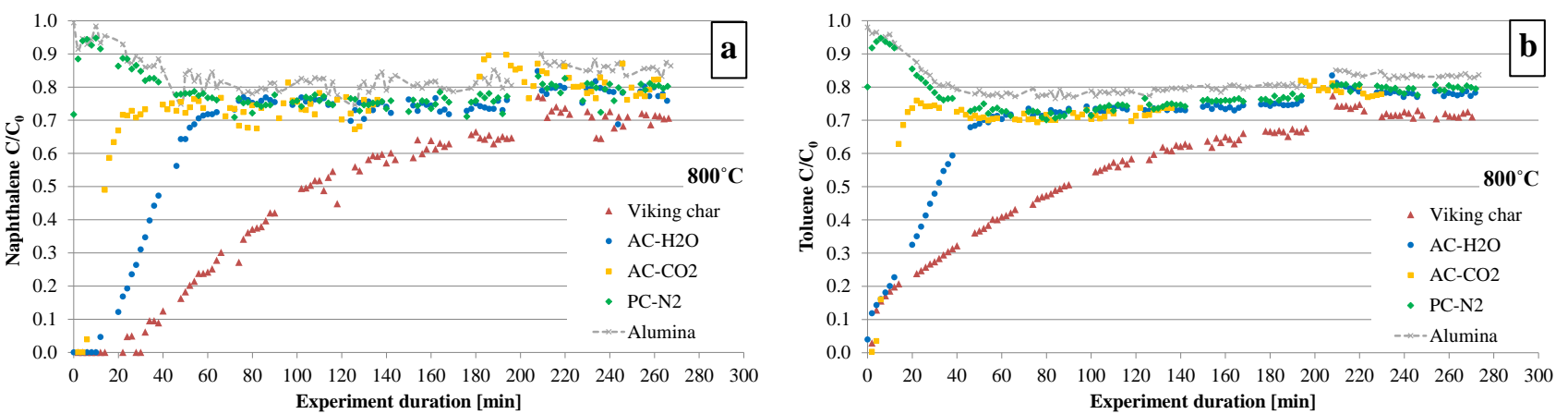

Figure 8: Evolution of the relative concentrations of naphthalene $(a)$ and toluene $(b)$ at the outlet of the reactor during experiments at $800^{\circ} \mathrm{C}$.

In these conditions the char $\mathrm{PC}-\mathrm{N}_{2}$ was also tested and it produced conversion values very similar to the blank test. However, in presence of this char, $\mathrm{C} / \mathrm{C}_{0}$ values remained slightly lower than the blank test, indicating a mild activity of the char surface. It is also interesting to notice the trend showed by both blank test and pyrolysis char test at the beginning of the experiment, with $\mathrm{C} / \mathrm{C} 0$ peaking close to 1 , then decreasing and stabilizing at $\mathrm{C} / \mathrm{C}_{0}$ between 0.7 and 0.8 . These trends indicate that in these two cases the deposition of carbon could actually support the decomposition of aromatics. The same effect was observed by Korus et al. [42], who found that coke-covered AC was still able to interact and decompose toluene, even if with a low level of conversion.

For the other chars, the very high conversion values were measured at the beginning of the tests: Viking char was the one performing better for naphthalene removal, attaining a complete conversion for about 30 minutes. Both $\mathrm{AC}-\mathrm{H}_{2} \mathrm{O}$ and $\mathrm{AC}-\mathrm{CO}_{2}$ achieved complete conversion for a shorter time (about 12 and 6 minutes, respectively). For toluene, complete conversion was observed for these chars only at the very beginning of the test. It appears as naphthalene was converted more efficiently than 
toluene. This observation agrees with the increased reactivity of chars towards compounds with increased aromaticity that has been observed in previous works $[4,8,9,29,45]$. However, it is worth to keep in mind that the concentrations of toluene and naphthalene differ by an order of magnitude (18345 $\pm 0.5 \%$ and $1852 \pm 0.1 \% \mathrm{mg} / \mathrm{Nm}^{3}$, respectively). This might have influenced their conversion efficiency.

Viking char, $\mathrm{AC}-\mathrm{H}_{2} \mathrm{O}$ and $\mathrm{AC}-\mathrm{CO}_{2}$ provided decreasing conversions over time as a consequence of surface deactivation. $\mathrm{AC}-\mathrm{H}_{2} \mathrm{O}$ and $\mathrm{AC}-\mathrm{CO}_{2}$ exhibited a fast deactivation, as they both converged with the $\mathrm{C} / \mathrm{C}_{0}$ values of $\mathrm{PC}-\mathrm{N}_{2}$ char in about 20 and 60 minutes, respectively. In contrast, Viking char produced a less abrupt increase of $\mathrm{C} / \mathrm{C}_{0}$, reaching a plateau after about 220 minutes from the start of the experiment. Also, the plateau value was still below the other chars.

The exact same trends can also be observed in the composition of the exit gas measured by micro-GC at the outlet of the system, as depicted in Figure 9. Again, the data gaps starting at 200 minutes originate from the measurement interruption to allow the syringe pump refilling. The gas conditioning system before the micro-GC required about 40 minutes for the instrument to show stable measurements. In the exit gas, $\mathrm{H}_{2}$ and $\mathrm{CH}_{4}$ were the only gases other than $\mathrm{N}_{2}$ that were detected by micro-GC. The absence of $\mathrm{CO}$ and $\mathrm{CO}_{2}$ was expected due to the lack of $\mathrm{O}_{2}$ and of any other reforming agent inside the reactor.
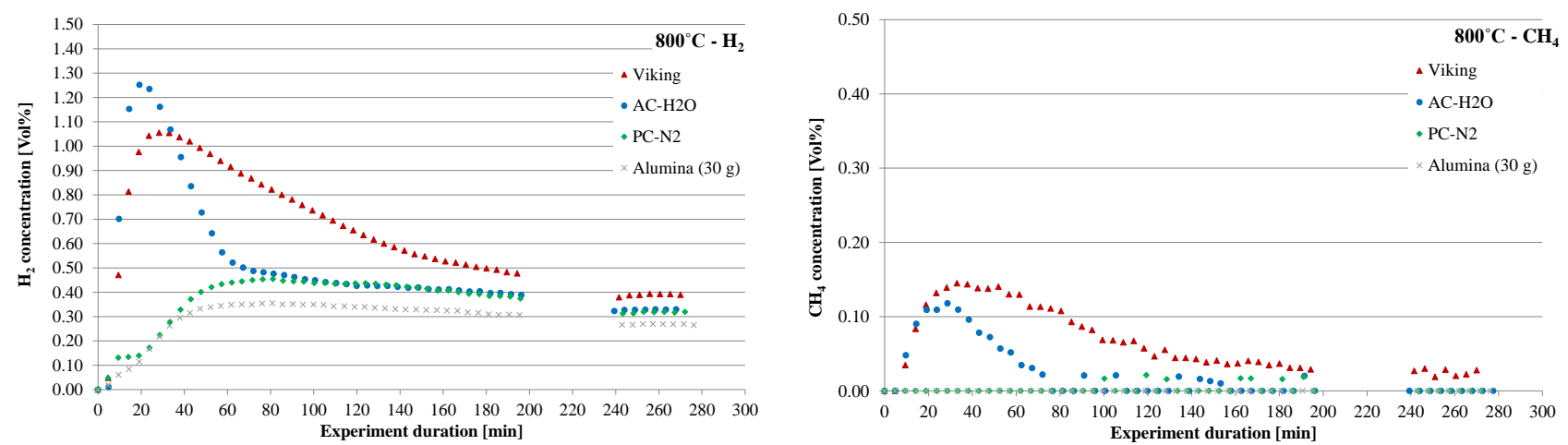

Figure 9: $\mathrm{H}_{2}$ and $\mathrm{CH}_{4}$ concentrations measured during of tests with Viking char, $\mathrm{AC}-\mathrm{H}_{2} \mathrm{O}, \mathrm{PC}-\mathrm{N}_{2}$ and blank test $\left(\mathrm{Al}_{2} \mathrm{O}_{3}\right)$. Note that different scales are used on the y-axes.

At $800^{\circ} \mathrm{C}$, the $\mathrm{H}_{2}$ production increased significantly if compared with the results at $600^{\circ} \mathrm{C}$, reaching peaks above $1 \mathrm{Vol} \%$ for both Viking char and $\mathrm{AC}-\mathrm{H}_{2} \mathrm{O}$. In addition, small amounts of $\mathrm{CH}_{4}$ could be detected in the exit gas. $\mathrm{H}_{2}$ formation was expected as a product of reaction (1). The presence of $\mathrm{CH}_{4}$ as a reaction product most probably originated from the hydrogenation of methyl radicals, which form 
upon the initiation of toluene pyrolysis [42,59]. It is possible that benzene was also a product of decomposition, but this molecule was not detected by the applied GC-FID method.

The declining trends in the production of both $\mathrm{H}_{2}$ and $\mathrm{CH}_{4}$ confirm the deactivation of the char surfaces, with the same patterns observed on the GC-FID results. AC- $\mathrm{H}_{2} \mathrm{O}$ showed a steeper decline in comparison with Viking char, and the production of both gases reached the levels of PC- $\mathrm{N}_{2}$ char between 60 and 80 minutes from the start. It was not possible to quantitavely compare the $\mathrm{H}_{2}$ and $\mathrm{CH}_{4}$ production generated by $\mathrm{AC}-\mathrm{CO}_{2}$ with the other results, because of a slight variation in the quantification baseline for the micro-GC. However, it was qualitatively similar to $\mathrm{AC}-\mathrm{H}_{2} \mathrm{O}$, with even steeper decreases in the concentration of both gases.

The same deactivation tendencies for the different chars are suggested by the evolution of the relative concentrations over time and by the composition of the exit gas. Viking char showed the slowest deactivation, even though considering the differences in the density of chars, the total surface area within the char beds was comparable (around $10.000 \mathrm{~m}^{2}$ ). The prolonged activity of the residual gasification char can be ascribed to the wide pore size distribution including micro- and mesopores that could have facilitated the diffusion of the aromatic molecules. Indeed, mesoporous chars with large surface area are in general considered to have better long-term activity than microporous chars $[41,60]$. On the other hand, the pore size distribution of both types of AC was narrow and shifted towards small pores, therefore parts of their surface area could have been inaccessible; or easily made so by carbon deposition. Because of the pore structures their activity declined quickly, once most of the micropores were clogged. The slower deactivation tendency of Viking char is therefore ascribed in part to the larger specific surface area and to the wider pore size distribution, but also to the higher content in minerals (especially $\mathrm{Ca}$ and $\mathrm{K}$ ), which might have migrated to the surface a consequence of the high temperatures encountered within the TwoStage gasification process. Indeed, the features that favored the activity of Viking char originated from the high degree of burn-off of this char.

It is important to underline that the described deactivation trends were observed in $\mathrm{N}_{2}$ inert atmosphere. $\underline{\text { In real conditions, other species present in the gas phase would interact with the char surface and the tar }}$ compounds. In particular, $\mathrm{CO}_{2}$ and steam would participate in reforming reactions of carbon and delay deactivation. However, these results can be considered as an indication of the deactivation tendency that tested chars would exhibit in real conditions. 
The detection of $\mathrm{H}_{2}$ as the main reaction product and the lack of light hydrocarbons in the exit gas confirm the mechanism of decomposition of aromatics over char described elsewhere [4,39,44], with dehydrogenation and coke formation through condensation/polymerization reactions. This reaction pathway was also confirmed by the characterization tests performed on the spent chars.

\subsection{Analysis on spent chars}

The results from tests at 600 and especially at $800^{\circ} \mathrm{C}$ gave evidence that the aromatic compounds were decomposed. In order to study the effect of such reactions on the surface of chars, the spent materials were carefully collected and analyzed.

The tests performed at $600^{\circ} \mathrm{C}$ had duration between 2 and 5 hours with the different char, depending on how fast deactivation was proceeding. As a result, it is difficult to compare the spent chars. However, the char beds (Viking char, $\mathrm{AC}-\mathrm{H}_{2} \mathrm{O}$ and $\mathrm{AC}-\mathrm{CO}_{2}$ ) all showed a slight weight gain around $2 \%$ of the original value.

On the other hand, all the experiments performed at $800^{\circ} \mathrm{C}$ had similar duration, therefore the results from post-analysis characterization can be compared. Significant differences between fresh and spent chars were found in the bed weight, specific surface area and carbon content on the samples obtained with experiments at $800^{\circ} \mathrm{C}$. Table 6 collects some of the values measured on the fresh and spent chars.

\begin{tabular}{|c|c|c|c|c|c|c|c|c|c|c|}
\hline & \multicolumn{2}{|c|}{$\begin{array}{c}\text { Bed weight } \\
{[\mathrm{g}]}\end{array}$} & \multicolumn{2}{|c|}{$\begin{array}{c}\text { Carbon } \\
\text { content } \\
{[\mathrm{g}]}\end{array}$} & \multicolumn{2}{|c|}{$\begin{array}{c}\text { Surface area } \\
\qquad\left[\mathrm{m}^{2} / \mathrm{g}\right]\end{array}$} & \multicolumn{2}{|c|}{$\begin{array}{c}\text { DFT pore } \\
\text { volume } \\
{\left[\mathrm{cm}^{3} / \mathrm{g}\right]}\end{array}$} & \multicolumn{2}{|c|}{$\begin{array}{c}\text { DFT } \\
\text { micropore } \\
\text { volume } \\
{\left[\mathrm{cm}^{3} / \mathrm{g}\right]}\end{array}$} \\
\hline & Fresh & Spent & Fresh & Spent & Fresh & Spent & Fresh & Spent & Fresh & Spent \\
\hline Viking & 9.0 & 14.7 & 7.9 & 13.8 & 1235 & 55.3 & 0.79 & 0.04 & 0.37 & 0.02 \\
\hline $\mathrm{AC}-\mathrm{H}_{2} \mathrm{O}$ & 22.4 & 24.2 & 19.9 & 22.8 & 553 & 389 & 0.24 & 0.17 & 0.19 & 0.13 \\
\hline $\mathrm{AC}-\mathrm{CO}_{2}$ & 14.1 & 14.6 & 12.8 & 13.7 & 564 & 366 & 0.24 & 0.16 & 0.19 & 0.12 \\
\hline PC-N ${ }_{2}$ & 20.5 & 19.8 & 19.0 & 18.7 & 35 & 267 & 0.02 & 0.13 & 0.01 & 0.08 \\
\hline
\end{tabular}

Table 6: Overview of the characterization results relative to fresh and spent chars (after tests at $800^{\circ} \mathrm{C}$ ). The duration of all the tests was $270 \mathrm{~min}$, with the exception of $\mathrm{AC}-\mathrm{CO}_{2}$ which was tested for 230 minutes. 
Viking char, $\mathrm{AC}-\mathrm{H}_{2} \mathrm{O}$ and $\mathrm{AC}-\mathrm{CO}_{2}$ after the tests exhibited a weight gain together with increased carbon content and decreased surface area. These results indicate that deactivation of the chars was a consequence of solid carbon deposition (via polymerization/coking) on the active sites as a result of cracking reactions. This effect was expected due to the fact that no reforming or oxidizing agent was made available to react with deposited carbon during the tests.

The characterization of $\mathrm{PC}-\mathrm{N}_{2}$ delivered opposite results: the bed weight loss, accompanied by reductions in $\mathrm{C}, \mathrm{H}, \mathrm{N}$ and $\mathrm{S}$ is ascribed to further pyrolysis reaction that took place inside the reactor prior to the start of the experiment. Indeed, $\mathrm{CO}$ was detected in the exit gas during the preliminary flushing of the reactor with pure $\mathrm{N}_{2}$ before the start of the test.

Experiments at $800^{\circ} \mathrm{C}$ were repeated for Viking char and $\mathrm{AC}-\mathrm{H}_{2} \mathrm{O}$, where chars were exposed to the flow of $\mathrm{N}_{2}$ and aromatics for a different duration. The repetitions confirmed the conversion values and deactivation patterns previously discussed and provided additional materials for the post-experiment characterization. It is important to keep in mind that the volume of the char beds was maintained constant in all experiments, but the weight of the materials varied as a consequence of the different density values (Table 4). Therefore, the change relative to the initial value (measured on the fresh char bed) is displayed in Figure 10 (a-c) for the bed weight, specific surface area and carbon content respectively.
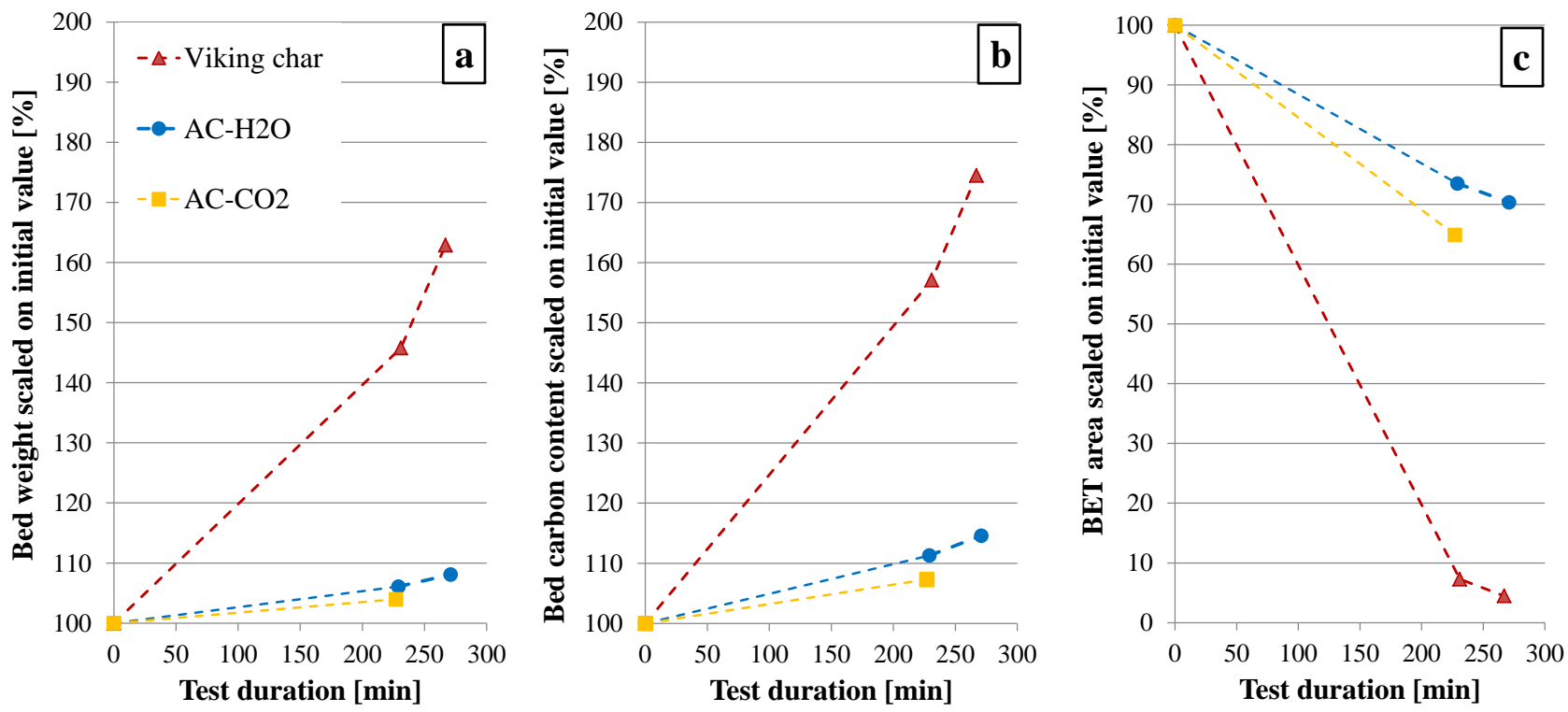

Figure 10: Change relative to the values of fresh char beds of bed weight (a), carbon content (b), surface area (c) for Viking char, $\mathrm{AC}-\mathrm{H}_{2} \mathrm{O}$ and $\mathrm{AC}-\mathrm{CO}_{2}$ spent at $800^{\circ} \mathrm{C}$. 
The increase in bed weight reflects the increased carbon content in the char beds, showing that the weight gain is given by deposition of elemental carbon. The decrease of specific surface area mirrors similar trends. The change in the DFT pore volume is not shown as it was virtually identical to the one for the BET surface area. Comparing the three materials, it is evident that Viking char was the one most affected by the experiments. Not only it gained the most weight (5.6 g in 270 minutes), but also its surface area decreased dramatically (from 1235 to $55 \mathrm{~m}^{2} / \mathrm{g}$ in 270 minutes). The strong decrease in surface area was accompanied by a sharp reduction of pore volume. In this regard, it can be interesting to consider how the pore size distribution changed for the different materials after the tests at $800^{\circ} \mathrm{C}$ (Figure 11). 

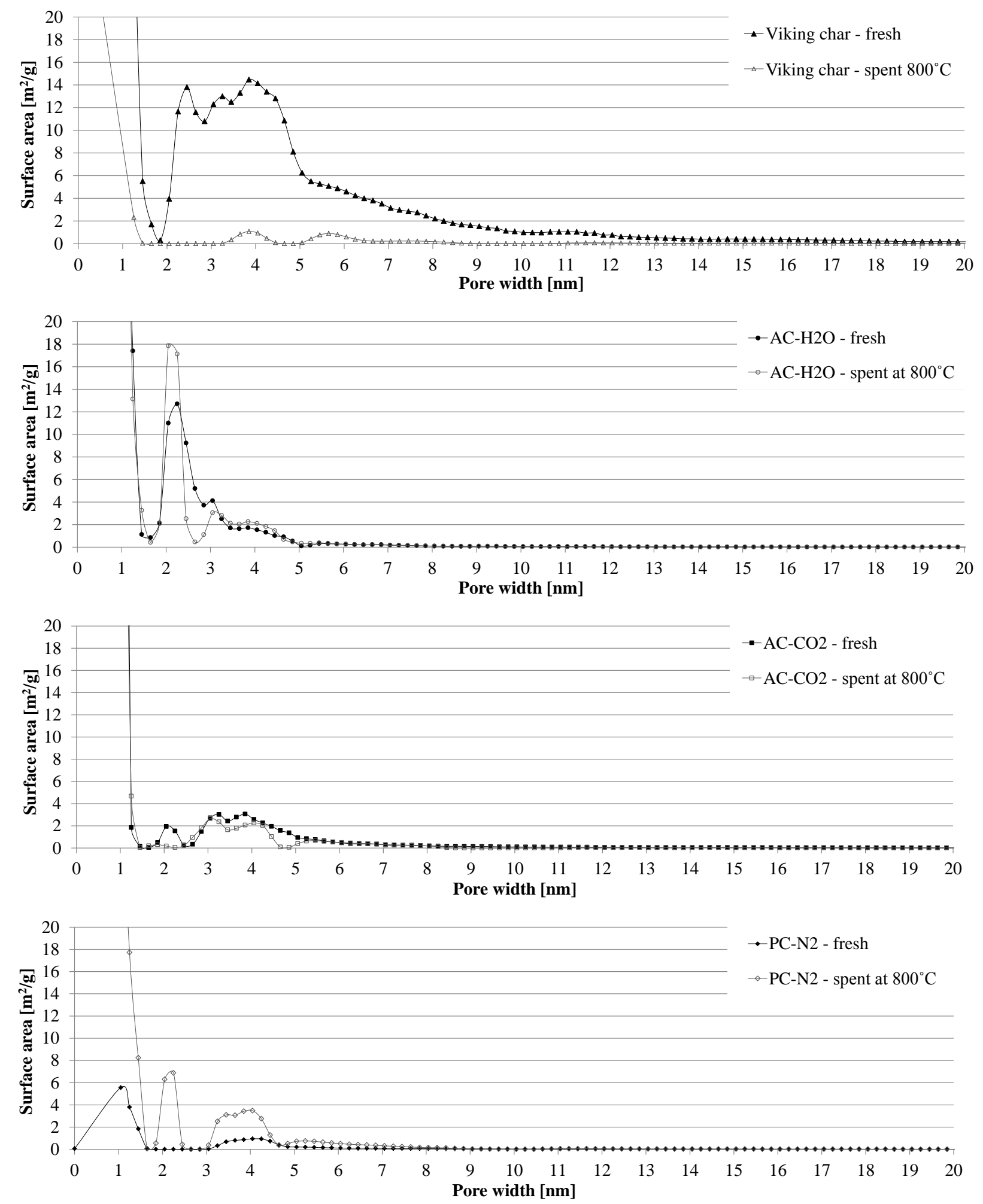

Figure 11: Surface area distribution over the pore size range $<20 \mathrm{~nm}$ for the tested chars. The plots represent fresh samples and spent ones after tests at $800^{\circ} \mathrm{C}$. 
It appears as, in the case of Viking char, the surface area reduction affected not only the micropores, but also the mesopores in the range 2-14 $\mathrm{nm}$. Interestingly, some of the mesopores on the surfaces of $\mathrm{AC}-\mathrm{H}_{2} \mathrm{O}$ and $\mathrm{AC}-\mathrm{CO}_{2}$ remained accessible for $\mathrm{N}_{2}$ even after the tests at $800^{\circ} \mathrm{C}$. Moreover, the spent $\mathrm{AC}$ maintained a larger micropore volume in comparison with Viking char (Table 6).

These results indicate that a larger fraction of the Viking char surface was active for tar decomposition, including surface area associated with micropores and small mesopores $(<13 \mathrm{~nm})$. Moreover, despite the remarkable drop in surface area and pore volume, Viking char showed a higher activity at the end of the tests in comparison with the two types of AC.

The greater activity of the Viking char surface can be explained by the higher content of inorganics, especially $\mathrm{Ca}$. It is possible that the inorganics contained in the Viking char were also more accessible thanks to the migration of mineral species towards the surface during gasification. This phenomenon has been observed on chars gasified at high temperature [6,61], such as Viking char was.

As in the previous results, also the change in the pore size distribution was completely different for the PC- $\mathrm{N}_{2}$ char that gained surface area both in the micropore and mesopore region. These results corroborate the hypothesis that this char underwent mild pyrolysis during the test: even though this char had been heat treated at $900^{\circ} \mathrm{C}$ for 2 hours prior to the test, this was not sufficient to guarantee its complete stability at $800^{\circ} \mathrm{C}$.

\section{Conclusions}

The performances of four wood-derived chars and AC in the adsorption and decomposition of toluene and naphthalene were evaluated and compared. Chars and $\mathrm{AC}$ were produced with different processes and featured various degrees of activation. Surface characterization revealed different surface areas and pore textures, while the compositional analysis showed discrepancies in the content of minerals and metals. The surface and compositional characteristics varied as a consequence of the different heat treatments that each material had undergone: gasification, pyrolysis, $\mathrm{H}_{2} \mathrm{O}$ - or $\mathrm{CO}_{2}$-activation.

During experiments in the lower range of temperatures $\left(250-400^{\circ} \mathrm{C}\right)$, char beds exerted a minimal effect on the concentration of toluene, but adsorbed naphthalene more efficiently. The absence of gaseous species other than $\mathrm{N}_{2}$ in the exit gas confirmed that the interaction between aromatic molecules and the surface of chars was limited to adsorption, as no decomposition reactions took place under these 
conditions. The highest naphthalene adsorption capacity was given by $\mathrm{AC}-\mathrm{CO}_{2}$. Viking char provided an adsorption capacity of naphthalene which was comparable with the two types of AC. On the contrary, PC- $\mathrm{N}_{2}$ char (non-activated) showed a poor adsorption capacity quantified as one order of magnitude below the other materials.

Increasing the char beds temperature to $400^{\circ} \mathrm{C}$ significantly diminished the adsorption capacities of the Viking char, $\mathrm{AC}-\mathrm{H}_{2} \mathrm{O}$ and $\mathrm{AC}-\mathrm{CO}_{2}$ without triggering cracking reactions.

On the other hand, when the temperature of the char bed was set to $600^{\circ} \mathrm{C}$, the aromatic compounds were subject to decomposition reactions yielding $\mathrm{H}_{2}$. At $800^{\circ} \mathrm{C}$ the $\mathrm{H}_{2}$ production increased significantly and was associated with $\mathrm{CH}_{4}$ generation; moreover, the difference in the performances of the different chars became appreciable. The performance of char PC- $\mathrm{N}_{2}$ was very similar to the blank test, with very low levels of conversion. In contrast, the other chars achieved complete conversion of naphthalene and toluene for a limited time at the beginning of the tests. Overall, naphthalene appeared to be cracked more extensively than toluene. Viking char $\mathrm{AC}-\mathrm{H}_{2} \mathrm{O}$ and $\mathrm{AC}-\mathrm{CO}_{2}$ surface deactivation following different trends. Viking char remained active for a longer time in comparison with the two types of AC. The same deactivation trends were observed in the production of $\mathrm{H}_{2}$ and $\mathrm{CH}_{4}$. The slower deactivation showed by Viking char was mainly ascribed to a better surface accessibility given by its pore texture, but also to a higher number of active sites as a results of a larger content of inorganics.

The characterization of the chars spent at $800^{\circ} \mathrm{C}$ clarified that deactivation was a consequence of solid carbon deposition on the surface of chars.

Results from tests in the temperature range $600-800^{\circ} \mathrm{C}$ indicated that gasification char performed better than $\mathrm{AC}$, providing a higher and protracted removal of both aromatic compounds. Chars with high burn-off, as the ones produced as solid residues of gasification process, might be particularly suitable for tar conversion applications in hot producer gas treatment at temperatures of $800^{\circ} \mathrm{C}$ and above. Nevertheless, the solid residues of gasification, or gasification chars, can have very different properties and surface structure depending on the operating conditions of the process and on the feedstock used. In order to be suitable and effective for hot gas treatment, the gasifier should have high carbon conversion efficiency, and should produce a solid residue with a large specific surface area and welldeveloped porosity. 


\section{Acknowledgements}

The authors thank Innovationsfonden (Denmark) for the financial support received as part of the project "SYNFUEL - Sustainable synthetic fuels from biomass gasification and electrolysis" (410600006B), as well as the German Federal Ministry of Education and Research for the funding to the junior research group "NWG-TCKON” (FKZ: 03SF0442).

The authors would also like to thank Mrs. Susanne Hoffmann (Technische Universität Berlin, Institut für Energietechnik) for the assistance with char analysis.

\section{References}

[1] Li C, Suzuki K. Tar property, analysis, reforming mechanism and model for biomass gasification - An overview 2010;13:594-604. doi:10.1016/j.rser.2008.01.009.

[2] Asadullah M. Biomass gasification gas cleaning for downstream applications: A comparative critical review. Renew Sustain Energy Rev 2014;40:118-32. doi:10.1016/j.rser.2014.07.132.

[3] Abu El-Rub Z, Bramer EA, Brem G. Experimental comparison of biomass chars with other catalysts for tar reduction. Fuel 2008;87:2243-52. doi:10.1016/j.fuel.2008.01.004.

[4] Hosokai S, Kumabe K, Ohshita M, Norinaga K, Li C, Hayashi J-I. Mechanism of decomposition of aromatics over charcoal and necessary condition for maintaining its activity. Fuel 2008;87:2914-22. doi:10.1016/j.fuel.2008.04.019.

[5] Fuentes-Cano D, Gómez-Barea A, Nilsson S, Ollero P. Decomposition kinetics of model tar compounds over chars with different internal structure to model hot tar removal in biomass gasification. Chem Eng J 2013;228:1223-33. doi:10.1016/j.cej.2013.03.130.

[6] Klinghoffer N, Castaldi MJ, Nzihou A. Catalyst Properties and Catalytic Performance of Char from Biomass Gasification. I\&Ec 2012:13113-22. doi:10.1021/ie3014082.

[7] D.M.L. Griffiths JRM. The cracking of tar vapour and aromatic compounds on activated carbon. Fuel 1967:167-76.

[8] Boroson ML, Howard JB, Longwell JP, Peters W a. Heterogeneous cracking of wood pyrolysis tars over fresh wood char surfaces. Energy \& Fuels 1989;3:735-40. doi:10.1021/ef00018a014.

[9] Brandt P, Larsen E, Henriksen U. High tar reduction in a two-stage gasifier. Energy and Fuels 2000;14:816-9. doi:10.1021/ef990182m. 
[10] Al-Rahbi AS, Onwudili JA, Williams PT. Thermal decomposition and gasification of biomass pyrolysis gases using a hot bed of waste derived pyrolysis char. Bioresour Technol 2016;204:71-9. doi:10.1016/j.biortech.2015.12.016.

[11] Krerkkaiwan S, Mueangta S, Thammarat P, Jaisat L, Kuchonthara P. Catalytic Biomass-Derived Tar Decomposition Using Char from the Co-pyrolysis of Coal and Giant Leucaena Wood Biomass. Energy \& Fuels 2015;29:3119-26. doi:10.1021/ef502792x.

[12] Park J, Lee Y, Ryu C. Reduction of primary tar vapor from biomass by hot char particles in fixed bed gasification. Biomass and Bioenergy 2016;90:114-21. doi:10.1016/j.biombioe.2016.04.001.

[13] Frazier RS, Jin E, Kumar A. Life cycle assessment of biochar versus metal catalysts used in syngas cleaning. Energies 2015;8:621-44. doi:10.3390/en8010621.

[14] Benedetti V, Patuzzi F, Baratieri M. Gasification char as a potential substitute of activated carbon in adsorption applications. Energy Procedia 2016;00.

[15] Benedetti V, Patuzzi F, Baratieri M. Characterization of char from biomass gasification and its similarities with activated carbon in adsorption applications. Appl Energy 2017:1-8. doi:10.1016/j.apenergy.2017.08.076.

[16] Galhetas M, Mestre AS, Pinto ML, Gulyurtlu I, Lopes H, Carvalho AP. Chars from gasification of coal and pine activated with $\mathrm{K} 2 \mathrm{CO} 3$ : Acetaminophen and caffeine adsorption from aqueous solutions. J Colloid Interface Sci 2014;433:94-103. doi:10.1016/j.jcis.2014.06.043.

[17] Ducousso M, Weiss-Hortala E, Nzihou A, Castaldi MJ. Reactivity enhancement of gasification biochars for catalytic applications. Fuel 2015;159:491-9. doi:10.1016/j.fuel.2015.06.100.

[18] García-García A, Gregório A, Franco C, Pinto F, Boavida D, Gulyurtlu I. Unconverted chars obtained during biomass gasification on a pilot-scale gasifier as a source of activated carbon production. Bioresour Technol 2003;88:27-32.

[19] Kilpimaa S, Runtti H, Kangas T, Lassi U, Kuokkanen T. Physical activation of carbon residue from biomass gasification: Novel sorbent for the removal of phosphates and nitrates from aqueous solution. J Ind Eng Chem 2015;21:1354-64. doi:10.1016/j.jiec.2014.06.006.

[20] Klinghoffer N. Utilization of char from biomass gasification in catalytic applications Naømi Klingho ffer. PhD Thesis-, Columbia University USA 2013.

[21] Hervy M, Berhanu S, Weiss-Hortala E, Chesnaud A, Gérente C, Villot A, et al. Multi-scale 
characterisation of chars mineral species for tar cracking. Fuel 2017;189:88-97. doi:10.1016/j.fuel.2016.10.089.

[22] Patuzzi F, Prando D, Vakalis S, Rizzo AM, Chiaramonti D, Tirler W, et al. Small-scale biomass gasification CHP systems: Comparative performance assessment and monitoring experiences in South Tyrol (Italy). Energy 2016;112:285-93. doi:10.1016/j.energy.2016.06.077.

[23] Hansen V, Müller-Stöver D, Ahrenfeldt J, Holm JK, Henriksen UB, Hauggaard-Nielsen H. Gasification biochar as a valuable by-product for carbon sequestration and soil amendment. Biomass and Bioenergy 2015;72:300-8. doi:http://dx.doi.org/10.1016/j.biombioe.2014.10.013.

[24] Mastral A, García T, Murrillo R, Callén MS, Lopez JM, Navarro M V, et al. Study of the Adsorption of Polyaromatic Hydrocarbon Binary Mixtures on Carbon Materials by Gas-Phase Fluorescence Detection. Energy \& Fuels 2003:669-76.

[25] García T, Murillo R, Cazorla-Amorós D, Mastral AM, Linares-Solano A. Role of the activated carbon surface chemistry in the adsorption of phenanthrene. Carbon N Y 2004;42:1683-9. doi:10.1016/j.carbon.2004.02.029.

[26] Hu X, Hanaoka T, Sakanishi K, Shinagawa T, Matsui S, Tada M, et al. Removal of Tar Model Compounds Produced from Biomass Gasification Using Activated Carbons. J Japan Inst Energy 2007;86:707-7011. doi:10.1093/bioinformatics/btu635.

[27] Sun Q, Yu S, Wang F, Wang J. Decomposition and gasification of pyrolysis volatiles from pine wood through a bed of hot char. Fuel 2011;90:1041-8. doi:10.1016/j.fuel.2010.12.015.

[28] Dabai F, Paterson N, Millan M, Fennell P, Kandiyoti R. Tar formation and destruction in a fixed-bed reactor simulating downdraft gasification: Equipment development and characterization of tar-cracking products. Energy and Fuels 2010;24:4560-70. doi:10.1021/ef100681u.

[29] Matsuhara T, Hosokai S, Norinaga K, Matsuoka K, Li CZ, Hayashi JI. In-situ reforming of tar from the rapid pyrolysis of a brown coal over char. Energy and Fuels 2010;24:76-83. doi:10.1021/ef9005109.

[30] Phuphuakrat T, Namioka T, Yoshikawa K. Tar removal from biomass pyrolysis gas in two-step function of decomposition and adsorption. Appl Energy 2010;87:2203-11. doi:10.1016/j.apenergy.2009.12.002.

[31] Sueyasu T, Oike T, Mori A, Kudo S, Norinaga K, Hayashi JI. Simultaneous steam reforming of 
tar and steam gasification of char from the pyrolysis of potassium-loaded woody biomass. Energy and Fuels 2012;26:199-208. doi:10.1021/ef201166a.

[32] Hosokai S, Norinaga K, Kimura T, Nakano M, Li C-Z, Hayashi J. Reforming of Volatiles from the Biomass Pyrolysis over Charcoal in a Sequence of Coke Deposition and Steam Gasification of Coke. Energy \& Fuels 2011;25:5387-93. doi:10.1021/ef2003766.

[33] Cudahy JJ, Helsel RW. Removal of products of incomplete combustion with carbon. Waste Manag 2000;20:339-45. doi:10.1016/S0956-053X(99)00335-9.

[34] Mastral AM, García T, Murillo R, Callén MS, López JM, Navarro M V. PAH Mixture Removal from Hot Gas by Porous Carbons . From Model Compounds to Real Conditions 2003:5280-6.

[35] Karatza D, Musmarra D. Fly Ash Capture of Mercuric Chloride Vapors from Exhaust Combustion Gas 1998;32:3999-4004.

[36] Jess A. Mechanisms and kinetics of thermal reactions of aromatic hydrocarbons from pyrolysis of solid fuels. Fuel 1996;75:1441-8. doi:10.1016/0016-2361(96)00136-6.

[37] Egsgaard H, Ahrenfeldt J, Ambus P, Schaumburg K, Henriksen UB. Gas cleaning with hot char beds studied by stable isotopes. J Anal Appl Pyrolysis 2014;107:174-82. doi:10.1016/j.jaap.2014.02.019.

[38] Mani S, Kastner JR, Juneja A. Catalytic decomposition of toluene using a biomass derived catalyst. Fuel Process Technol 2013;114:118-25. doi:10.1016/j.fuproc.2013.03.015.

[39] Song Y, Zhao Y, Hu X, Zhang L, Sun S, Li CZ. Destruction of tar during volatile-char interactions at low temperature. Fuel Process Technol 2018;171:215-22. doi:10.1016/j.fuproc.2017.11.023.

[40] Nestler F, Burhenne L, Amtenbrink MJ, Aicher T. Catalytic decomposition of biomass tars: The impact of wood char surface characteristics on the catalytic performance for naphthalene removal. Fuel Process Technol 2016;145:31-41. doi:10.1016/j.fuproc.2016.01.020.

[41] Fuentes-Cano D, Parrillo F, Ruoppolo G, Gómez-Barea A, Arena U. The influence of the char internal structure and composition on heterogeneous conversion of naphthalene. Fuel Process Technol 2018;172:125-32. doi:10.1016/j.fuproc.2017.12.015.

[42] Korus A, Samson A, Szle A, Katelbach-woz A. Pyrolytic toluene conversion to benzene and coke over activated carbon in a fixed-bed reactor. Fuel 2017;207:283-92. doi:10.1016/j.fuel.2017.06.088. 
[43] Nitsch X, Commandré J-M, Valette J, Volle G, Martin E. Conversion of Phenol-Based Tars over Biomass Char under H 2 and H 2 O Atmospheres. Energy \& Fuels 2014:28 (2014) 6936-6940. doi:10.1021/ef500980g.

[44] Zhang Y, Luo Y, Wu W, Zhao S, Long Y. Heterogeneous Cracking Reaction of Tar over Biomass Char, Using Naphthalene as Model Biomass Tar. Energy \& Fuels 2014;28:3129-37. doi:10.1021/ef4024349.

[45] Krerkkaiwan S, Tsutsumi A, Kuchonthara P. Biomass derived tar decomposition over coal char bed. ScienceAsia 2013;39:511. doi:10.2306/scienceasia1513-1874.2013.39.511.

[46] Di Gregorio F, Parrillo F, Salzano E, Cammarota F, Arena U. Removal of naphthalene by activated carbons from hot gas. Chem Eng J 2016;291:244-53. doi:10.1016/j.cej.2016.01.081.

[47] Quantachrome Instruments - DFT Models n.d. http://www.quantachrome.com/technical/dft.html (accessed June 6, 2018).

[48] Ahrenfeldt J, Henriksen U, Jensen TK, Gøbel B, Wiese L, Kather A, et al. Validation of a continuous combined heat and power (CHP) operation of a two-stage biomass gasifier. Energy and Fuels 2006;20:2672-80. doi:10.1021/ef0503616.

[49] Thommes M, Kaneko K, Neimark A V, Olivier JP, Rodriguez-reinoso F, Rouquerol J, et al. Physisorption of gases, with special reference to the evaluation of surface area and pore size distribution ( IUPAC Technical Report ). Pure Appl Chem 2015. doi:10.1515/pac-2014-1117.

[50] Sing KSW, Everett DH, Haul RAW, Moscou L, Pierotti RA, Rouqueról J, et al. REPORTING PHYSISORPTION DATA FOR GAS / SOLID SYSTEMS with Special Reference to the Determination of Surface Area and Porosity 1985;57:603-19.

[51] Coughlin RW, Ezra FS. Role of Surface Acidity in the Adsorption of Organic Pollutants on the Surface of Carbon. Environ Sci Technol 1968;2:291-7. doi:10.1021/es60016a002.

[52] Rodríguez-Reinoso F. The role of carbon materials in heterogeneous catalysis. Carbon N Y 1998;36:159-75. doi:10.1016/S0008-6223(97)00173-5.

[53] Bansal RC, Donnet J-B, Stoeckli F. Active Carbon. New York and Basel: Marcel Dekker, Inc.; 1988.

[54] Klinghoffer NB, Castaldi MJ, Nzihou A. Influence of char composition and inorganics on catalytic activity of char from biomass gasification. Fuel 2015;157:37-47. doi:10.1016/j.fuel.2015.04.036. 
[55] Lillo-Ródenas M, Cazorla-Amorós D, Linares-Solano A. Behaviour of activated carbons with different pore size distributions and surface oxygen groups for benzene and toluene adsorption at low concentrations. Carbon N Y 2005;43:1758-67. doi:10.1016/j.carbon.2005.02.023.

[56] Chiang Y, Chiang P, Huang C. Effects of pore structure and temperature on VOC adsorption on activated carbon. Carbon N Y 2001;39:523-34.

[57] Tomków K, Siemieniewska T, Czechowski F, Jankowska A. Formation of porous structures in activated brown-coal chars using O2, CO2 and H2O as activating agents. Fuel 1977;56:121-4.

[58] Mastral AM, García T, Murillo R, Callen MS, Lopez JM, Navarro M V. Development of efficient adsorbent materials for PAH cleaning from AFBC hot gas. Energy and Fuels 2004;18:202-8. doi:10.1021/ef030058+.

[59] Moldoveanu SC. Techniques and Instrumentation in Analytical Chemistry - Pyrolysis of Organic Molecules. vol. 28. Elsevier Science Ltd; 2009.

[60] Moliner R, Suelves I, Lázaro MJ, Moreno O. Thermocatalytic decomposition of methane over activated carbons: Influence of textural properties and surface chemistry. Int J Hydrogen Energy 2005;30:293-300. doi:10.1016/j.ijhydene.2004.03.035.

[61] Wu W, Luo Y, Su Y, Zhang Y, Zhao S, Wang Y. Nascent Biomass Tar Evolution Properties under Homogeneous/Heterogeneous Decomposition Conditions in a Two-Stage Reactor. Energy \& Fuels 2011;25:5394-406. doi:10.1021/ef2007276. 


\title{
Adsorption and decomposition of tar model compounds over the surface of gasification char and active carbon within the temperature range $250-800^{\circ} \mathrm{C}$
}

\author{
G. Ravenni $^{1^{*}}$, O.H. Elhami ${ }^{2}$, J. Ahrenfeldt ${ }^{1}$, U.B. Henriksen ${ }^{1}$, Y. Neubauer ${ }^{2}$ \\ ${ }^{1}$ Technical University of Denmark (DTU), Department of Chemical and Biochemical Engineering, \\ Frederiksborgvej 399, 4000 Roskilde, Denmark \\ ${ }^{2}$ Technische Universität Berlin, Institute of Energy Technology
}

Fasanenstrasse 89, 10623 Berlin, Germany

\begin{abstract}
The carbonaceous products of gasification or pyrolysis (chars) and active carbon (AC) have been found effective as adsorbents for tar species and active as catalysts for tar conversion. However, a deeper understanding of the interaction between aromatic compounds and carbonaceous surfaces is needed for the practical implementation and optimization of carbon-based gas cleaning systems. The aim of this work is to investigate the performance of various wood-derived chars and $\mathrm{AC}$ within a wide temperature range $\left(250-800^{\circ} \mathrm{C}\right)$. Residual char from gasification, pyrolysis char and two types of $\mathrm{AC}$ were tested for their capability to remove tar model compounds (toluene and naphthalene) from a gaseous flow. A dedicated setup was used for this purpose, while post-experimental characterization revealed the modifications occurring at the surface of chars. Adsorption was observed in the lower temperature range, whereas cracking reactions were found to initiate at $600^{\circ} \mathrm{C}$ and to become significant at $800^{\circ} \mathrm{C}$. Results suggested that $\mathrm{AC}$ represents a better option for tar adsorption applications (e.g. carbon filters) operating at temperatures of $250^{\circ} \mathrm{C}$ and possibly below, whereas gasification residual char resulted as the most promising substrate for tar cracking at temperatures of $800^{\circ} \mathrm{C}$ and above.
\end{abstract}

*Corresponding author Tel: +4593511592 E-mail: grav@kt.dtu.dk (Giulia Ravenni) 


\section{Introduction}

The quality of producer gas generated by gasification of biomass is one of the main issues hindering the commercialization of this thermochemical conversion process. In general, biomass producer gas contains tar, a mixture of condensable substances including light 1-ring aromatics, polycyclic aromatic hydrocarbons and heterocyclic aromatics [1]. Tar contamination prevents the widespread use of biomass producer gas as an alternative to fossil resources. If the gas quality issue is overcome, it could be used to fuel engines and turbines or for synthesis of biofuels and bio-chemicals.

Several options for producer gas treatment have been proposed and implemented including cold gas cleaning, hot gas filtration, thermal cracking, catalytic cracking by using metal-based catalysts (e.g. nickel, iron, noble metals) or mineral catalysts (e.g. dolomite, olivine) [2].

The use of char and active carbon (AC) to reduce the content of tar in producer gas has been suggested by a number of authors who worked with tar model compounds [3-6] and with tar derived from pyrolysis or gasification [7-12]. Overall, these carbonaceous materials appear as a viable alternative to metal and mineral catalysts, with manifold advantages. Firstly, they can be inexpensive, especially if residual char is used (for example from gasification plants). Secondly, they can be less harmful for the environment and for human health in comparison with synthetic catalysts [13], especially if not impregnated with metals, but directly used as a gas cleaning substrate. In addition, chars and AC can find several end-life applications such as being recycled as a solid fuel or as a precursor for carbon materials. Potentially they could even be used as biochar for soil amendment and carbon sequestration, if the relevant thresholds for noxious contaminants (e.g. heavy metals, polycyclic aromatic hydrocarbons, dioxins) are verified.

The solid residue of gasification is a specific kind of char which is usually considered as a waste material or a by-product of gasification plants. The properties of this char vary significantly depending on the feedstock and on the operating conditions of the gasifier. In general, it contains inorganics such as alkali and alkaline earth metals, which are naturally contained in the feedstock, and is rich in carbon. Indeed, only the carbon atoms arranged in the most stable structures endure gasification reactions. Such reactions are also responsible for the physical activation of char, which can produce a microporous material with a significant specific surface area. Oftentimes this material presents surface properties which are comparable to commercial AC [14]. For this reason, gasification char has been considered for various applications as a cheaper alternative to manufactured AC [15-19], as well as for tar removal 
and conversion applications [20,21]. The latter solution would be economically and environmentally beneficial for gasification plants: indeed the valorization of the solid by-product, which often does not meet the requirements for soil application as biochar, would improve the economic feasibility especially for small-scale systems [22].

The TwoStage gasification platform developed at DTU, Risø Campus (also known as "Viking gasifier") is able to produce a virtually tar-free gas as described in [9]. The solid residue of the TwoStage gasification process (hereby called "Viking char") presents a high carbon content and a very large specific surface area in comparison with chars generated from other gasification processes $[14,23]$. For these reasons it could be especially effective for gas treatment applications.

The practical implementation of carbon-based gas cleaning systems is still at the initial stage, as it is not yet clear which are the char characteristic and the reaction conditions required to optimize the removal of tar. In particular, some authors considered char as an adsorbent for tar [24-26], whereas others used it as a substrate for tar cracking [8,10,12,27,28] and reforming [11,29-32].

Adsorption on carbon surfaces has been extensively studied and used for removal of organic contaminants from gaseous streams [33,34]. Being an exothermic process, adsorption is hindered at high temperatures [35], as a consequence of the increased vapor pressure of the adsorbate [33]. Nevertheless, for adsorption of tar compounds on chars, it is advisable to work at a minimum temperature of $250^{\circ} \mathrm{C}$, as lower temperatures could lead to condensation of tar from the producer gas.

On the other hand, cracking of aromatic molecules making up the tar mixture requires much higher temperatures: around $1200^{\circ} \mathrm{C}$ in homogeneous conditions [36]. Char is able to act as a catalyst for cracking and reforming of aromatics. Indeed, an enhancement in the conversion of aromatic structures at temperatures as low as $600^{\circ} \mathrm{C}$ has been observed in presence of char [27,37-39].

Under inert atmosphere, the decomposition of aromatics on the surface of chars and activated carbons is considered to take place through carbon deposition by coking according to reaction (1) [4]:

$C_{m} H_{n}($ aromatic $)=C_{m} H_{x}($ coke $)+\frac{n-x}{2} H_{2}$

Such reaction is catalyzed by active sites. In absence of a reforming agent that can gasify the newly formed deposits, the carbon build-up gradually deactivates the carbonaceous surface. As a 
consequence, in practical applications it is advisable to consider the addition of air, steam or $\mathrm{CO}_{2}$ to prolong the activity of carbonaceous surfaces. The process has been documented by several authors in the temperature range $700-1000^{\circ} \mathrm{C}$ for different chars: commercial charcoal [4], activated carbons [4042], char from pyrolysis of wood [31,43], rice straw [44], coal [29,45] or waste [10].

On these grounds, temperature appears as the determinant factor defining the nature of the interaction between char and aromatic compounds. With this in mind, the purpose of this work was to observe the course of interaction between aromatics and the surface of char within the temperature range $250-$ $800^{\circ} \mathrm{C}$, differentiating between adsorption and cracking phenomena. A dedicated setup developed at TU Berlin has been used to examine the effects of char beds on selected tar model compounds, namely toluene and naphthalene. Both these substances are commonly used as tar model compounds, as representatives of light 1-ring aromatics and light polycyclic aromatic hydrocarbons, respectively. Naphthalene is also one of the most refractory and stable substances found in biomass tar [46].

To the best of our knowledge, this is the first time that the interaction between tar model compounds and chars was studied covering such a wide range of temperatures. This was done with the aim to gain useful information for the design of an actual carbon-based tar removal system. In addition, residual gasification char was compared to carbonaceous materials with different surface structures, including a commercial AC.

Adsorption and cracking experiments were performed under inert atmosphere, adopting $\mathrm{N}_{2}$ as carrier gas. In an actual gasification process, other gas species $\left(\mathrm{CO}, \mathrm{H}_{2}, \mathrm{CH}_{4}, \mathrm{CO}_{2}\right.$, steam) would be present and influence adsorption and cracking of tar at the surface of char. Nevertheless, results obtained from tests in inert atmosphere can be used to compare the performance of different carbonaceous materials and to understand the relationship between the properties of chars and their effectiveness in tar reduction. In order to evaluate the suitability of the tested chars for tar reduction applications at high temperature, their surface structure was also analyzed in detailbefore and after the experiments. The results provided valuable insight into the mechanism of deactivation and interaction between aromatics and the surface of chars. 


\subsection{Chars and activated carbons}

Four carbonaceous materials were tested in the setup. Residual gasification char was collected at the TwoStage demonstration plant at DTU (the Viking gasifier), where the solid residue is stockpiled inside a dedicated container. Before being used as a bed material in the experiments, the Viking char was crushed and sieved to obtain a particle size similar the other chars (1.4 to $2 \mathrm{~mm}$ ). The commercial $\mathrm{AC}$ has been kindly provided by Silcarbon Aktivkohle GmbH (Kirchhundem, Germany). According to the manufacturer this was a wood-derived AC which had been activated with steam for about 120 minutes at $800^{\circ} \mathrm{C}$. In the following it will be referred to as $\mathrm{AC}-\mathrm{H}_{2} \mathrm{O}$. The remaining two materials were produced in a screw pyrolysis unit at TU Berlin. Here, beech wood chips (Räuchergold ${ }^{\circledR}$, intended for food smoking) were pyrolyzed at $400^{\circ} \mathrm{C}$. After pyrolysis, char was subject to $\mathrm{CO}_{2}$ activation for 180 minutes at $750^{\circ} \mathrm{C}$ : the final product is referred to as $\mathrm{AC}-\mathrm{CO}_{2}$. Some of the material pyrolyzed at $400^{\circ} \mathrm{C}$ did not undergo activation, but heat treatment at $900^{\circ} \mathrm{C}$ under $\mathrm{N}_{2}$ atmosphere, to guarantee its thermal stability during high temperature experiments. Such pyrolysis-derived char will be referred to as PC$\mathrm{N}_{2}$. Figure 1 shows the different production and activation pathways. All chars were dried at $105^{\circ} \mathrm{C}$ for 3 hours and stored in a desiccator prior to be used in the experiments.

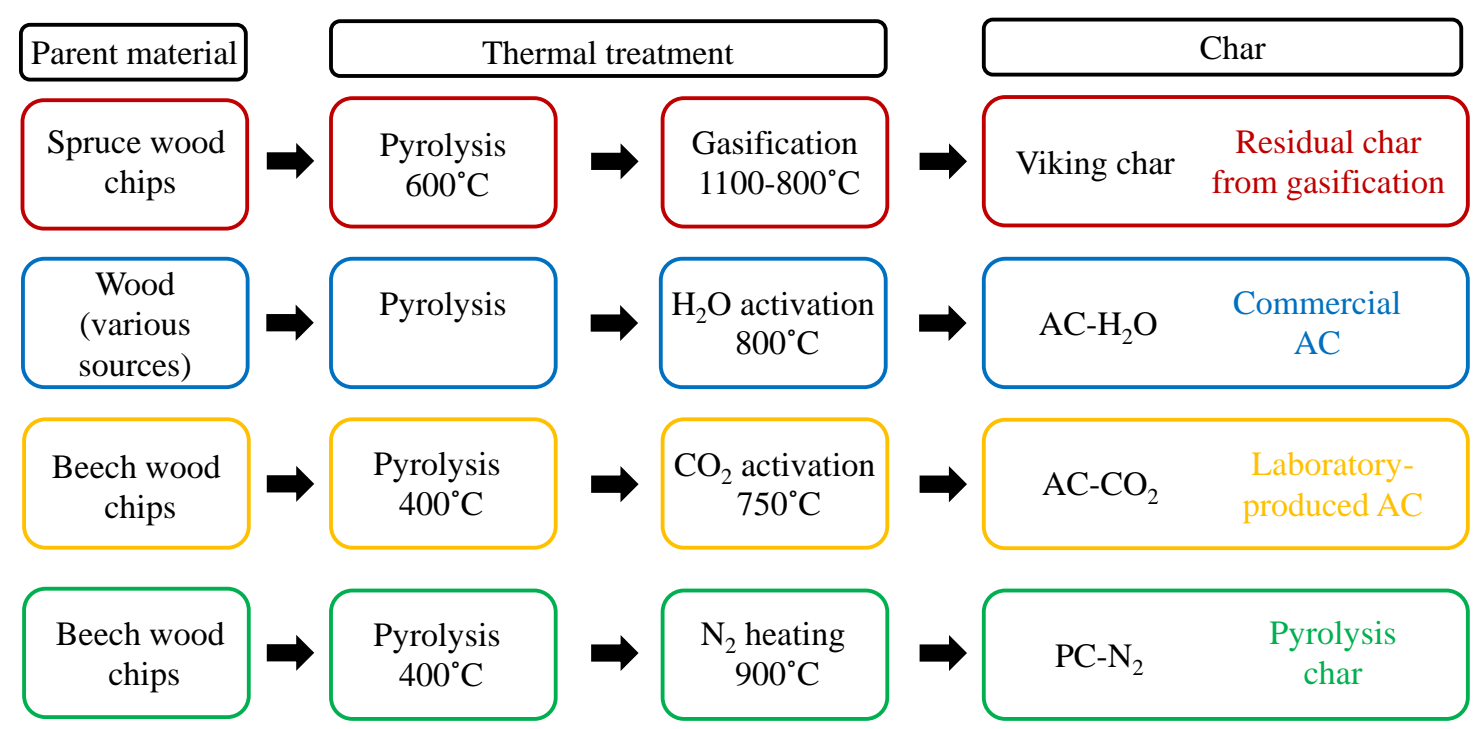

Figure 1: Production and activation of the tested chars. 


\subsection{Characterization of chars}

All the selected chars were characterized in terms of composition and surface properties. Prior to any analysis, chars were reduced to powder in a ball mill. The volatile and ash content of chars were evaluated by using a muffle furnace, following CEN/TS 15148 and DIN $51719\left(815^{\circ} \mathrm{C}\right)$ respectively.

The fixed carbon content was calculated by difference. The elemental composition (CHNS) was measured with a VarioEL III (Elementar Analysensystem GmbH, Germany). The trace elements present in the chars were detected by Inductively Coupled Plasma- Optical Emission Spectrometry (ICP-OES) (Varian 720 ES).

The specific surface area was quantified by Brunauer-Emmett-Teller (BET) analysis through $\mathrm{N}_{2}$ adsorption at $77 \mathrm{~K}$ (Nova 2200, Quantachrome Instruments, USA). Before each measurement, char samples were degassed at $150^{\circ} \mathrm{C}$ for 6 hours. The pore volume distribution was evaluated through Quenched Solid Density Functional Theory (QSDFT) using the calculation model for slit and cylindrical pores on the adsorption branch: this method is recommended for chemically and physically activated carbons [47]. The densities of char powders, used as inputs for the BET and DFT calculations, were measured with a helium pycnometer (Quantachrome Instruments, USA).

The bulk density of the chars used as bed materials (not grinded) was evaluated by using a scale and a graduated cylinder. The elemental composition (CHNS) and BET surface area were measured also on chars recovered after the tests, to evaluate the differences with fresh materials.

\subsection{Experimental setup}

The experimental setup for testing the performance of char beds (Figure 2) was designed and built at TU Berlin. The setup consisted of a stainless steel tube reactor $500 \mathrm{~mm}$ in length, with an internal diameter of $36 \mathrm{~mm}$ to contain the char bed. The reactor was placed inside an electric furnace (Lenton, UK) and connected at the top with a gas generation system, whereas the outlet at the bottom was connected to the gas analysis train. A $\mathrm{N}_{2}$ flow (4.7 1/min) was controlled with a mass flow controller (Vögtlin, Switzerland) and was mixed with vapors of a toluene-naphthalene solution dosed with a syringe pump (Nemesys, Cetoni, Germany). The feed solution was prepared by mixing analytical grade toluene (purity $>=99.5 \%$, Carl Roth, Germany) with naphthalene crystals (purity >=99\%, Carl Roth, Germany). The solution was prepared with a concentration of $0.63 \mathrm{~mol} / \mathrm{L}$. The dosing of the syringe was set between 107-109 $\mu \mathrm{l} / \mathrm{min}$, according to the exact concentration of naphthalene in the solution, so to maintain a stable feed in all tests. The concentrations of toluene and naphthalene in the $\mathrm{N}_{2}$ were 
calculated to be $18345 \pm 0.5 \%$ and $1852 \pm 0.1 \% \mathrm{mg} / \mathrm{Nm}^{3}$, respectively. Evaporation of the solution took place inside a capillary which was kept at a temperature of $200^{\circ} \mathrm{C}$ by a dedicated oven. Vapors were mixed with a pre-heated flow of $\mathrm{N}_{2}$ in the tubing contained in the oven. The aromatics-enriched gas was delivered to the char reactor through heated lines $\left(180^{\circ} \mathrm{C}\right)$ to avoid condensation. The system was equipped with a 3-way switching valve allowing the aromatics-enriched $\mathrm{N}_{2}$ flow to be conveyed directly to the analytical instruments for background measurements (reactor bypass mode), or to be passed through the heated reactor during experiments.

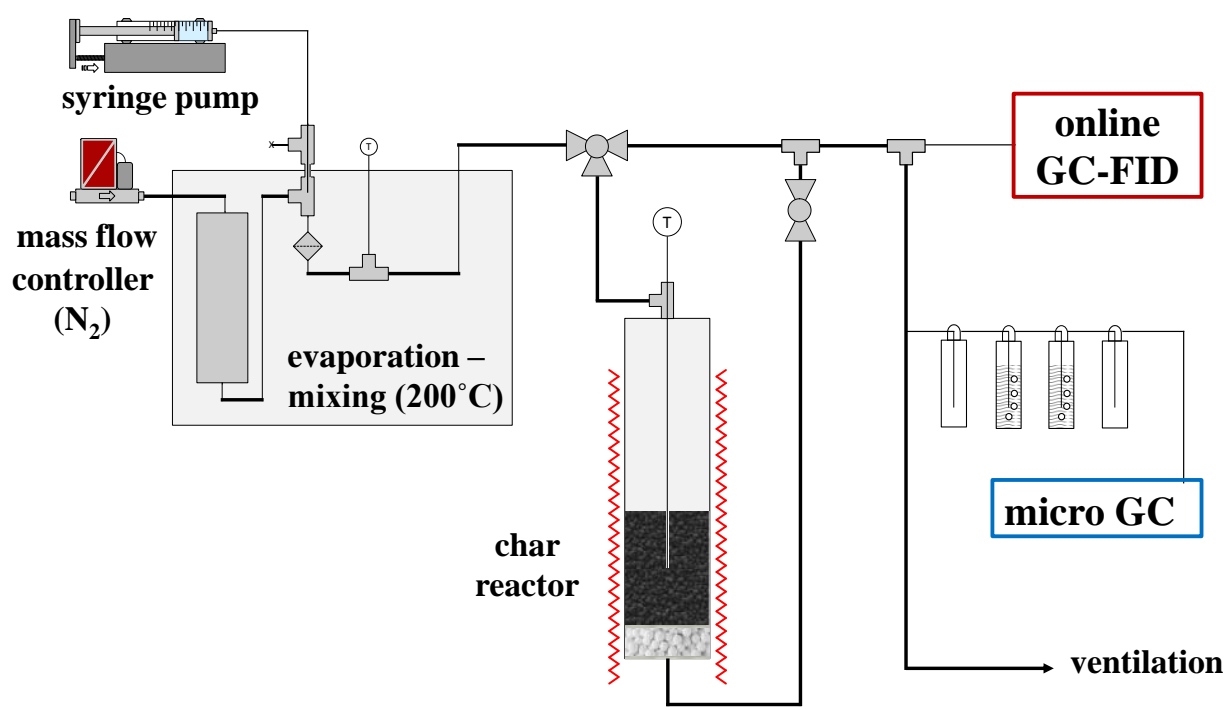

Figure 2: Diagram of the experimental setup.

2.4 Online gas analysis

The online analysis consisted of a compact GC-FID (SRI Instruments, USA) for detection of toluene and naphthalene in the flow: the samples were eluted through a $30 \mathrm{~m}$ FS Supreme-5ms $(5 \%$ Phenylpolysilphenylenphase) column, heated to a constant temperature of $180^{\circ} \mathrm{C}$. A system of valves was used for automatic sampling of the gas: injections were made in series of ten, every 2 minutes. For the duration of the experiment, each series was set to start automatically after 1 minute. Downstream, the flow was washed through cooled bottles filled with 2-propanol before being fed to a double channel micro-GC (Inficon, Switzerland) with TCD detectors. Channel A was equipped with a Molar Sieve $5 \AA$

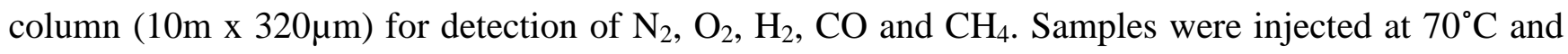
eluted at $80^{\circ} \mathrm{C}$ and 1.72 bar with Argon as carrier gas. Channel B mounted a PoraPlotQ column $(8 \mathrm{~m} \mathrm{x}$ $320 \mu \mathrm{m})$ for detection of $\mathrm{CO}_{2}$ and light hydrocarbons. Samples were injected at $70^{\circ} \mathrm{C}$ and eluted at 
$100^{\circ} \mathrm{C}$ and 1.38 bar with Helium as carrier gas. The micro-GC was programmed to inject a gas sample in both channels every 4.5 minutes.

\subsection{Adsorption and cracking tests}

Prior to each test, the reactor was carefully cleaned with compressed air. At the bottom of the reactor, $30 \mathrm{~g}$ of $\mathrm{Al}_{2} \mathrm{O}_{3}$ cylindrical beads $5 \times 5 \mathrm{~mm}$ (Sasol, Germany) were placed between two plugs of quartz wool to create a $5 \mathrm{~cm}$ tall support for the char. According to the producer, $\mathrm{Al}_{2} \mathrm{O}_{3}$ beads had a surface area of $204 \mathrm{~m}^{2} / \mathrm{g}$. The support was necessary so that the char bed would be positioned in the central part of the furnace, where the temperature was the closest to the oven set point. The bed material was then added in the reactor. The height of the char bed was kept constant in all experiments $(10 \mathrm{~cm})$ and the weight of the fresh bed varied from $8 \mathrm{~g}$ to $22 \mathrm{~g}$ depending on the bulk density of each char. In this way, the gas residence time in the char bed was maintained constant in the tests at the same temperature, varying from $0.72 \mathrm{~s}$ at $250^{\circ} \mathrm{C}$ to $0.35 \mathrm{~s}$ at $800^{\circ} \mathrm{C}$. The reactor was then sealed and placed inside the furnace. A thermocouple with the tip placed in the middle of the char bed was used to monitor the temperature inside the reactor.

Before the start of each experiment, the system was flushed with $\mathrm{N}_{2}$ to remove any oxygen present in the reactor or in the lines. As soon as no oxygen was detected by the micro-GC, the furnace and the lines were heated up to the desired set point. When the temperature set points in the system were reached and stable, the char bed was flushed with $\mathrm{N}_{2}$ for 60 minutes. Afterwards the syringe pump started dosing with the system in bypass mode, to verify the stability of the baseline concentrations. Each experiment was started by turning the 3-way valve so that the aromatics-enriched flow would pass through the reactor before encountering the gas analysis train. Long tests had to be interrupted for a refill of the syringe pump with fresh toluene-naphthalene solution. During refilling (1-2 minutes) the system was switched to bypass mode. Viking char and the two types of active carbon were tested at $250,400,600$ and $800^{\circ} \mathrm{C}$. PC $-\mathrm{N}_{2}$ char was tested only at the lowest and the highest temperature. An additional test was run with Viking char at the intermediate temperature of $500^{\circ} \mathrm{C}$. An overview of the experimental conditions is given in Table 1. 


\begin{tabular}{cccccc}
\hline Temperature $\left[^{\circ} \mathbf{C}\right]$ & 250 & 400 & 500 & 600 & 800 \\
\hline Residence time [s] & 0.72 & 0.56 & 0.49 & 0.43 & 0.35 \\
\hline Char bed (100 & Viking & Viking & Viking & Viking & Viking \\
mm) & $\mathrm{AC}-\mathrm{H}_{2} \mathrm{O}$ & $\mathrm{AC}-\mathrm{H}_{2} \mathrm{O}$ & & $\mathrm{AC}-\mathrm{H}_{2} \mathrm{O}$ & $\mathrm{AC}-\mathrm{H}_{2} \mathrm{O}$ \\
& $\mathrm{AC}-\mathrm{CO}_{2}$ & $\mathrm{AC}-\mathrm{CO}_{2}$ & & $\mathrm{AC}-\mathrm{CO}_{2}$ & $\mathrm{AC}-\mathrm{CO}_{2}$ \\
& $\mathrm{PC}-\mathrm{N}_{2}$ & & & & $\mathrm{PC}-\mathrm{N}_{2}$ \\
\hline
\end{tabular}

Table 1: Overview of experimental conditions. The gas residence time was calculated dividing the char bed height to the gas superficial velocity.

The baseline concentrations $\left(\mathrm{C}_{0}\right)$ of both toluene and naphthalene were measured with dedicated bypass runs for each experiment. During the whole campaign, the uncertainty on the baseline measurements was $7 \%$ for both compounds. This relatively large deviation was caused by the limited volume available in the lines between the syringe pump injection port and the measuring instrument. Whenever the flow was deviated through the reactor, therefore covering a longer path before reaching the instrument, the measured concentrations appeared more stable. Despite the oscillations recorded in the bypass mode, the average baseline values were stable from test to test. On these premises, the steadiness of the concentrations delivered by the mixing system was deemed satisfactory. 


\section{Results and Discussion}

\subsection{Preliminary char characterization}

Table 2 and 3 show the results of char compositional analysis, while Table 4 shows the results obtained by BET and DFT analysis, together with the bulk density of the bed materials.

\begin{tabular}{lccccccc}
\hline & \multicolumn{3}{c}{ Proximate composition (dry basis) } & \multicolumn{5}{c}{ Elemental composition } \\
& Volatiles & Fixed C & Ash & C & H & N & S \\
\hline Viking [wt\%] & 6.8 & 83.7 & 9.4 & 87.6 & 0.6 & 0.1 & $<0.1$ \\
$\mathbf{A C}-\mathbf{H}_{2} \mathbf{O}[\mathbf{w t} \%]$ & 4.4 & 90.8 & 4.9 & 88.9 & 0.2 & 0.3 & $<0.1$ \\
$\mathbf{A C - C O} \mathbf{C}_{\mathbf{2}}[\mathbf{w t} \%]$ & 4.1 & 93.1 & 2.6 & 90.9 & 0.7 & 0.3 & $<0.1$ \\
$\mathbf{P C}-\mathbf{N}_{2}[\mathbf{w t} \%]$ & 2.4 & 94.9 & 2.7 & 91.4 & 0.5 & 0.8 & $<0.1$ \\
\hline
\end{tabular}

Table 2: Proximate and elemental composition (dry basis) of the tested chars.

\begin{tabular}{cccccccccccc}
\hline & Na & Mg & $\mathbf{P}$ & $\mathbf{K}$ & $\mathbf{C a}$ & Al & $\mathbf{S}$ & $\mathbf{C r}$ & $\mathbf{M n}$ & $\mathbf{F e}$ & $\mathbf{N i}$ \\
\hline Viking [wt\%] & 0.101 & 0.205 & 0.124 & 2.070 & 2.092 & 0.024 & 0.081 & 0.002 & 0.047 & 0.089 & 0.001 \\
AC-H $\mathbf{H}_{2} \mathbf{O}[\mathbf{w t} \%]$ & 0.027 & 0.258 & 0.109 & 2.358 & 0.141 & 0.151 & 0.075 & 0.005 & 0.043 & 0.138 & 0.001 \\
AC-CO $_{2}[\mathbf{w t} \%]$ & 0.026 & 0.204 & 0.061 & 0.720 & 1.065 & 0.034 & 0.061 & 0.004 & 0.036 & 0.048 & 0 \\
\hline
\end{tabular}

Table 3: Overview of results of ICP-OES analysis.

The compositional analysis showed that the Viking char, in comparison with the other materials, had a smaller fraction of fixed carbon and higher ash content. This was expected considering that the Viking char had been exposed to harsh gasification reactions, as the TwoStage gasifier is known to achieve a carbon conversion efficiency close to 99\% [48]. The most abundant elements in the ashes were Ca and $\mathrm{K}$, followed by $\mathrm{Mg}, \mathrm{Fe}$ and $\mathrm{P}$. The largest difference among the tested materials was found in the abundance of $\mathrm{Ca}$ in the Viking char, and of $\mathrm{K}$ in both Viking char and $\mathrm{AC}-\mathrm{H}_{2} \mathrm{O}$. 
Table 4: Surface properties obtained with $\mathrm{N}_{2}$ adsorption at $77 \mathrm{~K}$.

The BET analysis showed that Viking char had the largest specific surface area, whereas PC-N $\mathrm{N}_{2}$ char had by far the lowest. The other two chars, that had undergone similar activation treatments, had a comparable BET area and pore volume. In order to understand the difference in the surface morphology of the tested materials, it is useful to consider the isotherms obtained with $\mathrm{N}_{2}$ adsorption at $77 \mathrm{~K}$ (Figure 3). Following the IUPAC classification [49], the isotherms obtained from both $\mathrm{AC}-\mathrm{H}_{2} \mathrm{O}$ and $\mathrm{AC}-\mathrm{CO}_{2}$ resemble a reversible type I, suggesting that these materials are microporous. Particularly the latter shows the narrowest pore size distribution. PC- $\mathrm{N}_{2}$ char also generated an isotherm resembling type I, but with much lower $\mathrm{N}_{2}$-uptake. In contrast, the isotherm obtained from Viking char is a composite of type I and II, with a marked hysteresis (type H4). This kind of isotherm indicates a micro - mesoporous materials, and is often associated with slit-shaped pores [49,50]. The adsorbed volume increasing at higher relative pressures indicates the presence of mesopores $(>2 \mathrm{~nm})$ and macropores $(>$ $50 \mathrm{~nm})$. 

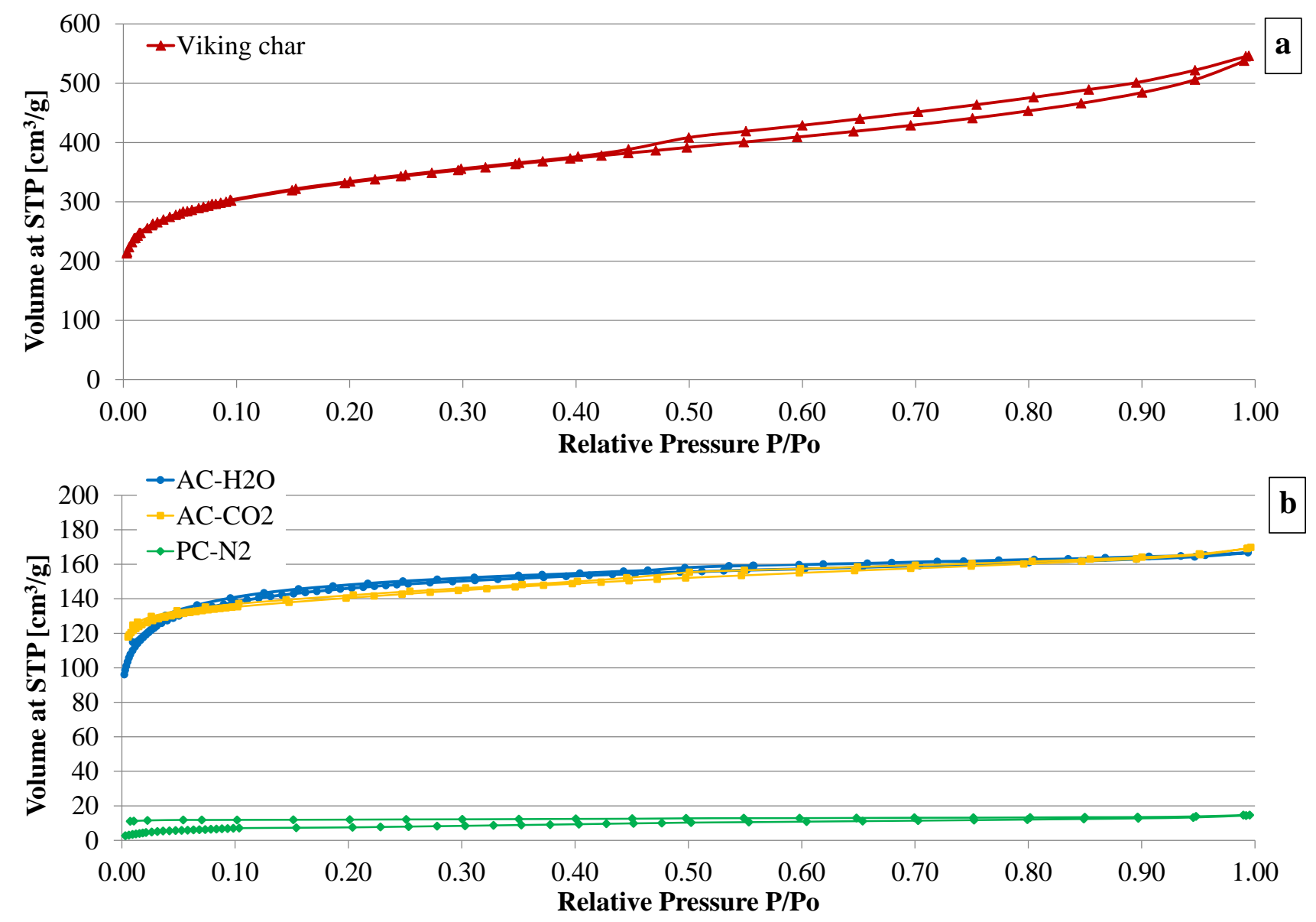

Figure 3: Comparison of isotherms obtained with $\mathrm{N}_{2}$ adsorption at $77 \mathrm{~K}$ on Viking char (a), $\mathrm{AC}-\mathrm{H}_{2} \mathrm{O}$, $A C-\mathrm{CO}_{2}$ and $\mathrm{PC}-\mathrm{N}_{2}(\mathrm{~b})$. Isotherms are plotted separately as they have a different scale on the $y$-axis.

Even though $\mathrm{N}_{2}$ adsorption at $77 \mathrm{~K}$ is not the optimal method to determine the micropore size distribution, in this instance it has been used to estimate the total micropore volumes for the sake of comparing the chars. The total pore volumes and micropore volumes obtained through DFT analysis are reported in Table 4. As for the BET surface area, the highest and lowest values were observed for the Viking char and the PC-N 2 char, respectively. The differences in the textural characteristics of the chars were confirmed by the distribution of the surface area over the pore sizes: significant deviations were observed in the pore size range between 2 and $15 \mathrm{~nm}$, showed in Figure 4.

Viking char appears to have the largest surface associated with mesopores, with pore width spanning from 2 to $12 \mathrm{~nm}$. AC- $\mathrm{H}_{2} \mathrm{O}$ exhibits a narrower distribution, confined between 2 and $5 \mathrm{~nm}$. In this size range, $\mathrm{PC}-\mathrm{N}_{2}$ and $\mathrm{AC}-\mathrm{CO}_{2}$ show similar distributions. This is not unexpected, as they are derived from 
the same parent material; however the effect of $\mathrm{CO}_{2}$ activation is evident not only in the increased surface area associated with micropores but also with mesopores between 2.5 and $6 \mathrm{~nm}$.

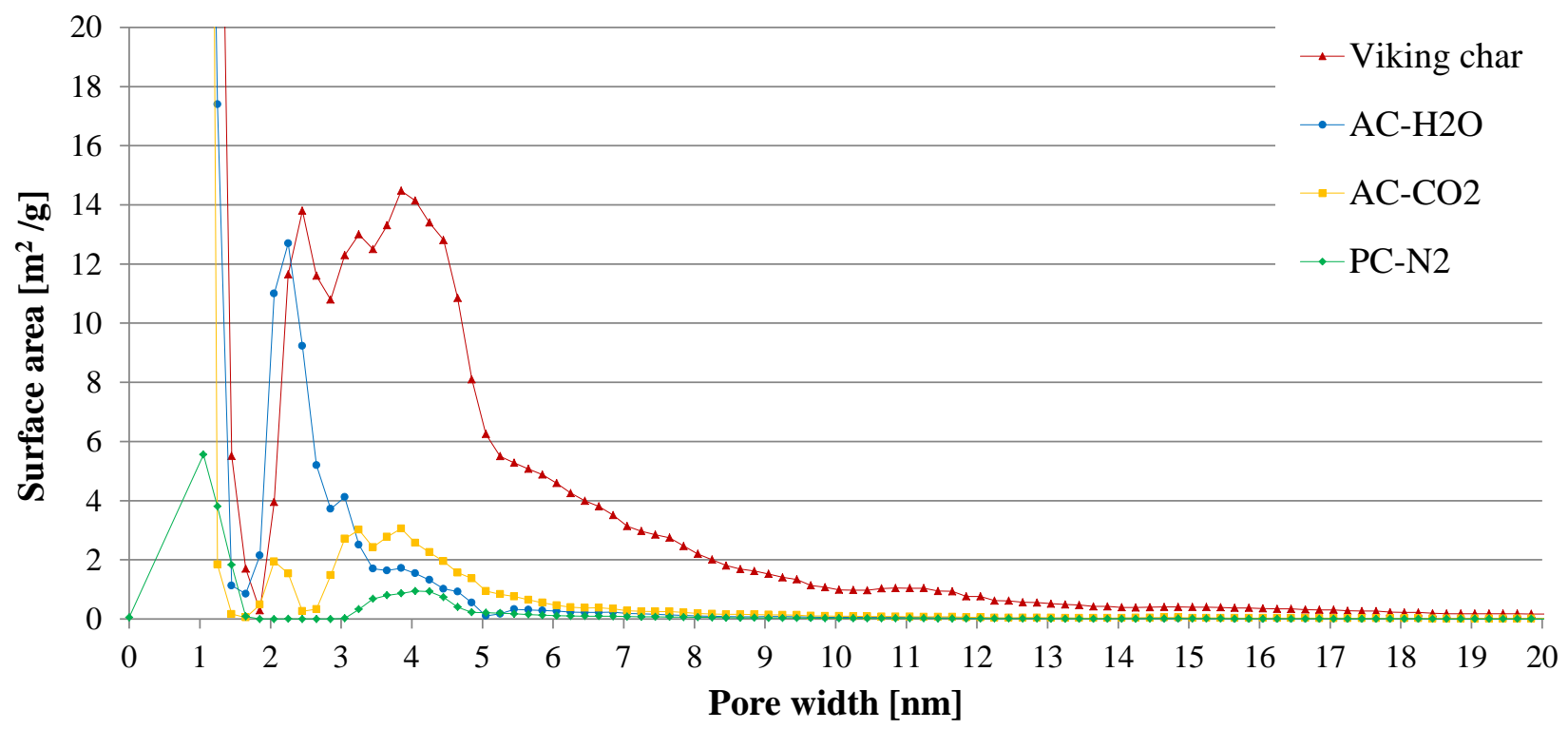

Figure 4: Comparison of surface area distributions in the small mesopores range, obtained with QSDFT analysis for the different chars.

The characterization analysis on the tested materials showed the marked differences among them, especially in regard to surface structure and pore distribution. The different surface properties affected significantly the interaction with the tested aromatic compounds.

The surface oxygen groups present on the surface of chars (lactones, carboxylic acid or phenol and basic groups such as carbonylic, quinonic and pyrone structures) are known to have an influence on the adsorption capacity at low adsorbate concentrations [51]. They might also affect the catalytic properties of chars [52]. However, the oxygen content of active carbon is known to decrease with increasing activation temperatures, reaching a minimum at temperatures above $1000^{\circ} \mathrm{C}$ [53]. Moreover, oxygen groups were found to desorb from the surface of chars at temperatures lower than $800^{\circ} \mathrm{C}$ [54]. In light of this, because the chars that have been tested in this work were treated at temperatures of $750^{\circ} \mathrm{C}$ or higher before being used as bed materials, oxygen functional groups were not considered to significantly affect the performances of chars. 
3.2 Results from experiments in the temperature range $250-400^{\circ} \mathrm{C}$

During the experiments performed with reactor temperatures of 250 and $400^{\circ} \mathrm{C}$, toluene permeated very quickly through the char beds. It regained the baseline concentration level after 10 minutes when the reactor contained Viking char, and in about 20 minutes with the two types of AC. When PC- $\mathrm{N}_{2}$ char was used in the reactor, the toluene concentration was hardly affected. The abrupt breakthroughs did not allow a reliable calculation of the adsorption capacity of toluene for the tested materials.

In contrast, chars and AC had a more pronounced effect on the concentration of naphthalene, which took a longer time to breakthrough in all tests. This effect can be ascribed to the high concentration of toluene that prompted a sudden breakthrough, but also to the predilection of the char surfaces for purely aromatic compounds. This is due to the specific interactions between $\pi$-electron rich regions of solid carbon and the aromatic rings and has been described for low adsorbate concentrations [25,55].

The breakthrough curves traced by the relative concentration of naphthalene $C / C_{0}$ are shown in Figure 5. $\mathrm{C}$ and $\mathrm{C}_{0}$ indicate the instantaneous concentration and the baseline concentration, respectively.

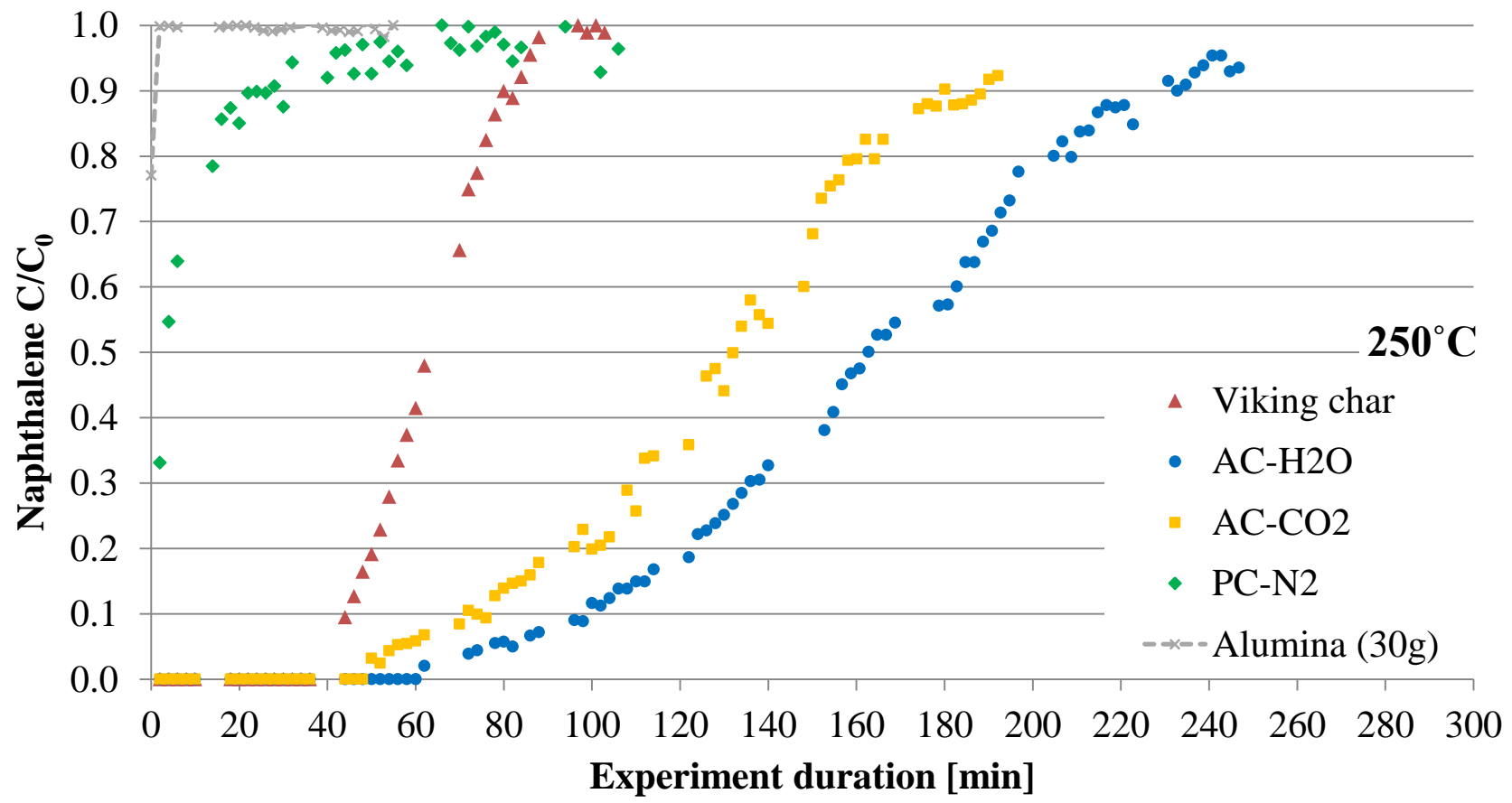

Figure 5: Naphthalene breakthrough curves obtained with different chars, bed temperature $250^{\circ} \mathrm{C}$. 
The tested chars showed different effects on the naphthalene concentration. $\mathrm{AC}-\mathrm{H}_{2} \mathrm{O}$ attained the longest breakthrough time, followed by $\mathrm{AC}-\mathrm{CO}_{2}$. Both chars produced a similar, gradual breakthrough curve. The long time to breakthrough was partly due to their well-developed microporosity, but also to the higher bulk density of these chars (see Table 4). Indeed, even if the bed volume was constant, the Viking char bed weighed $8 \mathrm{~g}$, while the beds of $\mathrm{AC}-\mathrm{H}_{2} \mathrm{O}$ and $\mathrm{AC}-\mathrm{CO}_{2}$ weighed 22.5 and $15 \mathrm{~g}$, respectively.

Despite the shorter breakthrough time, the specific adsorption capacity of Viking char was comparable with the two activated materials. The bed of $\mathrm{PC}-\mathrm{N}_{2}$ char had a minor effect on the naphthalene concentration, and the very short breakthrough time reflected a very low adsorption capacity.

The breakthrough curves obtained from the GC-FID measurements were used to calculate adsorption capacity $\mathrm{q}\left(\mathrm{mg} / \mathrm{g}_{\mathrm{char}}\right)$ of the chars following (2)

$q=\frac{Q}{W}\left[C_{0} t_{f}-\frac{1}{2} \sum_{0}^{t_{f}}\left[C\left(t_{n}\right)+C\left(t_{n-1}\right)\right] * \Delta t\right]$

Where $\mathrm{Q}$ is the nitrogen flow $\left(\mathrm{Nm}^{3} / \mathrm{min}\right), \mathrm{W}$ is the weight of the bed material in the reactor $(\mathrm{g}), \mathrm{C}_{0}$ is the inlet concentration $\left(\mathrm{mg} / \mathrm{Nm}^{3}\right), \mathrm{t}_{\mathrm{n}}$ is the $\mathrm{n}_{\mathrm{th}}$ data point, $\mathrm{t}_{\mathrm{f}}$ is the time (min) when complete breakthrough is reached and $\Delta \mathrm{t}=\mathrm{t}_{\mathrm{n}}-\mathrm{t}_{\mathrm{n}-1}$.

Viking char, $\mathrm{AC}-\mathrm{H}_{2} \mathrm{O}$ and $\mathrm{AC}-\mathrm{CO}_{2}$ were also tested for adsorption at $400^{\circ} \mathrm{C}$. At this temperature, breakthroughs were significantly faster: for Viking char, less than 30 minutes were sufficient for the relative concentration of naphthalene to reach 1 . Table 5 collects the calculated adsorption capacities for the tested materials.

\begin{tabular}{ccc}
\hline & \multicolumn{2}{c}{ Adsorption capacity for naphthalene } \\
\hline Char bed temperature & $250^{\circ} \mathrm{C}$ & $400^{\circ} \mathrm{C}$ \\
\hline & $\mathrm{mg} / \mathrm{g}_{\mathrm{char}}$ & $\mathrm{mg} / \mathrm{g}_{\mathrm{char}}$ \\
\hline Viking & 66.7 & 9.5 \\
$\mathbf{A C}-\mathbf{H}_{\mathbf{2}} \mathbf{O}$ & 60.5 & 9.7 \\
$\mathbf{A C}-\mathbf{C O}_{2}$ & 75.4 & 21.1 \\
$\mathbf{P C}-\mathbf{N}_{\mathbf{2}}$ & 4.1 & Not measured \\
\hline Table 5: Naphthalene adsorption capacities at $250^{\circ} \mathrm{C}$ and $400^{\circ} \mathrm{C}$.
\end{tabular}

Table 5: Naphthalene adsorption capacities at $250^{\circ} \mathrm{C}$ and $400^{\circ} \mathrm{C}$. 
The increase in bed temperature caused a sharp decline in the adsorption capacity for the tested chars. The negative correlation between adsorption capacity and temperature is due to the exothermic nature of the adsorption process and has been observed in previous works $[26,35,56]$. This trend was confirmed with an experiment performed with Viking char at $500^{\circ} \mathrm{C}$ : the breakthroughs of both toluene and naphthalene were almost instantaneous and the naphthalene adsorption capacity was found to drop further to $1.3 \mathrm{mg} / \mathrm{g}_{\text {char }}$. Figure 6 (a-c) shows the breakthrough curves obtained at different temperatures using Viking char, $\mathrm{AC}-\mathrm{H}_{2} \mathrm{O}$ and $\mathrm{AC}-\mathrm{CO}_{2}$ as bed materials.
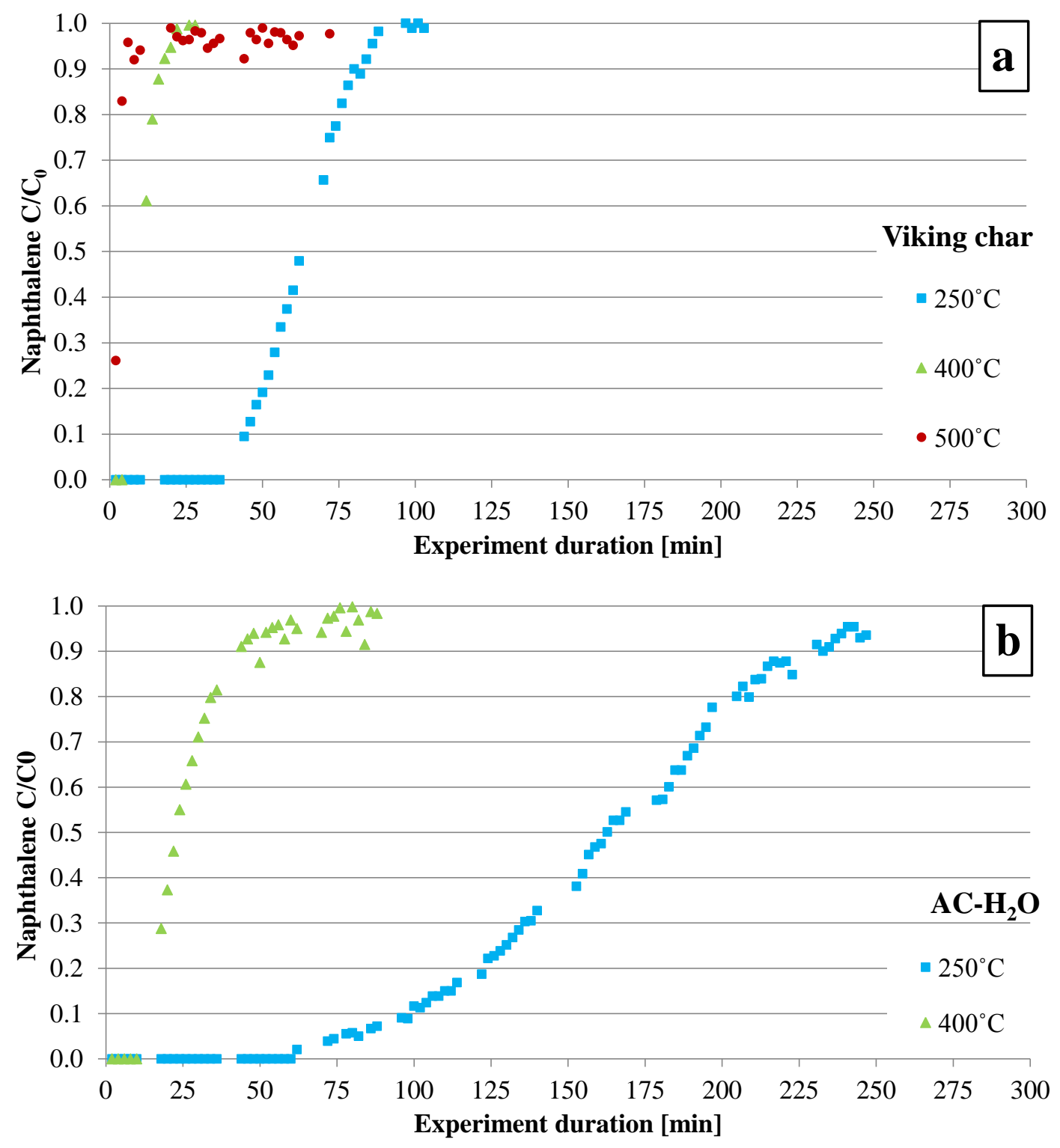


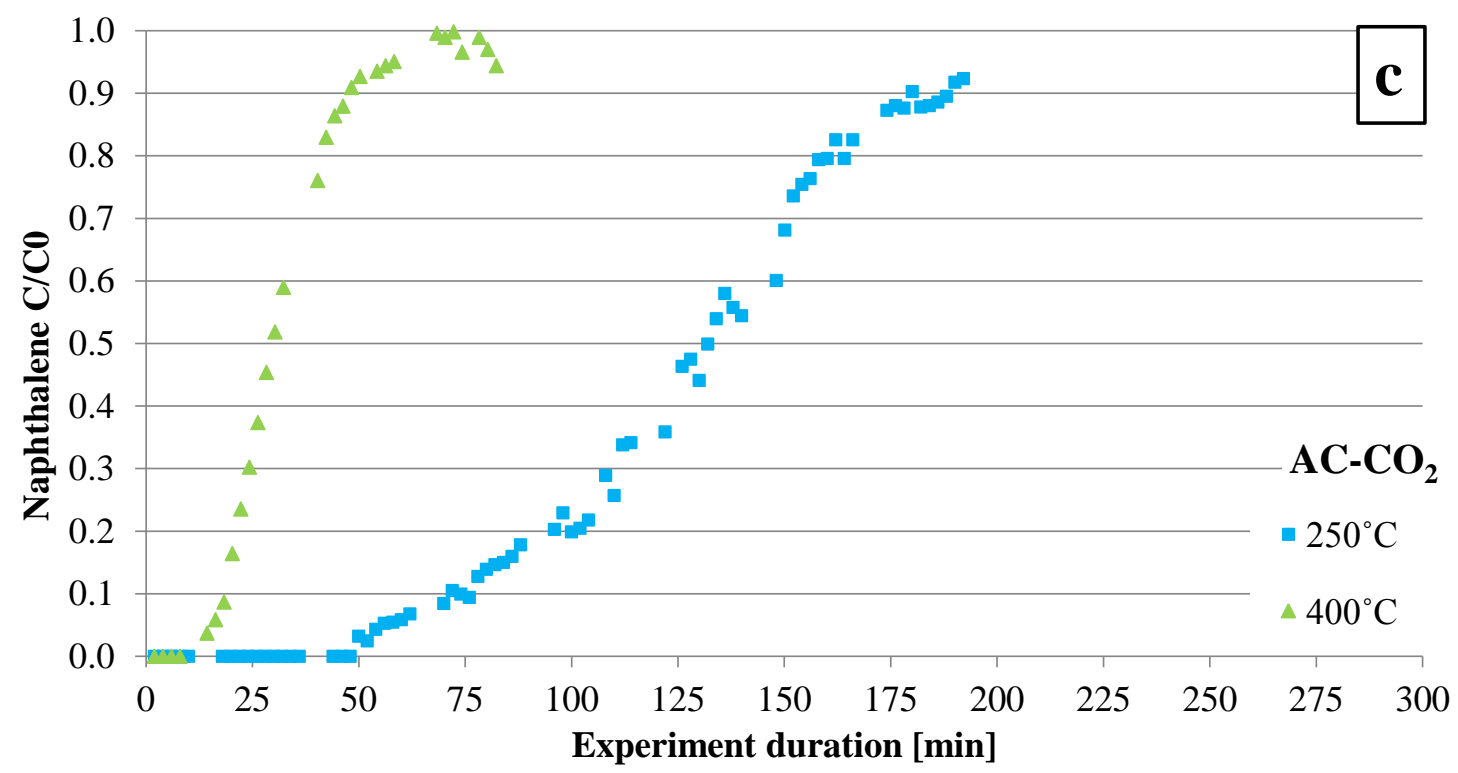

Figure 6: Naphthalene breakthrough obtained with Viking char (a), $\mathrm{AC}-\mathrm{H}_{2} \mathrm{O}(\mathrm{b})$ and $\mathrm{AC}-\mathrm{CO}_{2}(\mathrm{c})$ at different temperature levels.

These results suggested that adsorption performance of chars and activated carbons (e.g. if used in carbon filters) can be hindered by medium-high temperatures.

At 250 and $400^{\circ} \mathrm{C}, \mathrm{AC}-\mathrm{CO}_{2}$ showed the highest adsorption capacity for naphthalene: this can be ascribed to the surface texture of this char, which is the richest in micropores as a consequence of $\mathrm{CO}_{2}$ activation [57]. Viking char and $\mathrm{AC}-\mathrm{H}_{2} \mathrm{O}$ exhibited somehow comparable adsorption capacities, even though the highest density of char $\mathrm{AC}-\mathrm{H}_{2} \mathrm{O}$ led to a longer time to breakthrough. $\mathrm{PC}-\mathrm{N}_{2}$ showed a dramatically lower adsorption capacity in comparison with the other materials. According to Mastral et al. [58], total microporosity is the main factor influencing adsorption of aromatics on the surface of AC: the lack of micropores explains the poor performance of non-activated char.

Overall, microporous AC with high bulk density appeared as a promising material for tar adsorption applications at temperatures of $250^{\circ} \mathrm{C}$ and below. The performance of $\mathrm{AC}$ could be improved if the activation process during manufacturing would be optimized for this specific application. In real conditions, the tar mixture also contains aromatics larger than naphthalene (4- or 5- rings) which would also require pores in the mesoporous range for optimal adsorption [24]. In this instance, AC could be particularly useful in the fine cleaning of biomass producer gas, with low levels of tar contamination. It is worth to point out that in the temperature range 250 to $400^{\circ} \mathrm{C}$ no gases other than $\mathrm{N}_{2}$ were detected 
with micro-GC in the exit gas. The typical shape of breakthrough curves associated with adsorption phenomena and the absence of other gas species at the outlet of the system confirmed that no decomposition reactions took place in these conditions. Only in the experiment at $500^{\circ} \mathrm{C}$ with Viking char, traces of hydrogen were detected $(<0.01 \mathrm{Vol} \%)$, suggesting that cracking reactions were incipient at this temperature.

\subsection{Cracking of aromatics at 600 and $800^{\circ} \mathrm{C}$}

During experiments carried out at higher temperatures, the concentration of both toluene and naphthalene at the outlet of the system evolved somehow differently, and at the highest temperature complete breakthrough was not achieved. The evolution of relative concentrations $\left(\mathrm{C} / \mathrm{C}_{0}\right)$ of naphthalene and toluene at $600^{\circ} \mathrm{C}$ are depicted in Figure 7. The relative conversion of aromatics was calculated by using the average bypass concentration values measured for each experiment.
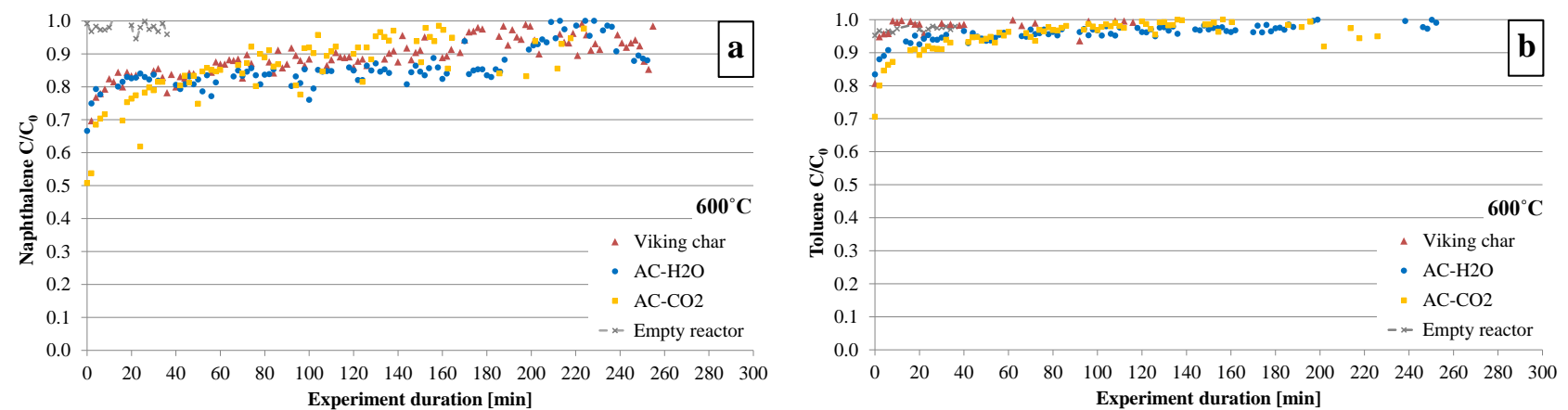

Figure 7: Evolution of the relative concentrations of naphthalene $(a)$ and toluene $(b)$ at the outlet of the reactor during experiments at $600^{\circ} \mathrm{C}$.

The change of $\mathrm{C} / \mathrm{C}_{0}$ over time shows that at $600^{\circ} \mathrm{C}$ the char beds had a limited effect on the concentration of aromatics in the gaseous flow, particularly in the case of toluene. Viking char, AC$\mathrm{H}_{2} \mathrm{O}$ and $\mathrm{AC}-\mathrm{CO}_{2}$ were tested in these conditions, but the type of char used in the reactor did not appear to significantly influence the conversion values. For all tested chars, small amounts of $\mathrm{H}_{2}$ were detected at the outlet of the system. $\mathrm{H}_{2}$ concentration in the exit gas exhibited similar trends over time with the three chars, peaking around $0.07 \mathrm{Vol} \%$ during the first hour of experiment, to decrease gradually afterwards and stabilizing around 0.03-0.04 Vol\%. 

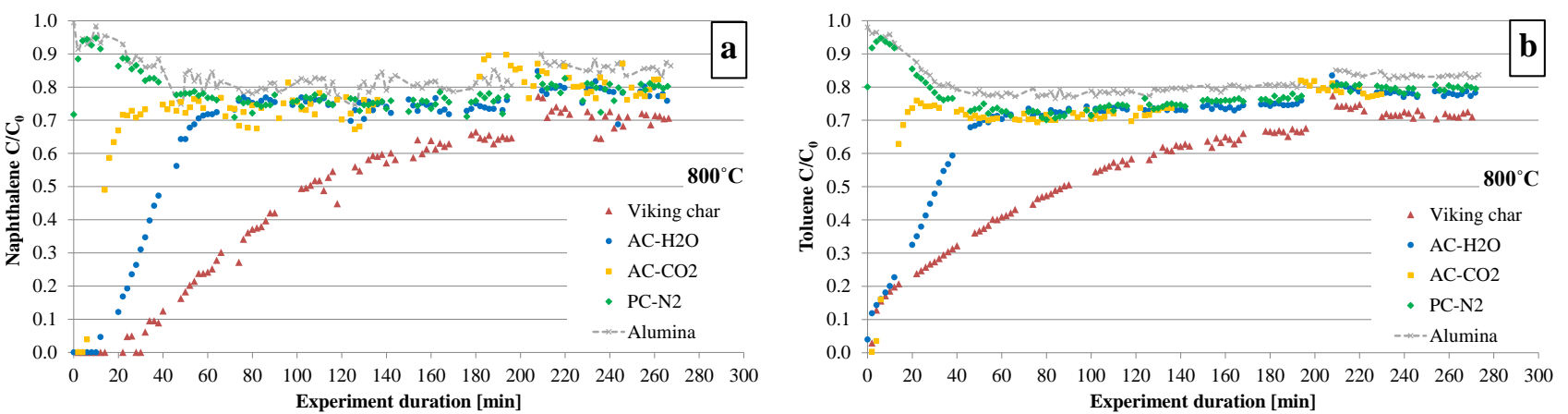

Figure 8: Evolution of the relative concentrations of naphthalene $(a)$ and toluene $(b)$ at the outlet of the reactor during experiments at $800^{\circ} \mathrm{C}$.

In these conditions the char $\mathrm{PC}-\mathrm{N}_{2}$ was also tested and it produced conversion values very similar to the blank test. However, in presence of this char, $\mathrm{C} / \mathrm{C}_{0}$ values remained slightly lower than the blank test, indicating a mild activity of the char surface. It is also interesting to notice the trend showed by both blank test and pyrolysis char test at the beginning of the experiment, with $\mathrm{C} / \mathrm{C} 0$ peaking close to 1 , then decreasing and stabilizing at $\mathrm{C} / \mathrm{C}_{0}$ between 0.7 and 0.8 . These trends indicate that in these two cases the deposition of carbon could actually support the decomposition of aromatics. The same effect was observed by Korus et al. [42], who found that coke-covered AC was still able to interact and decompose toluene, even if with a low level of conversion.

For the other chars, the very high conversion values were measured at the beginning of the tests: Viking char was the one performing better for naphthalene removal, attaining a complete conversion for about 30 minutes. Both $\mathrm{AC}-\mathrm{H}_{2} \mathrm{O}$ and $\mathrm{AC}-\mathrm{CO}_{2}$ achieved complete conversion for a shorter time (about 12 and 6 minutes, respectively). For toluene, complete conversion was observed for these chars only at the very beginning of the test. It appears as naphthalene was converted more efficiently than 
toluene. This observation agrees with the increased reactivity of chars towards compounds with increased aromaticity that has been observed in previous works $[4,8,9,29,45]$. However, it is worth to keep in mind that the concentrations of toluene and naphthalene differ by an order of magnitude (18345 $\pm 0.5 \%$ and $1852 \pm 0.1 \% \mathrm{mg} / \mathrm{Nm}^{3}$, respectively). This might have influenced their conversion efficiency.

Viking char, $\mathrm{AC}-\mathrm{H}_{2} \mathrm{O}$ and $\mathrm{AC}-\mathrm{CO}_{2}$ provided decreasing conversions over time as a consequence of surface deactivation. $\mathrm{AC}-\mathrm{H}_{2} \mathrm{O}$ and $\mathrm{AC}-\mathrm{CO}_{2}$ exhibited a fast deactivation, as they both converged with the $\mathrm{C} / \mathrm{C}_{0}$ values of $\mathrm{PC}-\mathrm{N}_{2}$ char in about 20 and 60 minutes, respectively. In contrast, Viking char produced a less abrupt increase of $\mathrm{C} / \mathrm{C}_{0}$, reaching a plateau after about 220 minutes from the start of the experiment. Also, the plateau value was still below the other chars.

The exact same trends can also be observed in the composition of the exit gas measured by micro-GC at the outlet of the system, as depicted in Figure 9. Again, the data gaps starting at 200 minutes originate from the measurement interruption to allow the syringe pump refilling. The gas conditioning system before the micro-GC required about 40 minutes for the instrument to show stable measurements. In the exit gas, $\mathrm{H}_{2}$ and $\mathrm{CH}_{4}$ were the only gases other than $\mathrm{N}_{2}$ that were detected by micro-GC. The absence of $\mathrm{CO}$ and $\mathrm{CO}_{2}$ was expected due to the lack of $\mathrm{O}_{2}$ and of any other reforming agent inside the reactor.
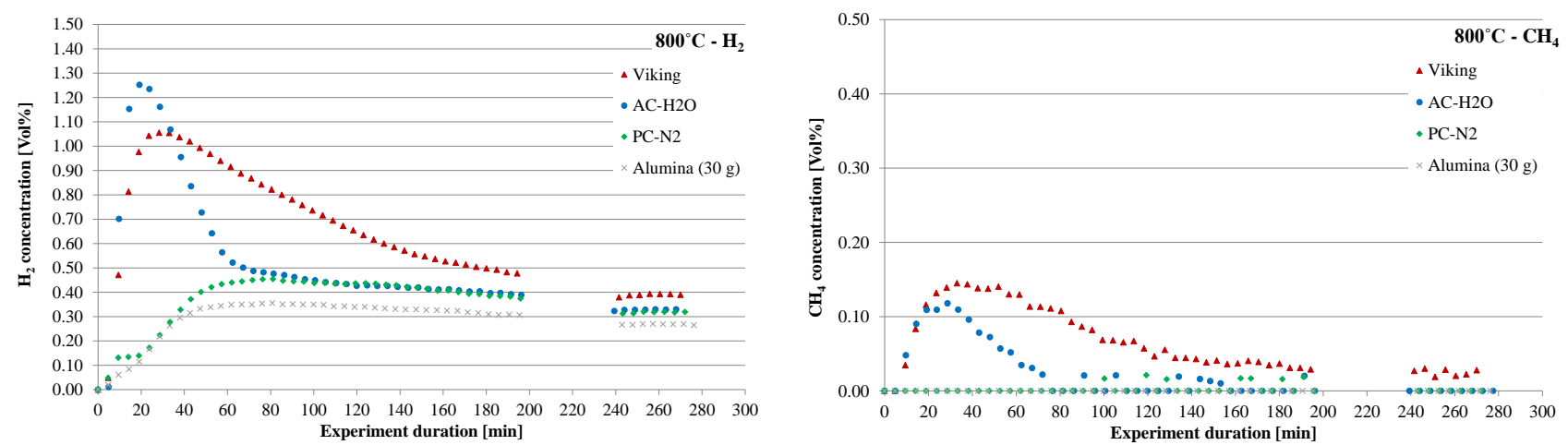

Figure 9: $\mathrm{H}_{2}$ and $\mathrm{CH}_{4}$ concentrations measured during of tests with Viking char, $\mathrm{AC}-\mathrm{H}_{2} \mathrm{O}, \mathrm{PC}-\mathrm{N}_{2}$ and blank test $\left(\mathrm{Al}_{2} \mathrm{O}_{3}\right)$. Note that different scales are used on the y-axes.

At $800^{\circ} \mathrm{C}$, the $\mathrm{H}_{2}$ production increased significantly if compared with the results at $600^{\circ} \mathrm{C}$, reaching peaks above $1 \mathrm{Vol} \%$ for both Viking char and $\mathrm{AC}-\mathrm{H}_{2} \mathrm{O}$. In addition, small amounts of $\mathrm{CH}_{4}$ could be detected in the exit gas. $\mathrm{H}_{2}$ formation was expected as a product of reaction (1). The presence of $\mathrm{CH}_{4}$ as a reaction product most probably originated from the hydrogenation of methyl radicals, which form 
upon the initiation of toluene pyrolysis [42,59]. It is possible that benzene was also a product of decomposition, but this molecule was not detected by the applied GC-FID method.

The declining trends in the production of both $\mathrm{H}_{2}$ and $\mathrm{CH}_{4}$ confirm the deactivation of the char surfaces, with the same patterns observed on the GC-FID results. AC- $\mathrm{H}_{2} \mathrm{O}$ showed a steeper decline in comparison with Viking char, and the production of both gases reached the levels of PC- $\mathrm{N}_{2}$ char between 60 and 80 minutes from the start. It was not possible to quantitavely compare the $\mathrm{H}_{2}$ and $\mathrm{CH}_{4}$ production generated by $\mathrm{AC}-\mathrm{CO}_{2}$ with the other results, because of a slight variation in the quantification baseline for the micro-GC. However, it was qualitatively similar to $\mathrm{AC}-\mathrm{H}_{2} \mathrm{O}$, with even steeper decreases in the concentration of both gases.

The same deactivation tendencies for the different chars are suggested by the evolution of the relative concentrations over time and by the composition of the exit gas. Viking char showed the slowest deactivation, even though considering the differences in the density of chars, the total surface area within the char beds was comparable (around $10.000 \mathrm{~m}^{2}$ ). The prolonged activity of the residual gasification char can be ascribed to the wide pore size distribution including micro- and mesopores that could have facilitated the diffusion of the aromatic molecules. Indeed, mesoporous chars with large surface area are in general considered to have better long-term activity than microporous chars $[41,60]$. On the other hand, the pore size distribution of both types of AC was narrow and shifted towards small pores, therefore parts of their surface area could have been inaccessible; or easily made so by carbon deposition. Because of the pore structures their activity declined quickly, once most of the micropores were clogged. The slower deactivation tendency of Viking char is therefore ascribed in part to the larger specific surface area and to the wider pore size distribution, but also to the higher content in minerals (especially $\mathrm{Ca}$ and $\mathrm{K}$ ), which might have migrated to the surface a consequence of the high temperatures encountered within the TwoStage gasification process. Indeed, the features that favored the activity of Viking char originated from the high degree of burn-off of this char.

It is important to underline that the described deactivation trends were observed in $\mathrm{N}_{2}$ inert atmosphere. In real conditions, other species present in the gas phase would interact with the char surface and the tar compounds. In particular, $\mathrm{CO}_{2}$ and steam would participate in reforming reactions of carbon and delay deactivation. However, these results can be considered as an indication of the deactivation tendency that tested chars would exhibit in real conditions. The detection of $\mathrm{H}_{2}$ as the main reaction product and the lack of light hydrocarbons in the exit gas confirm the mechanism of decomposition of aromatics 
over char described elsewhere [4,39,44], with dehydrogenation and coke formation through condensation/polymerization reactions. This reaction pathway was also confirmed by the characterization tests performed on the spent chars.

\subsection{Analysis on spent chars}

The results from tests at 600 and especially at $800^{\circ} \mathrm{C}$ gave evidence that the aromatic compounds were decomposed. In order to study the effect of such reactions on the surface of chars, the spent materials were carefully collected and analyzed.

The tests performed at $600^{\circ} \mathrm{C}$ had duration between 2 and 5 hours with the different char, depending on how fast deactivation was proceeding. As a result, it is difficult to compare the spent chars. However, the char beds (Viking char, $\mathrm{AC}-\mathrm{H}_{2} \mathrm{O}$ and $\mathrm{AC}-\mathrm{CO}_{2}$ ) all showed a slight weight gain around $2 \%$ of the original value.

On the other hand, all the experiments performed at $800^{\circ} \mathrm{C}$ had similar duration, therefore the results from post-analysis characterization can be compared. Significant differences between fresh and spent chars were found in the bed weight, specific surface area and carbon content on the samples obtained with experiments at $800^{\circ} \mathrm{C}$. Table 6 collects some of the values measured on the fresh and spent chars.

\begin{tabular}{|c|c|c|c|c|c|c|c|c|c|c|}
\hline & \multicolumn{2}{|c|}{$\begin{array}{c}\text { Bed weight } \\
{[\mathrm{g}]}\end{array}$} & \multicolumn{2}{|c|}{$\begin{array}{c}\text { Carbon } \\
\text { content } \\
{[\mathrm{g}]}\end{array}$} & \multicolumn{2}{|c|}{$\begin{array}{l}\text { Surface area } \\
\qquad\left[\mathrm{m}^{2} / \mathrm{g}\right]\end{array}$} & \multicolumn{2}{|c|}{$\begin{array}{c}\text { DFT pore } \\
\text { volume } \\
{\left[\mathrm{cm}^{3} / \mathrm{g}\right]}\end{array}$} & \multicolumn{2}{|c|}{$\begin{array}{c}\text { DFT } \\
\text { micropore } \\
\text { volume } \\
{\left[\mathrm{cm}^{3} / \mathrm{g}\right]}\end{array}$} \\
\hline & Fresh & Spent & Fresh & Spent & Fresh & Spent & Fresh & Spent & Fresh & Spent \\
\hline Viking & 9.0 & 14.7 & 7.9 & 13.8 & 1235 & 55.3 & 0.79 & 0.04 & 0.37 & 0.02 \\
\hline $\mathrm{AC}-\mathrm{H}_{2} \mathrm{O}$ & 22.4 & 24.2 & 19.9 & 22.8 & 553 & 389 & 0.24 & 0.17 & 0.19 & 0.13 \\
\hline $\mathrm{AC}-\mathrm{CO}_{2}$ & 14.1 & 14.6 & 12.8 & 13.7 & 564 & 366 & 0.24 & 0.16 & 0.19 & 0.12 \\
\hline PC-N ${ }_{2}$ & 20.5 & 19.8 & 19.0 & 18.7 & 35 & 267 & 0.02 & 0.13 & 0.01 & 0.08 \\
\hline
\end{tabular}

Table 6: Overview of the characterization results relative to fresh and spent chars (after tests at $800^{\circ} \mathrm{C}$ ). The duration of all the tests was $270 \mathrm{~min}$, with the exception of $\mathrm{AC}-\mathrm{CO}_{2}$ which was tested for 230 minutes. 
Viking char, $\mathrm{AC}-\mathrm{H}_{2} \mathrm{O}$ and $\mathrm{AC}-\mathrm{CO}_{2}$ after the tests exhibited a weight gain together with increased carbon content and decreased surface area. These results indicate that deactivation of the chars was a consequence of solid carbon deposition (via polymerization/coking) on the active sites as a result of cracking reactions. This effect was expected due to the fact that no reforming or oxidizing agent was made available to react with deposited carbon during the tests.

The characterization of $\mathrm{PC}-\mathrm{N}_{2}$ delivered opposite results: the bed weight loss, accompanied by reductions in $\mathrm{C}, \mathrm{H}, \mathrm{N}$ and $\mathrm{S}$ is ascribed to further pyrolysis reaction that took place inside the reactor prior to the start of the experiment. Indeed, $\mathrm{CO}$ was detected in the exit gas during the preliminary flushing of the reactor with pure $\mathrm{N}_{2}$ before the start of the test.

Experiments at $800^{\circ} \mathrm{C}$ were repeated for Viking char and $\mathrm{AC}-\mathrm{H}_{2} \mathrm{O}$, where chars were exposed to the flow of $\mathrm{N}_{2}$ and aromatics for a different duration. The repetitions confirmed the conversion values and deactivation patterns previously discussed and provided additional materials for the post-experiment characterization. It is important to keep in mind that the volume of the char beds was maintained constant in all experiments, but the weight of the materials varied as a consequence of the different density values (Table 4). Therefore, the change relative to the initial value (measured on the fresh char bed) is displayed in Figure 10 (a-c) for the bed weight, specific surface area and carbon content respectively.
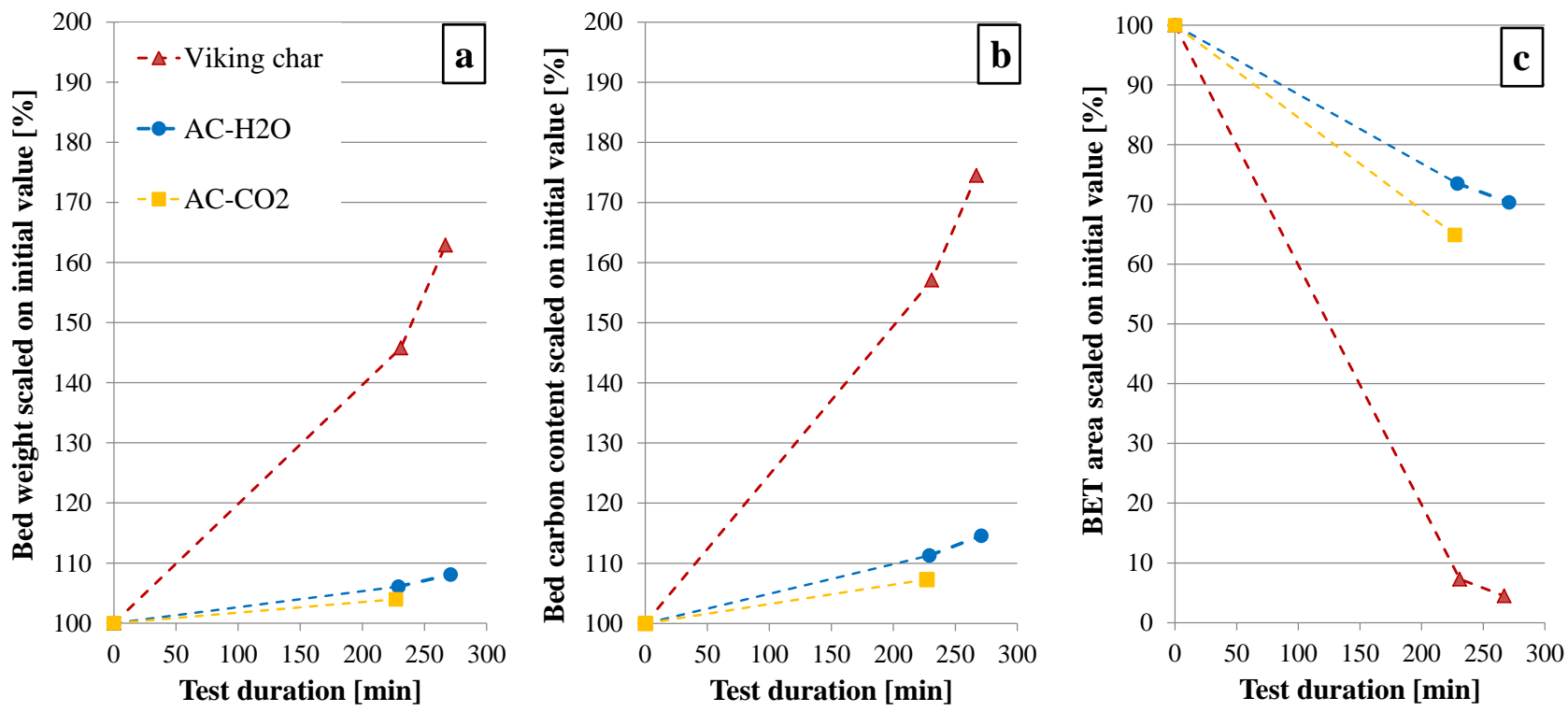

Figure 10: Change relative to the values of fresh char beds of bed weight (a), carbon content (b), surface area (c) for Viking char, $\mathrm{AC}-\mathrm{H}_{2} \mathrm{O}$ and $\mathrm{AC}-\mathrm{CO}_{2}$ spent at $800^{\circ} \mathrm{C}$. 
The increase in bed weight reflects the increased carbon content in the char beds, showing that the weight gain is given by deposition of elemental carbon. The decrease of specific surface area mirrors similar trends. The change in the DFT pore volume is not shown as it was virtually identical to the one for the BET surface area. Comparing the three materials, it is evident that Viking char was the one most affected by the experiments. Not only it gained the most weight (5.6 g in 270 minutes), but also its surface area decreased dramatically (from 1235 to $55 \mathrm{~m}^{2} / \mathrm{g}$ in 270 minutes). The strong decrease in surface area was accompanied by a sharp reduction of pore volume. In this regard, it can be interesting to consider how the pore size distribution changed for the different materials after the tests at $800^{\circ} \mathrm{C}$ (Figure 11). 

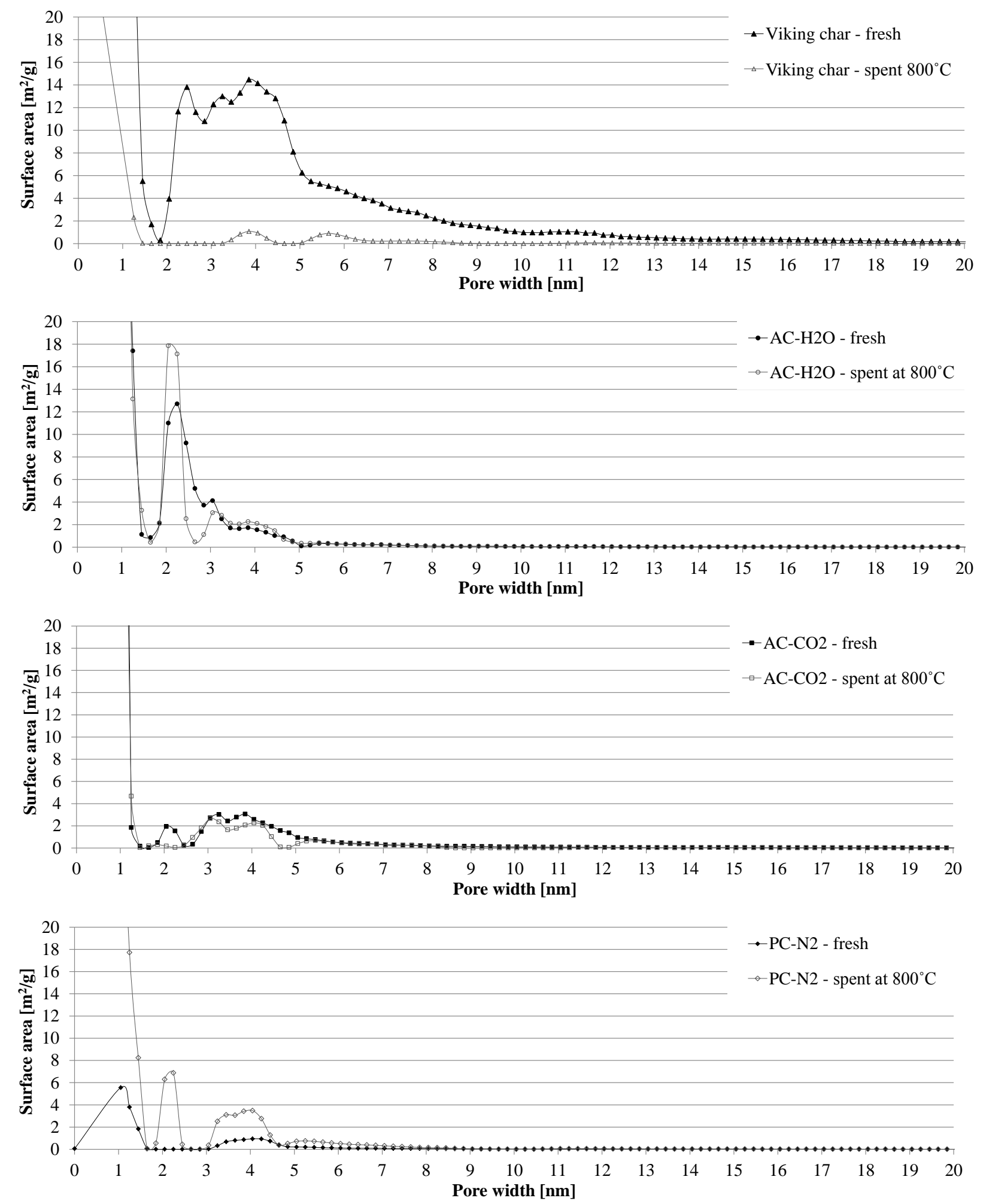

Figure 11: Surface area distribution over the pore size range $<20 \mathrm{~nm}$ for the tested chars. The plots represent fresh samples and spent ones after tests at $800^{\circ} \mathrm{C}$. 
It appears as, in the case of Viking char, the surface area reduction affected not only the micropores, but also the mesopores in the range 2-14 $\mathrm{nm}$. Interestingly, some of the mesopores on the surfaces of $\mathrm{AC}-\mathrm{H}_{2} \mathrm{O}$ and $\mathrm{AC}-\mathrm{CO}_{2}$ remained accessible for $\mathrm{N}_{2}$ even after the tests at $800^{\circ} \mathrm{C}$. Moreover, the spent $\mathrm{AC}$ maintained a larger micropore volume in comparison with Viking char (Table 6).

These results indicate that a larger fraction of the Viking char surface was active for tar decomposition, including surface area associated with micropores and small mesopores $(<13 \mathrm{~nm})$. Moreover, despite the remarkable drop in surface area and pore volume, Viking char showed a higher activity at the end of the tests in comparison with the two types of AC.

The greater activity of the Viking char surface can be explained by the higher content of inorganics, especially $\mathrm{Ca}$. It is possible that the inorganics contained in the Viking char were also more accessible thanks to the migration of mineral species towards the surface during gasification. This phenomenon has been observed on chars gasified at high temperature [6,61], such as Viking char was.

As in the previous results, also the change in the pore size distribution was completely different for the PC- $\mathrm{N}_{2}$ char that gained surface area both in the micropore and mesopore region. These results corroborate the hypothesis that this char underwent mild pyrolysis during the test: even though this char had been heat treated at $900^{\circ} \mathrm{C}$ for 2 hours prior to the test, this was not sufficient to guarantee its complete stability at $800^{\circ} \mathrm{C}$.

\section{Conclusions}

The performances of four wood-derived chars and AC in the adsorption and decomposition of toluene and naphthalene were evaluated and compared. Chars and $\mathrm{AC}$ were produced with different processes and featured various degrees of activation. Surface characterization revealed different surface areas and pore textures, while the compositional analysis showed discrepancies in the content of minerals and metals. The surface and compositional characteristics varied as a consequence of the different heat treatments that each material had undergone: gasification, pyrolysis, $\mathrm{H}_{2} \mathrm{O}$ - or $\mathrm{CO}_{2}$-activation.

During experiments in the lower range of temperatures $\left(250-400^{\circ} \mathrm{C}\right)$, char beds exerted a minimal effect on the concentration of toluene, but adsorbed naphthalene more efficiently. The absence of gaseous species other than $\mathrm{N}_{2}$ in the exit gas confirmed that the interaction between aromatic molecules and the surface of chars was limited to adsorption, as no decomposition reactions took place under these 
conditions. The highest naphthalene adsorption capacity was given by $\mathrm{AC}-\mathrm{CO}_{2}$. Viking char provided an adsorption capacity of naphthalene which was comparable with the two types of AC. On the contrary, PC- $\mathrm{N}_{2}$ char (non-activated) showed a poor adsorption capacity quantified as one order of magnitude below the other materials.

Increasing the char beds temperature to $400^{\circ} \mathrm{C}$ significantly diminished the adsorption capacities of the Viking char, $\mathrm{AC}-\mathrm{H}_{2} \mathrm{O}$ and $\mathrm{AC}-\mathrm{CO}_{2}$ without triggering cracking reactions.

On the other hand, when the temperature of the char bed was set to $600^{\circ} \mathrm{C}$, the aromatic compounds were subject to decomposition reactions yielding $\mathrm{H}_{2}$. At $800^{\circ} \mathrm{C}$ the $\mathrm{H}_{2}$ production increased significantly and was associated with $\mathrm{CH}_{4}$ generation; moreover, the difference in the performances of the different chars became appreciable. The performance of char PC- $\mathrm{N}_{2}$ was very similar to the blank test, with very low levels of conversion. In contrast, the other chars achieved complete conversion of naphthalene and toluene for a limited time at the beginning of the tests. Overall, naphthalene appeared to be cracked more extensively than toluene. Viking char $\mathrm{AC}-\mathrm{H}_{2} \mathrm{O}$ and $\mathrm{AC}-\mathrm{CO}_{2}$ surface deactivation following different trends. Viking char remained active for a longer time in comparison with the two types of AC. The same deactivation trends were observed in the production of $\mathrm{H}_{2}$ and $\mathrm{CH}_{4}$. The slower deactivation showed by Viking char was mainly ascribed to a better surface accessibility given by its pore texture, but also to a higher number of active sites as a results of a larger content of inorganics.

The characterization of the chars spent at $800^{\circ} \mathrm{C}$ clarified that deactivation was a consequence of solid carbon deposition on the surface of chars.

Results from tests in the temperature range $600-800^{\circ} \mathrm{C}$ indicated that gasification char performed better than $\mathrm{AC}$, providing a higher and protracted removal of both aromatic compounds. Chars with high burn-off, as the ones produced as solid residues of gasification process, might be particularly suitable for tar conversion applications in hot producer gas treatment at temperatures of $800^{\circ} \mathrm{C}$ and above. Nevertheless, the solid residues of gasification, or gasification chars, can have very different properties and surface structure depending on the operating conditions of the process and on the feedstock used. In order to be suitable and effective for hot gas treatment, the gasifier should have high carbon conversion efficiency, and should produce a solid residue with a large specific surface area and welldeveloped porosity. 


\section{Acknowledgements}

The authors thank Innovationsfonden (Denmark) for the financial support received as part of the project "SYNFUEL - Sustainable synthetic fuels from biomass gasification and electrolysis" (410600006B), as well as the German Federal Ministry of Education and Research for the funding to the junior research group "NWG-TCKON” (FKZ: 03SF0442).

The authors would also like to thank Mrs. Susanne Hoffmann (Technische Universität Berlin, Institut für Energietechnik) for the assistance with char analysis.

\section{References}

[1] Li C, Suzuki K. Tar property, analysis, reforming mechanism and model for biomass gasification - An overview 2010;13:594-604. doi:10.1016/j.rser.2008.01.009.

[2] Asadullah M. Biomass gasification gas cleaning for downstream applications: A comparative critical review. Renew Sustain Energy Rev 2014;40:118-32. doi:10.1016/j.rser.2014.07.132.

[3] Abu El-Rub Z, Bramer EA, Brem G. Experimental comparison of biomass chars with other catalysts for tar reduction. Fuel 2008;87:2243-52. doi:10.1016/j.fuel.2008.01.004.

[4] Hosokai S, Kumabe K, Ohshita M, Norinaga K, Li C, Hayashi J-I. Mechanism of decomposition of aromatics over charcoal and necessary condition for maintaining its activity. Fuel 2008;87:2914-22. doi:10.1016/j.fuel.2008.04.019.

[5] Fuentes-Cano D, Gómez-Barea A, Nilsson S, Ollero P. Decomposition kinetics of model tar compounds over chars with different internal structure to model hot tar removal in biomass gasification. Chem Eng J 2013;228:1223-33. doi:10.1016/j.cej.2013.03.130.

[6] Klinghoffer N, Castaldi MJ, Nzihou A. Catalyst Properties and Catalytic Performance of Char from Biomass Gasification. I\&Ec 2012:13113-22. doi:10.1021/ie3014082.

[7] D.M.L. Griffiths JRM. The cracking of tar vapour and aromatic compounds on activated carbon. Fuel 1967:167-76.

[8] Boroson ML, Howard JB, Longwell JP, Peters W a. Heterogeneous cracking of wood pyrolysis tars over fresh wood char surfaces. Energy \& Fuels 1989;3:735-40. doi:10.1021/ef00018a014.

[9] Brandt P, Larsen E, Henriksen U. High tar reduction in a two-stage gasifier. Energy and Fuels 2000;14:816-9. doi:10.1021/ef990182m. 
[10] Al-Rahbi AS, Onwudili JA, Williams PT. Thermal decomposition and gasification of biomass pyrolysis gases using a hot bed of waste derived pyrolysis char. Bioresour Technol 2016;204:71-9. doi:10.1016/j.biortech.2015.12.016.

[11] Krerkkaiwan S, Mueangta S, Thammarat P, Jaisat L, Kuchonthara P. Catalytic Biomass-Derived Tar Decomposition Using Char from the Co-pyrolysis of Coal and Giant Leucaena Wood Biomass. Energy \& Fuels 2015;29:3119-26. doi:10.1021/ef502792x.

[12] Park J, Lee Y, Ryu C. Reduction of primary tar vapor from biomass by hot char particles in fixed bed gasification. Biomass and Bioenergy 2016;90:114-21. doi:10.1016/j.biombioe.2016.04.001.

[13] Frazier RS, Jin E, Kumar A. Life cycle assessment of biochar versus metal catalysts used in syngas cleaning. Energies 2015;8:621-44. doi:10.3390/en8010621.

[14] Benedetti V, Patuzzi F, Baratieri M. Gasification char as a potential substitute of activated carbon in adsorption applications. Energy Procedia 2016;00.

[15] Benedetti V, Patuzzi F, Baratieri M. Characterization of char from biomass gasification and its similarities with activated carbon in adsorption applications. Appl Energy 2017:1-8. doi:10.1016/j.apenergy.2017.08.076.

[16] Galhetas M, Mestre AS, Pinto ML, Gulyurtlu I, Lopes H, Carvalho AP. Chars from gasification of coal and pine activated with $\mathrm{K} 2 \mathrm{CO} 3$ : Acetaminophen and caffeine adsorption from aqueous solutions. J Colloid Interface Sci 2014;433:94-103. doi:10.1016/j.jcis.2014.06.043.

[17] Ducousso M, Weiss-Hortala E, Nzihou A, Castaldi MJ. Reactivity enhancement of gasification biochars for catalytic applications. Fuel 2015;159:491-9. doi:10.1016/j.fuel.2015.06.100.

[18] García-García A, Gregório A, Franco C, Pinto F, Boavida D, Gulyurtlu I. Unconverted chars obtained during biomass gasification on a pilot-scale gasifier as a source of activated carbon production. Bioresour Technol 2003;88:27-32.

[19] Kilpimaa S, Runtti H, Kangas T, Lassi U, Kuokkanen T. Physical activation of carbon residue from biomass gasification: Novel sorbent for the removal of phosphates and nitrates from aqueous solution. J Ind Eng Chem 2015;21:1354-64. doi:10.1016/j.jiec.2014.06.006.

[20] Klinghoffer N. Utilization of char from biomass gasification in catalytic applications . $\mathrm{PhD}$ Thesis, Columbia University USA 2013.

[21] Hervy M, Berhanu S, Weiss-Hortala E, Chesnaud A, Gérente C, Villot A, et al. Multi-scale 
characterisation of chars mineral species for tar cracking. Fuel 2017;189:88-97. doi:10.1016/j.fuel.2016.10.089.

[22] Patuzzi F, Prando D, Vakalis S, Rizzo AM, Chiaramonti D, Tirler W, et al. Small-scale biomass gasification CHP systems: Comparative performance assessment and monitoring experiences in South Tyrol (Italy). Energy 2016;112:285-93. doi:10.1016/j.energy.2016.06.077.

[23] Hansen V, Müller-Stöver D, Ahrenfeldt J, Holm JK, Henriksen UB, Hauggaard-Nielsen H. Gasification biochar as a valuable by-product for carbon sequestration and soil amendment. Biomass and Bioenergy 2015;72:300-8. doi:http://dx.doi.org/10.1016/j.biombioe.2014.10.013.

[24] Mastral A, García T, Murrillo R, Callén MS, Lopez JM, Navarro M V, et al. Study of the Adsorption of Polyaromatic Hydrocarbon Binary Mixtures on Carbon Materials by Gas-Phase Fluorescence Detection. Energy \& Fuels 2003:669-76.

[25] García T, Murillo R, Cazorla-Amorós D, Mastral AM, Linares-Solano A. Role of the activated carbon surface chemistry in the adsorption of phenanthrene. Carbon N Y 2004;42:1683-9. doi:10.1016/j.carbon.2004.02.029.

[26] Hu X, Hanaoka T, Sakanishi K, Shinagawa T, Matsui S, Tada M, et al. Removal of Tar Model Compounds Produced from Biomass Gasification Using Activated Carbons. J Japan Inst Energy 2007;86:707-7011. doi:10.1093/bioinformatics/btu635.

[27] Sun Q, Yu S, Wang F, Wang J. Decomposition and gasification of pyrolysis volatiles from pine wood through a bed of hot char. Fuel 2011;90:1041-8. doi:10.1016/j.fuel.2010.12.015.

[28] Dabai F, Paterson N, Millan M, Fennell P, Kandiyoti R. Tar formation and destruction in a fixed-bed reactor simulating downdraft gasification: Equipment development and characterization of tar-cracking products. Energy and Fuels 2010;24:4560-70. doi:10.1021/ef100681u.

[29] Matsuhara T, Hosokai S, Norinaga K, Matsuoka K, Li CZ, Hayashi JI. In-situ reforming of tar from the rapid pyrolysis of a brown coal over char. Energy and Fuels 2010;24:76-83. doi:10.1021/ef9005109.

[30] Phuphuakrat T, Namioka T, Yoshikawa K. Tar removal from biomass pyrolysis gas in two-step function of decomposition and adsorption. Appl Energy 2010;87:2203-11. doi:10.1016/j.apenergy.2009.12.002.

[31] Sueyasu T, Oike T, Mori A, Kudo S, Norinaga K, Hayashi JI. Simultaneous steam reforming of 
tar and steam gasification of char from the pyrolysis of potassium-loaded woody biomass. Energy and Fuels 2012;26:199-208. doi:10.1021/ef201166a.

[32] Hosokai S, Norinaga K, Kimura T, Nakano M, Li C-Z, Hayashi J. Reforming of Volatiles from the Biomass Pyrolysis over Charcoal in a Sequence of Coke Deposition and Steam Gasification of Coke. Energy \& Fuels 2011;25:5387-93. doi:10.1021/ef2003766.

[33] Cudahy JJ, Helsel RW. Removal of products of incomplete combustion with carbon. Waste Manag 2000;20:339-45. doi:10.1016/S0956-053X(99)00335-9.

[34] Mastral AM, García T, Murillo R, Callén MS, López JM, Navarro M V. PAH Mixture Removal from Hot Gas by Porous Carbons . From Model Compounds to Real Conditions 2003:5280-6.

[35] Karatza D, Musmarra D. Fly Ash Capture of Mercuric Chloride Vapors from Exhaust Combustion Gas 1998;32:3999-4004.

[36] Jess A. Mechanisms and kinetics of thermal reactions of aromatic hydrocarbons from pyrolysis of solid fuels. Fuel 1996;75:1441-8. doi:10.1016/0016-2361(96)00136-6.

[37] Egsgaard H, Ahrenfeldt J, Ambus P, Schaumburg K, Henriksen UB. Gas cleaning with hot char beds studied by stable isotopes. J Anal Appl Pyrolysis 2014;107:174-82. doi:10.1016/j.jaap.2014.02.019.

[38] Mani S, Kastner JR, Juneja A. Catalytic decomposition of toluene using a biomass derived catalyst. Fuel Process Technol 2013;114:118-25. doi:10.1016/j.fuproc.2013.03.015.

[39] Song Y, Zhao Y, Hu X, Zhang L, Sun S, Li CZ. Destruction of tar during volatile-char interactions at low temperature. Fuel Process Technol 2018;171:215-22. doi:10.1016/j.fuproc.2017.11.023.

[40] Nestler F, Burhenne L, Amtenbrink MJ, Aicher T. Catalytic decomposition of biomass tars: The impact of wood char surface characteristics on the catalytic performance for naphthalene removal. Fuel Process Technol 2016;145:31-41. doi:10.1016/j.fuproc.2016.01.020.

[41] Fuentes-Cano D, Parrillo F, Ruoppolo G, Gómez-Barea A, Arena U. The influence of the char internal structure and composition on heterogeneous conversion of naphthalene. Fuel Process Technol 2018;172:125-32. doi:10.1016/j.fuproc.2017.12.015.

[42] Korus A, Samson A, Szle A, Katelbach-woz A. Pyrolytic toluene conversion to benzene and coke over activated carbon in a fixed-bed reactor. Fuel 2017;207:283-92. doi:10.1016/j.fuel.2017.06.088. 
[43] Nitsch X, Commandré J-M, Valette J, Volle G, Martin E. Conversion of Phenol-Based Tars over Biomass Char under H 2 and H 2 O Atmospheres. Energy \& Fuels 2014:28 (2014) 6936-6940. doi:10.1021/ef500980g.

[44] Zhang Y, Luo Y, Wu W, Zhao S, Long Y. Heterogeneous Cracking Reaction of Tar over Biomass Char, Using Naphthalene as Model Biomass Tar. Energy \& Fuels 2014;28:3129-37. doi:10.1021/ef4024349.

[45] Krerkkaiwan S, Tsutsumi A, Kuchonthara P. Biomass derived tar decomposition over coal char bed. ScienceAsia 2013;39:511. doi:10.2306/scienceasia1513-1874.2013.39.511.

[46] Di Gregorio F, Parrillo F, Salzano E, Cammarota F, Arena U. Removal of naphthalene by activated carbons from hot gas. Chem Eng J 2016;291:244-53. doi:10.1016/j.cej.2016.01.081.

[47] Quantachrome Instruments - DFT Models n.d. http://www.quantachrome.com/technical/dft.html (accessed June 6, 2018).

[48] Ahrenfeldt J, Henriksen U, Jensen TK, Gøbel B, Wiese L, Kather A, et al. Validation of a continuous combined heat and power (CHP) operation of a two-stage biomass gasifier. Energy and Fuels 2006;20:2672-80. doi:10.1021/ef0503616.

[49] Thommes M, Kaneko K, Neimark A V, Olivier JP, Rodriguez-reinoso F, Rouquerol J, et al. Physisorption of gases, with special reference to the evaluation of surface area and pore size distribution ( IUPAC Technical Report ). Pure Appl Chem 2015. doi:10.1515/pac-2014-1117.

[50] Sing KSW, Everett DH, Haul RAW, Moscou L, Pierotti RA, Rouqueról J, et al. REPORTING PHYSISORPTION DATA FOR GAS / SOLID SYSTEMS with Special Reference to the Determination of Surface Area and Porosity 1985;57:603-19.

[51] Coughlin RW, Ezra FS. Role of Surface Acidity in the Adsorption of Organic Pollutants on the Surface of Carbon. Environ Sci Technol 1968;2:291-7. doi:10.1021/es60016a002.

[52] Rodríguez-Reinoso F. The role of carbon materials in heterogeneous catalysis. Carbon N Y 1998;36:159-75. doi:10.1016/S0008-6223(97)00173-5.

[53] Bansal RC, Donnet J-B, Stoeckli F. Active Carbon. New York and Basel: Marcel Dekker, Inc.; 1988.

[54] Klinghoffer NB, Castaldi MJ, Nzihou A. Influence of char composition and inorganics on catalytic activity of char from biomass gasification. Fuel 2015;157:37-47. doi:10.1016/j.fuel.2015.04.036. 
[55] Lillo-Ródenas M, Cazorla-Amorós D, Linares-Solano A. Behaviour of activated carbons with different pore size distributions and surface oxygen groups for benzene and toluene adsorption at low concentrations. Carbon N Y 2005;43:1758-67. doi:10.1016/j.carbon.2005.02.023.

[56] Chiang Y, Chiang P, Huang C. Effects of pore structure and temperature on VOC adsorption on activated carbon. Carbon N Y 2001;39:523-34.

[57] Tomków K, Siemieniewska T, Czechowski F, Jankowska A. Formation of porous structures in activated brown-coal chars using O2, CO2 and H2O as activating agents. Fuel 1977;56:121-4.

[58] Mastral AM, García T, Murillo R, Callen MS, Lopez JM, Navarro M V. Development of efficient adsorbent materials for PAH cleaning from AFBC hot gas. Energy and Fuels 2004;18:202-8. doi:10.1021/ef030058+.

[59] Moldoveanu SC. Techniques and Instrumentation in Analytical Chemistry - Pyrolysis of Organic Molecules. vol. 28. Elsevier Science Ltd; 2009.

[60] Moliner R, Suelves I, Lázaro MJ, Moreno O. Thermocatalytic decomposition of methane over activated carbons: Influence of textural properties and surface chemistry. Int J Hydrogen Energy 2005;30:293-300. doi:10.1016/j.ijhydene.2004.03.035.

[61] Wu W, Luo Y, Su Y, Zhang Y, Zhao S, Wang Y. Nascent Biomass Tar Evolution Properties under Homogeneous/Heterogeneous Decomposition Conditions in a Two-Stage Reactor. Energy \& Fuels 2011;25:5394-406. doi:10.1021/ef2007276. 